\title{
Innovative Separations Technologies
}

J. Tripp

N. Soelberg

R. Wigeland

May 2011

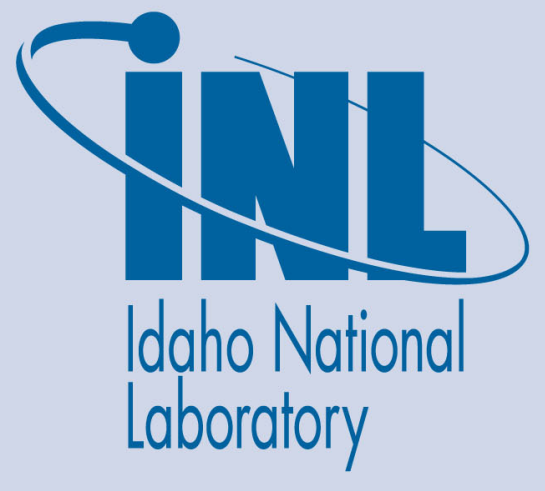

The INL is a U.S. Department of Energy National Laboratory operated by Battelle Energy Alliance 
INL/EXT-11-22297

FCR\&D-SYSA-2011-000097

\title{
Innovative Separations Technologies
}

\author{
J. Tripp \\ N. Soelberg \\ R. Wigeland
}

May 2011

\section{Idaho National Laboratory \\ Fuel Cycle Research \& Development Idaho Falls, Idaho 83415}

http://www.inl.gov

Prepared for the

U.S. Department of Energy

Office of Nuclear Energy

Under DOE Idaho Operations Office

Contract DE-AC07-05ID14517 


\section{DISCLAIMER}

This information was prepared as an account of work sponsored by an agency of the U.S. Government. Neither the U.S. Government nor any agency thereof, nor any of their employees, makes any warranty, expressed or implied, or assumes any legal liability or responsibility for the accuracy, completeness, or usefulness, of any information, apparatus, product, or process disclosed, or represents that its use would not infringe privately owned rights. References herein to any specific commercial product, process, or service by trade name, trade mark, manufacturer, or otherwise, does not necessarily constitute or imply its endorsement, recommendation, or favoring by the U.S. Government or any agency thereof. The views and opinions of authors expressed herein do not necessarily state or reflect those of the U.S. Government or any agency thereof. 


\section{SUMMARY}

Reprocessing used nuclear fuel (UNF) is a multi-faceted problem involving chemistry, material properties, and engineering. Technology options are available to meet a variety of processing goals. A decision about which reprocessing method is best depends significantly on the process attributes considered to be a priority. New methods of reprocessing that could provide advantages over the aqueous Plutonium Uranium Reduction Extraction (PUREX) and Uranium Extraction + (UREX+) processes, electrochemical, and other approaches are under investigation in the Fuel Cycle Research and Development (FCR\&D) Separations Campaign.

In an attempt to develop a revolutionary approach to UNF recycle that may have more favorable characteristics than existing technologies, five innovative separations projects have been initiated. These include:

- Nitrogen Trifluoride for UNF Processing

- Reactive Fluoride Gas $\left(\mathrm{SF}_{6}\right)$ for UNF Processing

- Dry Head-end Nitration Processing

- Chlorination Processing of UNF

- Enhanced Oxidation/Chlorination Processing of UNF

This report provides a description of the proposed processes, explores how they fit into the Modified Open Cycle (MOC) and Full Recycle (FR) fuel cycles, and identifies performance differences when compared to "reference" advanced aqueous and fluoride volatility separations cases. To be able to highlight the key changes to the reference case, general background on advanced aqueous solvent extraction, advanced oxidative processes (e.g., volumetric oxidation, or "voloxidation," which is high temperature reaction of oxide UNF with oxygen, or modified using other oxidizing and reducing gases), and fluorination and chlorination processes is provided.

In the context of MOC and FR fuel cycles, some general observations about the five innovative technologies can be made. It must be recognized that process losses and product stream contamination are very important attributes of the separations process for the integrated fuel cycle; however, information on these topics is not yet available from the projects. At this time, it appears that separations capabilities may not be able to match that achievable by the reference advanced aqueous process except for the headend nitration processing which uses advanced aqueous processes. Many of the processes under evaluation are not attempting to achieve that high degree of separation to improve proliferation resistance (for instance by keeping Pu with fission products (FPs) instead of producing a separate Pu stream). The performance measures for the MOC or FR fuel cycle are not defined sufficiently at this point to determine whether the innovative separation technologies will be as attractive as the advanced aqueous separations.

It appears that four of the five innovative processes have a uranium stream as the main product stream, although in one case it is also contaminated with $\mathrm{Nb}$ and $\mathrm{Np}$. If of sufficient purity, the uranium product stream could be used directly for re-enrichment, supporting those fuel cycles where re-enrichment is envisioned. The purity of the uranium product stream from these processes (except for the head-end nitration which would be the same as for the advanced aqueous process) is still being determined. If insufficiently pure, further processing of the uranium product stream would be needed to obtain a product that could be used for new fuel fabrication.

If the recycle of one or more of the TRU elements is desired in a candidate fuel cycle, then further processing of the appropriate product or waste stream may also be needed to recover the TRU elements. The fuel requirements for MOC and FR options are generally not defined well enough to know how pure a TRU stream is needed to be beneficially used. A potential advantage in this regard is that the 
processing throughput requirements for the TRU-containing stream would be greatly decreased in three of the methods since the uranium has already been recovered separately. In addition, the radiation level for the TRU-containing stream is also much lower for these technologies, facilitating processing.

In terms of the measures being used for the assessment, the following general observations are made:

- Separations - Separations purity is not expected to be as high as for the reference advanced aqueous process except for head-end nitration which uses aqueous processing after the head-end treatment.

- Engineering Issues - All of the gas phase processes face engineering challenges with respect to materials due to the use of halide-bearing or otherwise relatively corrosive reagents, although industrial experience indicates that these can be resolved.

- Safety / Environmental - The innovative processes substitute less hazardous materials (instead of HF or $\mathrm{F}_{2}$ used in prior fluorination processes) to address this issue.

- Waste Management - Most of the innovative process descriptions indicate that they do not efficiently separate and recycle TRU elements (unless these streams are further processed), and so will result in waste streams with higher levels of radiation, heat, and radiotoxicity compared to the reference aqueous separations process that does separate and recycle the TRU elements. The same gaseous fission products (tritium, iodine 129, carbon 14, and krypton 85) that could require capture in aqueous separations will also require capture and conversion to waste forms in the innovative processes. However, the addition of fluorine or chlorine compounds in most of the innovative processes could affect the capture of I-129, and could contaminate and significantly increase amount of the I-129 waste form. Details about how the added halides might impact the capture and waste forms for the gaseous fission products are not yet available. The presence of $\mathrm{F}$ or $\mathrm{Cl}$ species in the waste stream(s) that will contain the non-volatile and semi-volatile radionuclides will impact how the waste streams are handled - either the waste loading might need to be decreased for existing glass waste forms, the halides in the waste stream(s) will need to be removed, or new waste forms such as phosphate glass will need to be developed to tolerate and contain the halide species. Researchers have indicated that that "dry" processes should not generate as much waste as aqueous processes, but this conclusion may not account for the impact of halides on the waste forms.

- Used fuel disposal / Suitability for Recycle - All of the processes appear suitable for recovery of uranium for re-enrichment. Recovery of one or more TRU elements would generally require further processing, but in several cases smaller facilities would be needed to accomplish further TRU separations since the uranium and many of the fission products have been removed.

- Economics / Footprint reduction - In general, the information was not sufficient to make an evaluation at this time.

- Resource sustainability - These separations processes will not increase the conservation of uranium resources compared to the aqueous separations reference case, because the reference aqueous case already can recover and recycle the actinides (which is one of the ways to increase uranium conservation). The conservation of uranium resources also depends on the degree to which natural uranium is utilized to produce power. Fuel cycles in which depleted uranium is used and not discarded, and in which $U$ and TRU in used fuel is recycled, maximize uranium utilization. Those innovative separations processes that are not designed to recover and recycle all of the actinides in the used fuel will not enable uranium utilization as efficiently as those processes that do enable recycle of all of the actinides. 
- Proliferation resistance and physical security - The flowsheets developed for the innovative technologies indicate that application of safeguards would be possible, similar to that for aqueous processing. No significant vulnerabilities or advantages with respect to the reference advanced aqueous process were identified. Less complete separations of the TRU elements and FPs by some of the innovative technologies is intended to make the TRU-containing streams more self-protective.

Since studies of these innovative processes have only recently been initiated, information gaps exist that prevent a more complete evaluation. The following is a list of the data needs, as well as other potential activities that would be conducted in the Systems Analysis campaign.

- More complete determination of separation factors

- Modeling using the Fuel Cycle Integration and Trade-off (FIT) model to estimate viability of recycle product materials, levels of contamination compared to known fuel limits, and separations efficiencies needed to enable viable fuel with acceptable levels of contaminants

- Analysis to determine if it is economically feasible/desirable to recycle fuel only a few times such as in many MOC cases versus Full Recycle

- Mass balances to assess process flowrates, equipment size requirements, amounts of reagents, etc.

- More complete process definition such as halide recycling (or not), operating temperatures, corrosion and equipment degradation, handling of solids materials, capture of off-gas particulate matter and gaseous fission products, and process performance

- Development and demonstration of waste form concepts designed to maximize waste loading considering the presence of halides in the waste streams. 


\section{CONTENTS}

ACRONYMS vii

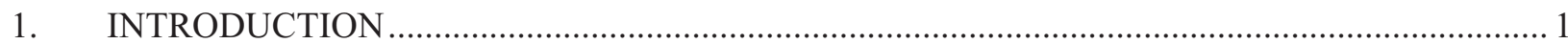

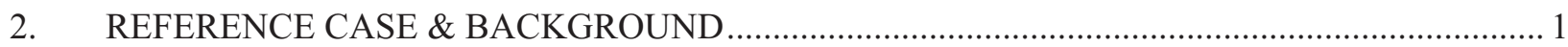

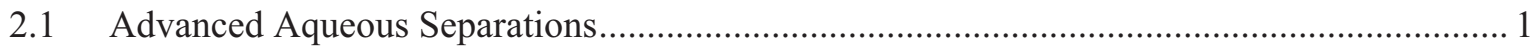

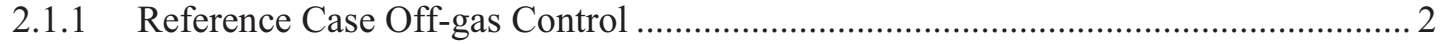

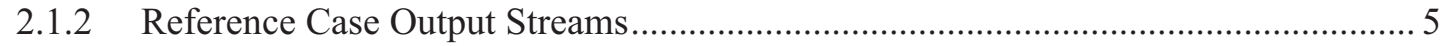

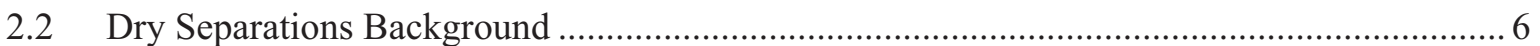

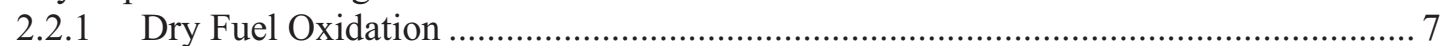

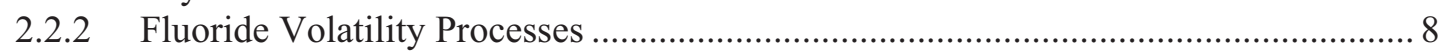

2.2.3 Chloride Volatility Processes ............................................................................... 12

2.2.4 Waste Forms for Halide-laden Waste Streams ........................................................ 12

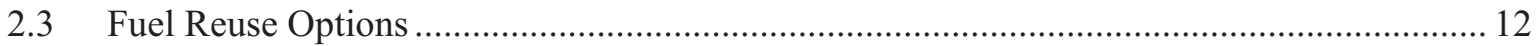

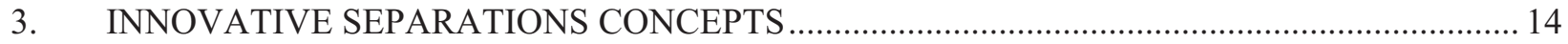

3.1 Nitrogen Trifluoride for UNF Processing (PNNL) ....................................................... 14

3.2 Reactive Fluoride Gas $\left(\mathrm{SF}_{6}\right)$ for UNF Processing (SRNL) ........................................... 16

3.3 Dry Head-End Nitration Processing (ORNL) ................................................................... 18

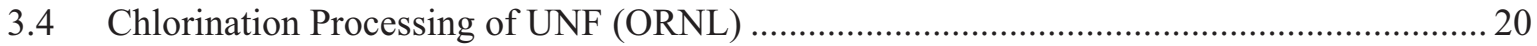

3.5 Enhanced Oxidation/Chlorination Processing of UNF (INL) .......................................... 22

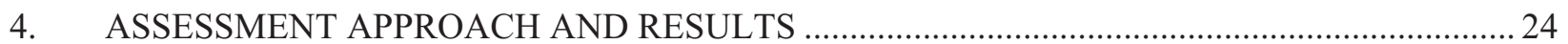

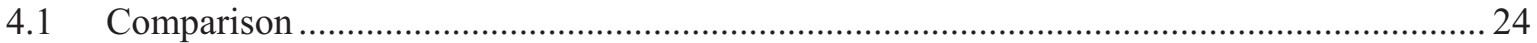

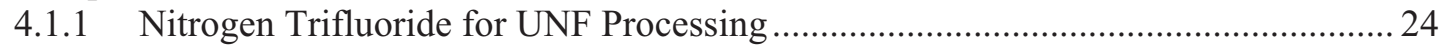

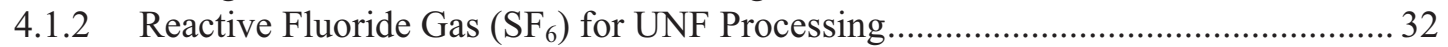

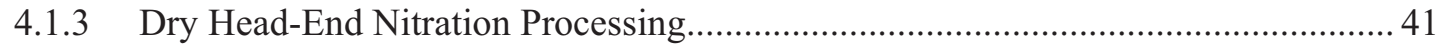

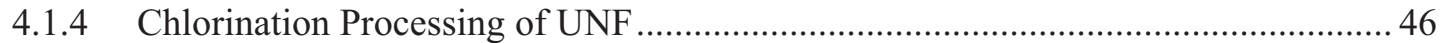

4.1.5 Enhanced Oxidation/Chlorination Processing of UNF .......................................... 53

4.2 Potential Advantages and Disadvantages of Dry Reprocessing .......................................... 59

4.3 Information Needs and Possible Activities .......................................................................... 61

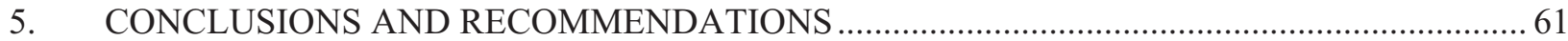

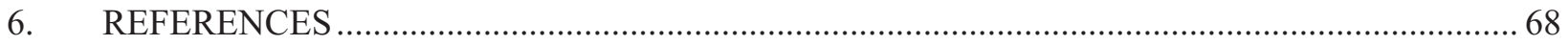




\section{FIGURES}

Figure 2-1. Reference advanced aqueous separations diagram. ........................................................... 2

Figure 2-2. Overview of reference case off-gas control systems........................................................ 3

Figure 2-3. Reference case off-gas control for particulate matter and gaseous fission products................ 4

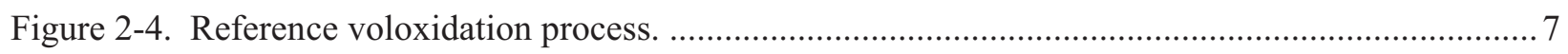

Figure 2-5. Periodic table indicating volatile fluorides (blue), nonvolatile elements (purple) and

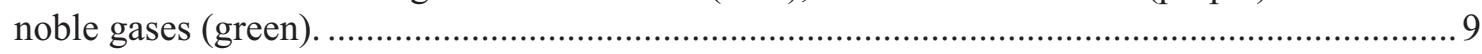

Figure 2-6. Reference fluoride volatility flowsheet [Kok 2009] ........................................................ 10

Figure 2-7. Steps in conventional uranium refining process [Benedict 1981] ....................................... 11

Figure 2-8. General nuclear fuel cycle categories [DOE 2010] ......................................................... 13

Figure 3-1. Potential nitrogen trifluoride UNF processing diagram.................................................... 15

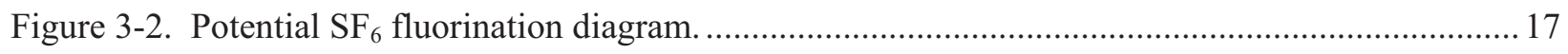

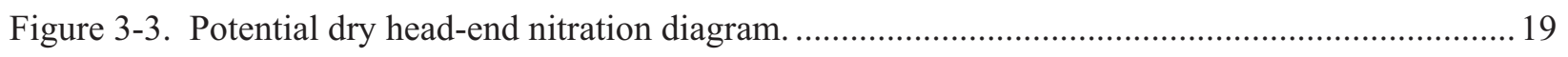

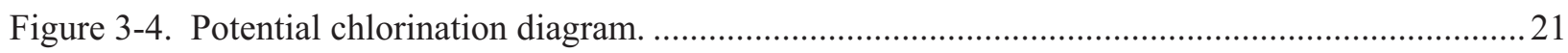

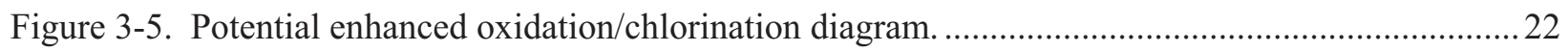

\section{TABLES}

Table 2-1. Primary output streams for an advanced aqueous system with basic voloxidation.................... 5

Table 2-2. Behavior of species in fluorination process [Gray 2010] .................................................... 9

Table 4-1. Product and waste stream comparison for nitrogen trifluoride system. ................................25

Table 4-2. Hazard parameter comparison for $\mathrm{NF}_{3}$ process versus reference process. …..........................29

Table 4-3. Product and waste stream comparison for reactive fluoride gas $\left(\mathrm{SF}_{6}\right)$ system....................... 33

Table 4-4. Some voloxidation/AIROX results listed in literature...........................................................35

Table 4-5. Hazard parameter comparison for $\mathrm{SF}_{6}$ process versus reference the fluoride volatility

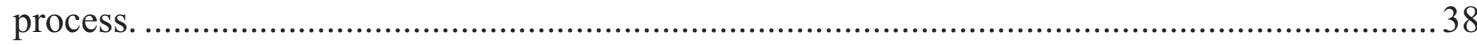

Table 4-6. Product and waste stream comparison for dry head-end nitration system...............................41

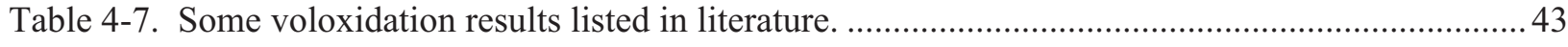

Table 4-8. Hazard parameter comparison for dry head-end process versus reference process...................44

Table 4-9. Product and waste stream comparison for Chlorination/Oxychlorination system................... 46

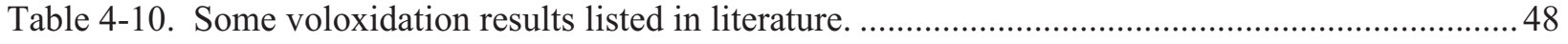

Table 4-11. Results from Run \#6- exposure of surrogate fuel to $350^{\circ} \mathrm{C}$ and $1: 1 \mathrm{Cl}_{2}: \mathrm{He}$ for 120

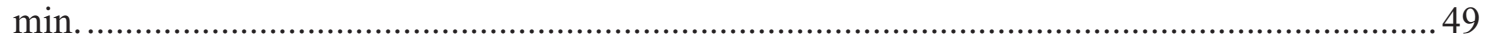

Table 4-12. Hazard parameter comparison for chlorination process versus reference process. ................. 50

Table 4-13. Product and waste stream comparison for Enhanced Oxidation/Chlorination system...........53

Table 4-14. Past results from voloxidation/OREOX testing on UNF...................................................55 
Table 4-15. Hazard parameter comparison for chlorination process versus reference process. .................56

Table 5-1. Summary of the reference and innovative separations processes..........................................63

Table 5-2. Unique features and differences for the innovative separations processes compared to the reference separations processes. 


\section{ACRONYMS}

$\begin{array}{ll}\text { AIROX } & \text { Atomics International Reduction-Oxidation } \\ \text { BSG } & \text { borosilicate glass } \\ \text { CANDU } & \text { Canada Deuterium Uranium } \\ \text { COG } & \text { cell off-gas } \\ \text { DEOX } & \text { declad and oxidize } \\ \text { DOE } & \text { Department of Energy } \\ \text { DOG } & \text { dissolver off-gas } \\ \text { DU } & \text { depleted uranium } \\ \text { FCR\&D } & \text { Fuel Cycle Research \& Development } \\ \text { FIT } & \text { Fuel Cycle Integration and Trade-off } \\ \text { FP } & \text { fission product } \\ \text { FR } & \text { full recycle } \\ \text { HEPA } & \text { high efficiency particulate air } \\ \text { HLW } & \text { high level waste } \\ \text { HOG } & \text { head-end off-gas } \\ \text { HTGR } & \text { high temperature gas reactor } \\ \text { HTO } & \text { tritiated water } \\ \text { HVAC } & \text { heating, ventilation \& air conditioning } \\ \text { ICPP } & \text { Idaho Chemical Process Plant } \\ \text { INL } & \text { Idaho National Laboratory } \\ \text { KAERI } & \text { Korea Atomic Energy Research Institute } \\ \text { LDRD } & \text { laboratory directed research and development } \\ \text { LWR } & \text { light water reactor } \\ \text { MC\&A } & \text { material control and accountability } \\ \text { MOC } & \text { modified open fuel cycle } \\ \text { MOX } & \text { mixed oxide fuel } \\ \text { MWF } & \text { metal waste form } \\ \text { OREOX } & \text { oxidation and reduction of oxide fuel } \\ \text { ORNL } & \text { Oak Ridge National Laboratory } \\ \text { once-through fuel cycle }\end{array}$


POG process off-gas

RU recovered uranium

SAP silica/alumina/phosphate

SRNL Savannah River National Laboratory

SS stainless steel

TBP tributylphosphate

TRU transuranic

UDS undissolved solids

UNF used nuclear fuel

UREX+ uranium reduction extraction +

VOG vessel off-gas

WF waste form

ZIT zinc encapsulated titanium oxide 


\section{SYSTEMS ANALYSIS CAMPAIGN INNOVATIVE SEPARATIONS PROCESSES}

\section{INTRODUCTION}

Reprocessing of used nuclear fuel (UNF) is a multi-faceted problem involving chemistry, material properties, and engineering. Technology options are available to meet a variety of processing goals. A decision about which reprocessing method is best depends significantly on the process attributes considered to be a priority. New methods of reprocessing that could provide advantages over the aqueous Plutonium Uranium Reduction Extraction (PUREX) and Uranium Extraction + $(\mathrm{UREX}+)$ processes, electrochemical, and other approaches are under investigation in the Fuel Cycle Research and Development (FCR\&D) Separations campaign.

In an attempt to develop a revolutionary approach to UNF recycle that may have more favorable characteristics than existing technologies, five innovative separations projects have been initiated. These include:

- Nitrogen Trifluoride for UNF Processing

- Reactive Fluoride Gas $\left(\mathrm{SF}_{6}\right)$ for UNF Processing

- Dry Head-end Nitration Processing

- Chlorination Processing of UNF

- Enhanced Oxidation/Chlorination Processing of UNF

The following sections will provide a description of the proposed processes, demonstrate how they fit into the Modified Open Cycle (MOC) and Full Recycle (FR) fuel cycles, and identify performance differences when compared to a "reference" advanced aqueous separations case. To be able to highlight the key changes to the reference case, it is valuable to give some general background on advanced aqueous solvent extraction, advanced oxidative processes (e.g., volumetric oxidation, or "voloxidation," which is high temperature reaction of oxide UNF with oxygen, or modified using other oxidizing and reducing gases), and fluorination and chlorination processes.

\section{REFERENCE CASE \& BACKGROUND}

\subsection{Advanced Aqueous Separations}

The innovative separation concepts are being proposed as alternatives or modifications to using existing advanced aqueous solvent extraction processes for recycling UNF. A high level block diagram of an advanced aqueous UNF processing concept is shown in Figure 2-1. This concept represents the types of aqueous separations processes that are used or have been demonstrated as at least reasonably viable technologies for reprocessing UNF. It is provided in this report to aid in understanding the differences in performance that may result from the proposed innovative separations approaches. The advanced aqueous processing is considered the "baseline" technology for comparisons in this report.

The reference UNF used in this analysis is Zircaloy-clad enriched uranium oxide fuel with a burnup of 51 $\mathrm{GWd}$ /tonne in a light water reactor (LWR), cooled 20 years after irradiation. Advanced aqueous reprocessing of LWR UNF includes the following main steps:

1. Chop the LWR fuel bundles (after removing stainless steel structural assembly components).

2. Load the chopped pieces into a concentrated nitric acid dissolver, prolonged acid digestion/dissolution and off-gas treatment, removal of metallic cladding and hardware pieces from the dissolver.

3. Filter the solution to remove undissolved solids (UDS).

4. Extract selective components from the acid solution using multi-stage solvent extraction. Separation of $U$ and $\mathrm{Pu}$ is done using a solution of tributylphosphate (TBP) in kerosene or dodecane. Optional separation of other elements in the fuel such as transuranic (TRU) elements, Tc, and $\mathrm{Cs} / \mathrm{Sr} / \mathrm{Rb} / \mathrm{Ba}$ using other solvents is also possible, although only separation of $\mathrm{U}$ and $\mathrm{Pu}$ has been done thus far commercially. 
5. Dry/calcine the separated products, acid and solvent recovery, and conversion of the remaining solution containing fission products (FPs) and minor actinide elements to waste forms.

6. Control systems for off-gas from the process, i.e., gaseous and volatile elements and compounds in the UNF that are released during processing and need to be captured to prevent any subsequent release into the environment.

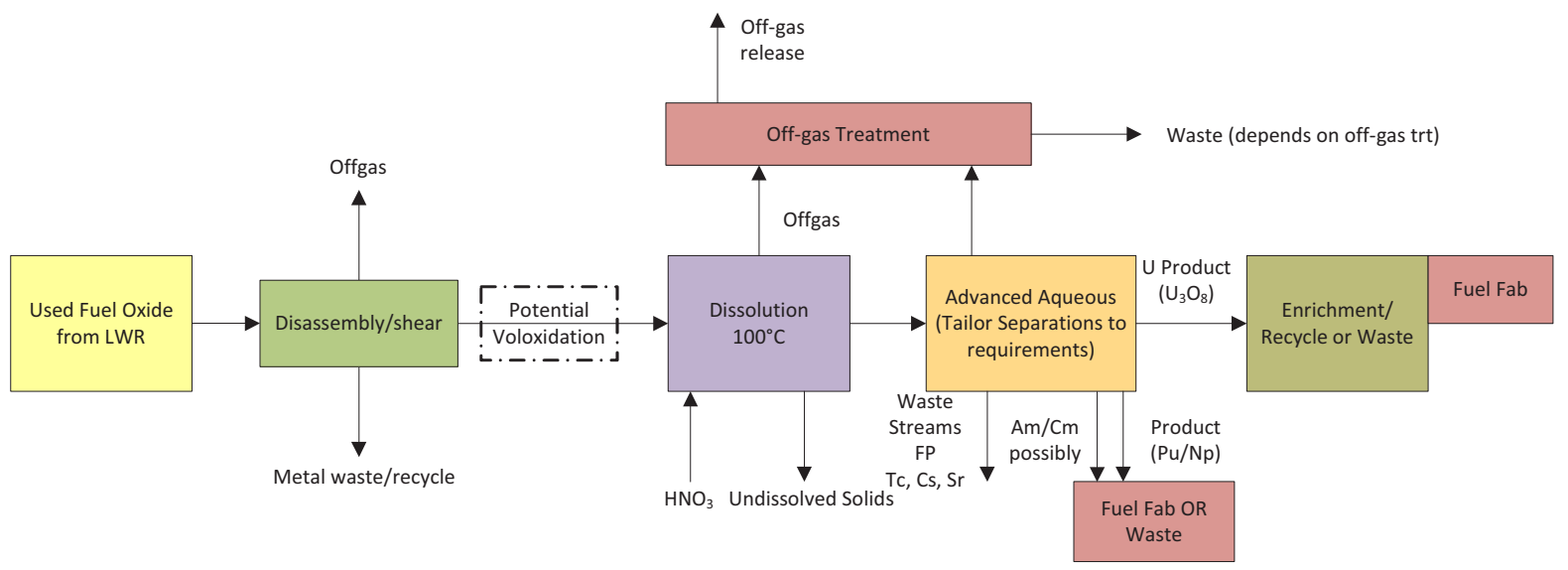

Innovative separations pfds.vsd

Figure 2-1. Reference advanced aqueous separations diagram.

The solution going into the first step in the solvent extraction portion of the separations process is an aqueous solution of uranyl nitrate, plutonium (IV) nitrate, nitric acid, small concentrations of neptunium, americium, and curium nitrates, and almost all of the nonvolatile FPs that were present in the fuel. Primary decontamination occurs in the first solvent extraction step, in which 99 to $99.9 \%$ of the FP are separated from the $\mathrm{U}$ and $\mathrm{Pu}$.

No separations processes are perfect. Thermodynamic, kinetic, or mass transfer limitations prevent $100 \%$ efficient separations of one element or group of elements from others. All separated product streams will contain various levels of undesired contaminants. Contaminants in recycled product streams can make recycled fuel fabrication more challenging and may adversely affect the performance of the fuel. Waste stream contamination by TRU elements and by radioactive waste elements in waste streams other than their intended destination may affect how those waste streams are processed into their final waste forms, their waste loadings, waste classification, radiolytic heat generation, radiolysis characteristics, radiotoxicity, storage, shipping, and their final disposition.

\subsubsection{Reference Case Off-gas Control}

Considering that most of the different innovative separations processes analyzed in this study include additional elements going to the off-gas, the reference case off-gas control systems require some definition. Various off-gas control systems in the reference case are needed for various parts of the aqueous processing system, including head-end off-gas (HOG), dissolver off-gas (DOG), vessel off-gas (VOG), process off-gas (POG), cell off-gas (COG), and building heating, ventilation, and air conditioning (HVAC). These will include separate, dedicated filtration and other control stages as necessary to capture and control gaseous species including gaseous FPs that are not efficiently captured in particulate filters and wet scrubbers.

Figure 2-2 illustrates how these separate off-gas systems might relate to each other. Due to different compositions, temperatures, and flowrates, it is impractical to use a single off-gas control system for all of these gas streams. But combining some (such as HOG, DOG, POG and VOG off-gas systems) that may contain the majority of some contaminants and have sufficiently similar flowrates and compositions may be possible and desired for capturing certain gaseous FPs. This figure shows all gas streams converging into an Atmospheric Protection System that provides final high efficiency particulate-air (HEPA) filtration. This 
convergence is not necessary, and multiple separate final HEPA filtration and stacks might be more practical depending on the detailed implementation of the separations technology in the processing facility.

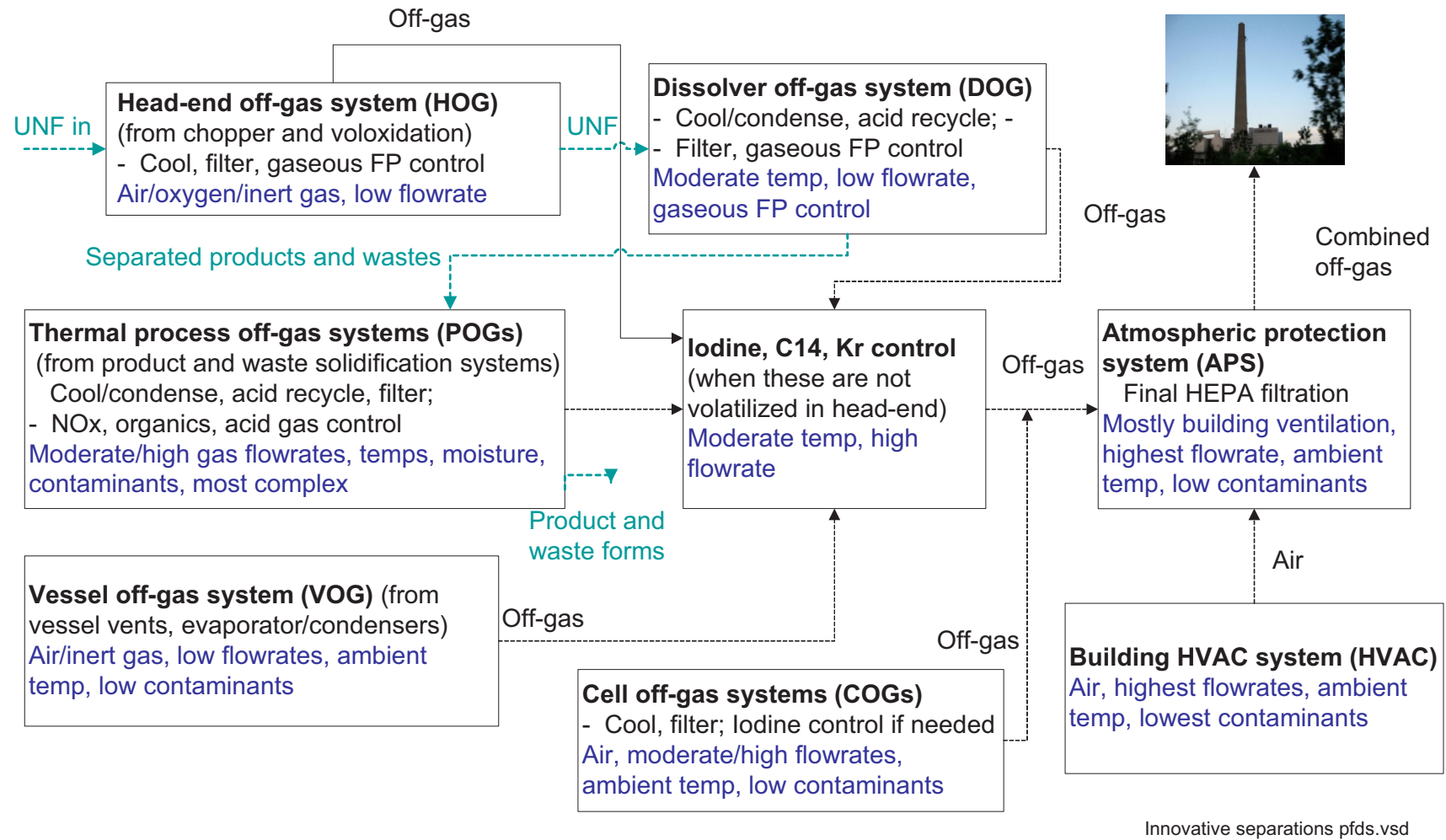

Figure 2-2. Overview of reference case off-gas control systems.

Figure 2-3 shows the reference case off-gas control system capable of controlling temperature and condensation, filtration of condensed and particulate matter, and efficient capture, if necessary, of iodine, tritium, carbon-14, and krypton.

This process includes cooling the off-gas to $<100^{\circ} \mathrm{C}$, followed by filtering to remove particulate. The fission product-laden particulate matter collected on the filter would be combined with other FP waste streams, or, in aqueous separations processes, it could be returned to the dissolver. The innovative technologies reviewed in this report may add $\mathrm{F}, \mathrm{Cl}$, or nitrate species into the collected particulate, which may present operational difficulties due to their propensities to plate out, and would likely affect the waste form required. I-129 would be sorbed onto silver zeolite (AgZ), which will also collect other halide FPs or trace halide contaminants, resulting in a larger waste stream for the innovative technologies using halides or halide compounds as part of the processing. In this design, the capture of iodine is performed first, before the capture of tritiated water or other gaseous fission products, to better prevent I-129 contamination in the waste forms for $\mathrm{H}-3, \mathrm{C}-14$, and $\mathrm{Kr} / \mathrm{Xe}$. 


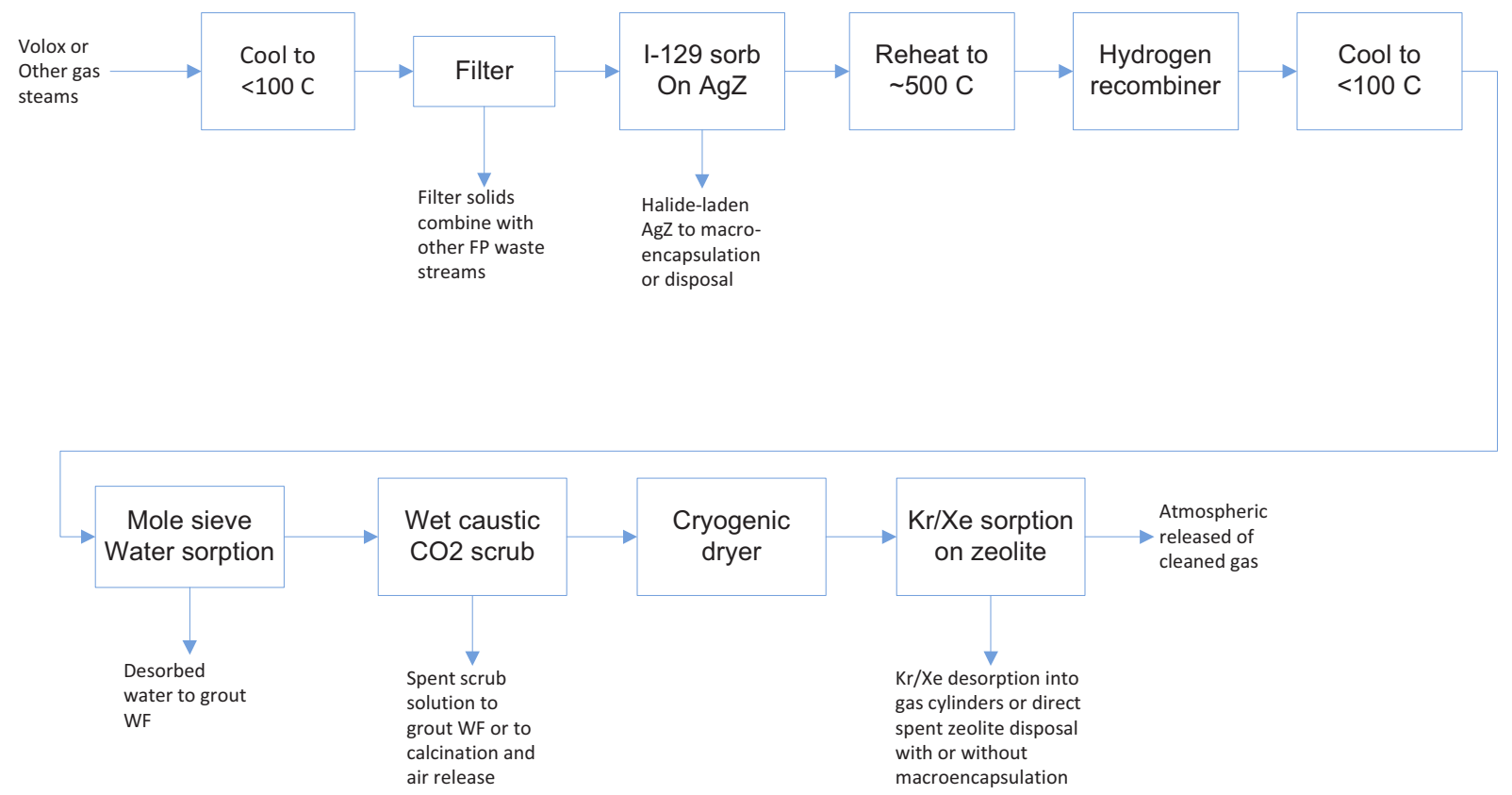

Figure 2-3. Reference case off-gas control for particulate matter and gaseous fission products.

The hydrogen recombiner will convert any tritium released from the UNF to tritiated water which is then removed from the off-gas with a molecular sieve desiccant. There is some potential for the desiccant to be contaminated with other isotopes and residual dust if they are not removed in the upstream processes. This could affect the disposition of the tritium waste stream, so the efficient capture of particulate matter and species like $\mathrm{I}_{2}$ upstream of the tritium capture stage is preferred where possible. The desiccant is thermally regenerated many times by heating the desiccant to temperatures up to about $250^{\circ} \mathrm{C}$, which desorbs the sorbed water and tritiated water, which is then captured in a condenser (backed by another desiccant stage). The C14, expected to exist in the off-gas as ${ }^{14} \mathrm{CO}_{2}$, is captured as ${ }^{14} \mathrm{CO}_{3}$ ion in a wet caustic scrubber. The scrub solution that is laden with either dissolved ${ }^{14} \mathrm{CO}_{3}$ ions or precipitated $\mathrm{CaCO}_{3}$, is solidified in Portland cement for disposal. After off-gas cryogenic drying, the $\mathrm{Kr}$ and $\mathrm{Xe}$ are removed by sorbing on zeolite. They can then potentially be desorbed and stored in gas cylinders or the spent zeolite is sent to waste.

Variations in this reference case off-gas system are possible, depending on the off-gas capture objectives. For example, the I-129 capture stage on silver zeolite (AgZ) may be located downstream, rather than upstream, of the molecular sieve desiccant tritiated water capture stage. This sequence may be best in aqueous separations processes when iodine capture is needed for dissolver or other gas streams that contain evaporated water along with iodine, to avoid the unnecessary capture of evaporated water in the desiccant used to capture tritiated water, and the undesired contamination of the tritiated water waste form with non-tritiated water.

Separate waste forms are included in the reference case for off-gas control of iodine (iodine-laden silver zeolite, with or without macroencapsulation), tritium (tritiated water in Portland cement), carbon-14 (grouted carbonate containing the $\mathrm{C}-14$ ), and krypton (gas cylinders containing $\mathrm{Kr}$ with stable $\mathrm{Xe}$, unless the $\mathrm{Xe}$ is separated from the radioactive $\mathrm{Kr}-85$ ). Solid particulate material is captured on filters as close as practical to the off-gas source, and will be returned to the process they came from or can be combined with other FP waste streams for combining into a waste form (typically a glass waste form) or placed into a separate waste form for disposal. This controls radioactive contamination and radiation levels within portions of the facility that are as small as possible, helping to reduce the size of hot cells and the amount of equipment in hot cells. 


\subsubsection{Reference Case Output Streams}

The output product and waste streams are two of the primary differentiators for the innovative separations processes in comparison to existing technologies. Table 2-1 summarizes the output streams for the reference case.

Table 2-1. Primary output streams for an advanced aqueous system with basic voloxidation.

\begin{tabular}{|c|c|}
\hline Process & Reference Case: Advanced Aqueous w/ Basic Voloxidation \\
\hline $\begin{array}{l}\text { Disassemble } \\
\text { and Chop }\end{array}$ & $\begin{array}{l}\text { 1. Metal Fuel Assembly parts (activated and/or contaminated) } \\
\text { 2. Chopped fuel elements } \\
\text { 3. Off-gas - Up to } 10 \% \mathrm{Kr}, \mathrm{Xe} \text {, (some C-14, H-3, and other FP) }\end{array}$ \\
\hline $\begin{array}{l}\text { Fuel } \\
\text { Oxidation }\end{array}$ & $\begin{array}{l}\text { 1. Zr cladding contaminated with FPs and actinides (when voloxidation is not } \\
\text { used to separate cladding from fuel, the cladding is separated during } \\
\text { dissolution) } \\
\text { 2. Off-gas : }>99.8 \% \mathrm{H}-3,6 \% \mathrm{Kr}, 6 \% \mathrm{Xe}, 50 \% \mathrm{C}, 1 \% \mathrm{I}, \mathrm{Br},<0.2 \% \mathrm{Ru}, \mathrm{Sb}, \mathrm{Cs} \text { at } \\
\text { moderate temps/rxn times }\end{array}$ \\
\hline $\begin{array}{l}\text { Dissolution/ } \\
\text { Filtration }\end{array}$ & $\begin{array}{l}\text { 1. Undissolved solids (can be combined with FP in glass, or with Tc, stainless } \\
\text { steel (SS), and Zircaloy in melted metal waste form) } \\
\text { 2. Off-gas [w/ no voloxidation: all remaining Kr, } 90 \% \text { of the I, some C-14, some } \\
\text { H-3] } \\
\text { 3. Zr cladding (contaminated with FPs and actinides) when voloxidation is not } \\
\text { used to separate fuel from cladding }\end{array}$ \\
\hline Separation & $\begin{array}{l}\text { Several options are possible depending on uranium and TRU recycle or if separate } \\
\text { waste management pathways for different FPs are desired: } \\
\text { Product streams: } \\
\text { 1. Uranium } \\
\text { 2. TRU, possibly with uranium } \\
\text { 3. Pu, Np, Am, Cm, \& other TRU, either separately or in groups } \\
\text { Primary waste streams: } \\
\text { 1. FP in high level waste (HLW) glass- includes the acidic FP waste stream } \\
\text { (raffinate) from } 1 \text { st cycle, Tank waste, and UDS (vitrified) } \\
\text { 2. Tc in } \mathrm{Zr} / \mathrm{SS} / \mathrm{Tc} / \mathrm{UDS} \text { metal waste form (MWF), if the Tc is separated from } \\
\text { other FPs and if the UDS is placed into MWF instead of glass } \\
\text { 3. } \mathrm{Cs} / \mathrm{Sr} / \mathrm{Rb} / \mathrm{Ba} \text { in mineral waste form if separated from other FPs } \\
\text { 4. } \mathrm{Np}, \mathrm{Am}, \mathrm{Cm} \text {, and other TRU if separated for disposal instead of recycle }\end{array}$ \\
\hline $\begin{array}{l}\text { Off-gas } \\
\text { control } \\
\text { systems }\end{array}$ & $\begin{array}{l}\text { The reference gaseous FP waste forms are: } \\
\text { 1. } \mathrm{H}-3 \text { in tritiated water (HTO) in grouted waste form } \\
\text { 2. } \mathrm{I}-129 \text { in glass-bonded silver zeolite waste form } \\
\text { 3. } \mathrm{C}-14 \text { in } \mathrm{CO}_{2} \text { grouted waste form } \\
\text { 4. } \mathrm{Kr}-85 \text { (with or without nonradioactive Xe) in compressed gas cylinders. } \\
\text { Particulate matter formed from entrained dust and condensed semi-volatile matter } \\
\text { in the head-end and dissolver off-gas systems is filtered in cleanable filters and } \\
\text { returned to the dissolver for dissolution. Particulate matter recovered from the } \\
\text { process gas streams (from treating the product and waste streams) is returned to } \\
\text { those processes or is solidified into a separate secondary waste form. The much } \\
\text { smaller amounts of particulate matter captured on HEPA filters is assumed to be } \\
\text { disposed with the filters. }\end{array}$ \\
\hline
\end{tabular}

The incoming UNF assemblies are disassembled to separate the stainless steel structural components from the fuel rods. These structural components are assumed to be radioactive due to activated isotopes, and are disposed as radioactive waste, although it is possible to reuse these materials in principle. After disassembly, the fuel rods are chopped. Alternatives to chopping may include drilling multiple holes in the cladding to 
expose the fuel, and then allowing fuel expansion during voloxidation to complete the process of splitting open the cladding. Small amounts of gaseous FPs are released at this step. It is assumed that the chopping process can be contained inside an enclosure that is vented to the head-end off-gas system to avoid contaminating the entire hot cell with these small amounts of FPs.

The chopped fuel is then loaded into the dissolver. Dissolution occurs in a hot concentrated nitric acid solution, but about $1 \%$ of the UNF doesn't dissolve and remains as UDS that either remain with the cladding or must be filtered from the solution prior to the solvent extraction steps. The cladding removed from the dissolver is rinsed, but the cladding remains radioactive due to the small amount of remaining radioactive FPs and actinides from the UNF and because of activation products in the metal. The UDS is filtered from the nitric acid solution, and may be discarded in one of at least two options - vitrification with FPs in glass, or addition to a metal alloy waste form with Tc, stainless steel, and Zircaloy. This metal alloy waste form may not use all of either the stainless steel or Zircaloy recovered from the UNF assembly and any unused steel and Zircaloy is discarded in a compacted MWF.

When moderate-temperature fuel oxidation/voloxidation is included in the reference case prior to dissolution, then the fuel is oxidized from $\mathrm{UO}_{2}$ to $\mathrm{U}_{3} \mathrm{O}_{8}$, swells to a larger volume that causes separation from the cladding and is pulverized due to the chemical change, allowing some volatilization of volatile and semi-volatile FPs and release of some of the gaseous fission products.

The reference aqueous separations process represents various alternative processes downstream of the dissolver for separating (or not) the $\mathrm{U}, \mathrm{Pu}$, and minor actinides into recyclable product streams; and separating (or not) $\mathrm{Tc}, \mathrm{Cs} / \mathrm{Sr} / \mathrm{Rb} / \mathrm{Ba}$, and lanthanides into separate FP waste streams. These separated product and waste streams are aqueous solutions that contain amounts of nitric acid and incompletely recovered organic solvents. These liquid waste streams are processed through evaporators to recover and recycle water and acid, and then processed to convert the product streams into the appropriate $\mathrm{U}, \mathrm{Pu}$, and/or TRU products for fuel fabrication; to convert the FP waste and UDS into a vitrified borosilicate glass (BSG); and to optionally convert the Tc into a steel/Zircaloy/Tc/UDS metal alloy, convert separated $\mathrm{Cs} / \mathrm{Sr} / \mathrm{Rb} / \mathrm{Ba}$ into a mineral waste form, and to convert separated lanthanides into a lanthanide BSG.

The reference aqueous case assumes that the gaseous FPs I, C-14, and $\mathrm{Kr}$, must be nearly entirely captured. When no voloxidation is used or when moderate voloxidation is used, the I, C-14, and $\mathrm{Kr}$ are not completely separated upstream of the dissolver. The $\mathrm{Kr}$ can be nearly completely volatilized in the head-end and dissolver, but the I-129 and C-14 can be distributed among multiple off-gas streams, and nearly complete capture, if necessary, becomes more complex and costly.

When no voloxidation is used, H-3 is not completely released from the UNF upstream of the dissolver. Once the UNF is loaded into the dissolver, the H-3 in the fuel is converted to tritiated water (HTO), then the H-3 is diluted with hydrogen in the dissolver water and downstream process streams, which makes separation and capture impractical. If nearly complete $\mathrm{H}-3$ recovery is necessary, then voloxidation or a similar process is necessary to completely release the H-3 from the UNF upstream of the dissolver.

\subsection{Dry Separations Background}

A dry separations process is typically defined as one that does not use any aqueous processing. Examples include electrochemical processing at high temperature using molten salt, or gaseous processing at high temperature. Dry oxidation of the fuel is one type of dry process. It takes advantage of the different vapor pressures of the elements or compounds by heating the fuel in various atmospheres to facilitate release of gaseous FPs such as the noble gases, I, C-14, and H-3 from the UNF, and, at higher temperatures, Cs and Tc. Halide volatility is another class of dry separation technology. Halides (fluorides or chlorides) can form volatile or water soluble compounds with the actinide elements. By converting UNF into halide forms, fractional distillation or dissolution with alternate solvents (water, etc.) of the actinide halides allows separation from the bulk of the FPs. 


\subsubsection{Dry Fuel Oxidation}

In all five innovative approaches being investigated some form of high temperature oxidation of the fuel is assumed for removal of the cladding from the chopped fuel, to increase surface area for reactions, and to remove gaseous and volatile FPs. Much research work has taken place on this type of process and a variety of flowsheets/conditions have been investigated but none have been implemented in a commercial facility. As an example, two fuel oxidation alternatives, voloxidation and the Atomics International Reduction-Oxidation (AIROX) process, are described below.

Voloxidation (short for volumetric oxidation) was developed as a dry head-end method for separating the fuel from the cladding, increasing the fuel particle surface area for better dissolution and separations, and removing tritium from UNF prior to aqueous processing. As discussed above, it is important to remove the tritium prior to contact with an aqueous solution to avoid tritium contamination throughout the entire aqueous system. In voloxidation, the $\mathrm{UO}_{2}$ fuel reacts with oxygen to form $\mathrm{U}_{3} \mathrm{O}_{8}$ which results in a restructuring of the crystallite accompanied by particle crumbling. This increases the available surface area for reaction and releases the fuel from the segments of chopped cladding.

Figure 2-4 shows the role of voloxidation in a separations process. Oxidation of the fuel at moderate temperatures in air releases over $99.8 \%$ of the tritium. The voloxidation process usually takes place at $480^{\circ} \mathrm{C}$ $600^{\circ} \mathrm{C}$. Higher temperatures increase the reaction rate but may affect plutonium solubility in the typical nitric acid dissolution process. Powder size distribution also depends on the temperature (typically forming particles less than $20 \mu \mathrm{m}$ ). In this process (about $480^{\circ} \mathrm{C}$ and 4 hours processing) about half of the $\mathrm{C}-14,6 \%$ of the $\mathrm{Kr}$ and $\mathrm{Xe}, 1 \%$ of the $\mathrm{I}$ and $\mathrm{Br}$ and $<0.2 \%$ of the $\mathrm{Ru}, \mathrm{Sb}$, and $\mathrm{Cs}$ are volatilized. With higher temperatures and longer reaction times larger fractions of the noble gases and semi-volatiles are released (for instance at $750^{\circ} \mathrm{C}$ 8-10hr, up to $60 \% \mathrm{Kr}$ released) [ORNL 2009].

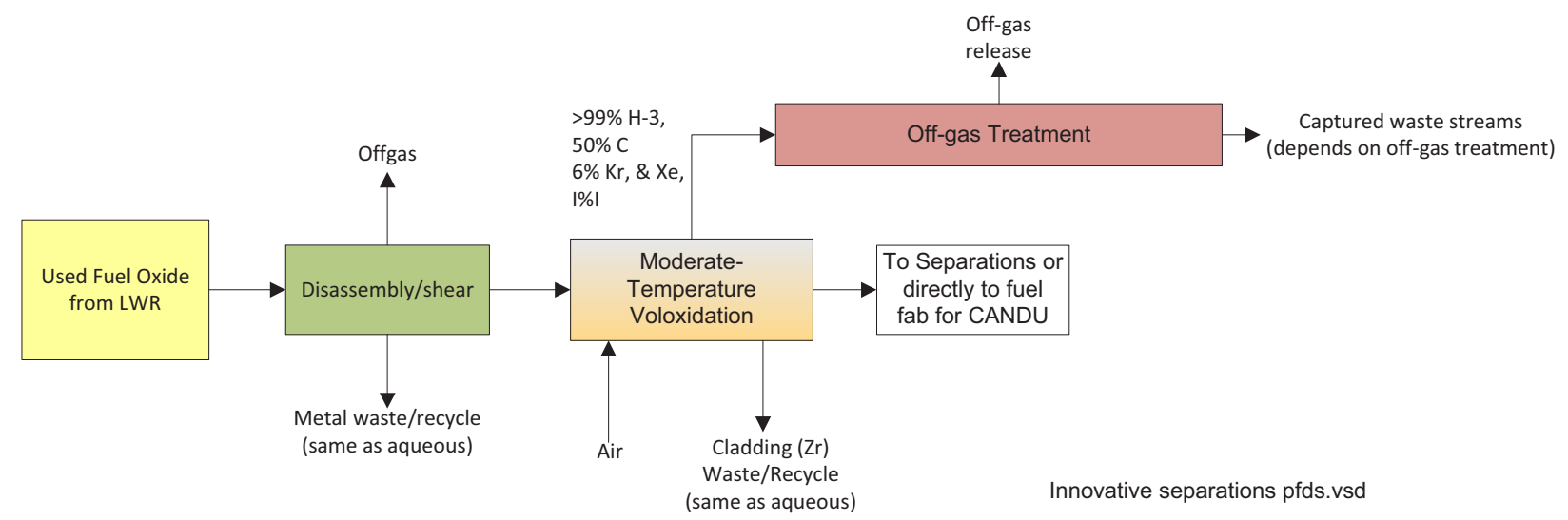

Figure 2-4. Reference voloxidation process.

A similar process, the AIROX process, is a dry method for processing of LWR UNF. It involves pulling the fuel rods from the fuel assembly, puncturing the cladding of each fuel rod at about $2.5 \mathrm{~cm}$ intervals, and exposing the fuel rods to multiple high temperature cycles of $\mathrm{O}_{2}$ and $\mathrm{H}_{2}$ to convert the $\mathrm{UO}_{2}$ to $\mathrm{U}_{3} \mathrm{O}_{8}$. The pulverization of the $\mathrm{UO}_{2}$ takes place by oxidation with $\mathrm{O}_{2}$ in argon at about $400^{\circ} \mathrm{C}$ which expands the fuel volume by about $30 \%$ while forming the $\mathrm{U}_{3} \mathrm{O}_{8}$. The volume increase ruptures the cladding and pulverizes the fuel. The $\mathrm{U}_{3} \mathrm{O}_{8}$ is reduced back to $\mathrm{UO}_{2}$ with dilute hydrogen $(10-20 \%)$ in argon at about $600^{\circ} \mathrm{C}$. Up to three oxidation-reduction cycles are used to achieve the desired particle size distribution. The initial intent of this process was to remove FPs that could be volatilized at these temperatures and to produce a powder that could be blended with highly enriched uranium/plutonium oxide to produce recycled fuel pellets, sintered (at $1700^{\circ} \mathrm{C}$ ), and loaded into reconstituted fuel rods and assemblies [Majumdar 1992].

During the AIROX process, nearly $100 \%$ of the volatile FPs (Kr, Xe, I and tritium) can be released from the fuel. Various references reported different AIROX removal results in the following ranges: Cs (95-100\%), Ru 
(67-90\%), Te (50-99\%), Tc (0-99.9\%), Cd (0-99\%), In (0-99.9\%), possibly Ag, Mo, Ir, Rd, Rh, and Se. Medium and low-volatility FPs (Ba, Sr, Ce, $\mathrm{La}, \mathrm{Td}$, and $\mathrm{Zr}$ ) remain in the fuel, as do the U, Pu and higher actinides [Christian 1999, Piet 2010]. In addition, some of the semi-volatile FPs are released during pellet sintering due to the higher temperatures.

\subsubsection{Fluoride Volatility Processes}

The fluoride volatility process has been widely researched as a method for the separation of metals for many years. The procedure involves exposing the metal to a highly reactive fluorinating agent, usually hydrogen fluoride $(\mathrm{HF})$, fluorine gas $\left(\mathrm{F}_{2}\right)$, or halogen fluoride (interhalogen) compounds $\left(\mathrm{BrF}_{3}, \mathrm{BrF}_{5}, \mathrm{ClF}_{3}\right)$. $\mathrm{HF}$ reacts with the metals, forming volatile metallic fluorides of elements with valence of five or greater. This increased volatility is exploited to achieve separation with standard distillation/absorption techniques. The fluoride volatility process is typically used in preparing natural uranium for enrichment and has over five decades of commercial industrial experience.

The original development of this method of UNF reprocessing was motivated in the past by the anticipation of the deployment of fast breeder reactors. Economic application of fast breeder reactors required a closed fuel cycle where all UNF is reprocessed. However, reprocessing of high burn-up, short-cooling-time (i.e. high radiation levels and decay heat) fast reactor UNF was unsuitable for the advanced aqueous processes which use organic extractants and solvents that are susceptible to excessive degradation in high radiation fields. Hence, the most intensive effort in the development of the fluoride volatility method was in the 1960s and 1970s together with the development of fast breeder reactors [Uhlir 2009].

Table 2-2 shows the projected separation efficiencies of the principle UNF elements using fluoride volatility. Thermodynamic calculations have been performed to understand the volatilization of the UNF elements to determine their theoretical phase separation behavior for potential separation [Gray 2010].

Plutonium forms a volatile hexafluoride with characteristics similar to uranium hexafluoride; therefore, it became apparent that plutonium and uranium could be recovered from irradiated fuels by using differences in volatility of the fluoride compounds. Few other elements form volatile fluorides. Exceptions among the FPs are $\mathrm{Mo}, \mathrm{Tc}$, and $\mathrm{Ru}$, and to a lesser extent, Te and I. Te and I can be oxidized to a higher oxidation state to make them more volatile as fluorides than $\mathrm{Pu}$ and $\mathrm{U}$ so they can be separated by simple distillation methods [CGER 1996]. Figure 2-5 shows the periodic table with green indicating the noble gases, blue the elements that have volatile fluoride compounds and purple the elements that do not have volatile fluoride compounds [Piet 2011]. 
Table 2-2. Behavior of species in fluorination process [Gray 2010].

\begin{tabular}{|c|c|c|c|c|c|}
\hline Group & $\begin{array}{l}\text { Chemical } \\
\text { Form }\end{array}$ & $\begin{array}{l}\text { Volatile/Non } \\
\text { Volatile }\end{array}$ & $\begin{array}{l}\text { Melting } \\
\text { Point }\left({ }^{\circ} \mathrm{C}\right)\end{array}$ & $\begin{array}{l}\text { Boiling (or } \\
\text { Sublimation) } \\
\text { Point }\left({ }^{\circ} \mathrm{C}\right)\end{array}$ & $\begin{array}{l}\text { Separation } \\
\text { Efficiency }(\%)\end{array}$ \\
\hline \multirow[t]{6}{*}{ Actinides } & $\mathrm{UF}_{6}$ & Volatile & 64.8 & 56.5 & $95-99.5$ \\
\hline & $\mathrm{UF}_{4}$ & Non-volatile & $960[\mathrm{CRC}]$ & & \\
\hline & $\mathrm{PuF}_{6}$ & Volatile & 62 & 52 & $\sim 98-99.5$ \\
\hline & $\mathrm{PuF}_{4}$ & Non-volatile & 1037 [CRC] & & \\
\hline & $\mathrm{NpF}_{6}$ & Volatile & 54.8 & 55.2 & $\sim 60-70$ \\
\hline & $\mathrm{AmF}_{3}$ & Non-volatile & & & \\
\hline Alkali Metals & $\mathrm{CsF}$ & Non-volatile & 682 & 1251 & \\
\hline \multirow[t]{2}{*}{ Alkaline Earth Metals } & $\mathrm{SrF}_{2}$ & Non-volatile & 1477 & 2460 & \\
\hline & $\mathrm{BaF}_{2}$ & Non-volatile & 1355 [CRC] & $2137[\mathrm{CRC}]$ & \\
\hline \multirow[t]{8}{*}{ Transition Metals } & $\mathrm{ZrF}_{4}$ & Non-volatile & 932 & 905 & \\
\hline & $\mathrm{NbF}_{5}$ & Volatile & 79 & 234 & $\sim 95-99$ \\
\hline & $\mathrm{MoF}_{6}$ & Volatile & 17.4 & 34 & \\
\hline & $\mathrm{TcF}_{6}$ & Volatile & 37.4 & 55.3 & \\
\hline & $\mathrm{RuF}_{5}$ & Volatile & $101[\mathrm{CRC}]$ & $250[\mathrm{CRC}]$ & $\sim 95-99$ \\
\hline & $\mathrm{RuF}_{6}$ & Volatile & 32.1 & 45.9 & \\
\hline & $\mathrm{RhF}_{5}$ & Volatile & & 95.5 & \\
\hline & $\mathrm{RhF}_{6}$ & Volatile & 70 & 73.5 & \\
\hline \multirow[t]{4}{*}{ Typical elements } & $\mathrm{TeF}_{6}$ & Volatile & -38 & -39 & \\
\hline & $\mathrm{SeF}_{6}$ & Volatile & & -34.5 & \\
\hline & $\mathrm{IF}_{5}$ & Volatile & 9.4 & 98 & \\
\hline & $\mathrm{IF}_{7}$ & Volatile & 5 & 4 & \\
\hline \multirow[t]{3}{*}{ Lanthanides } & $\mathrm{LaF}_{3}$ & Non-volatile & 1493 & & \\
\hline & $\mathrm{CeF}_{3}$ & Non-volatile & 1430 & 2327 & \\
\hline & $\mathrm{NdF}_{3}$ & Non-volatile & 1374 & 2300 & \\
\hline
\end{tabular}

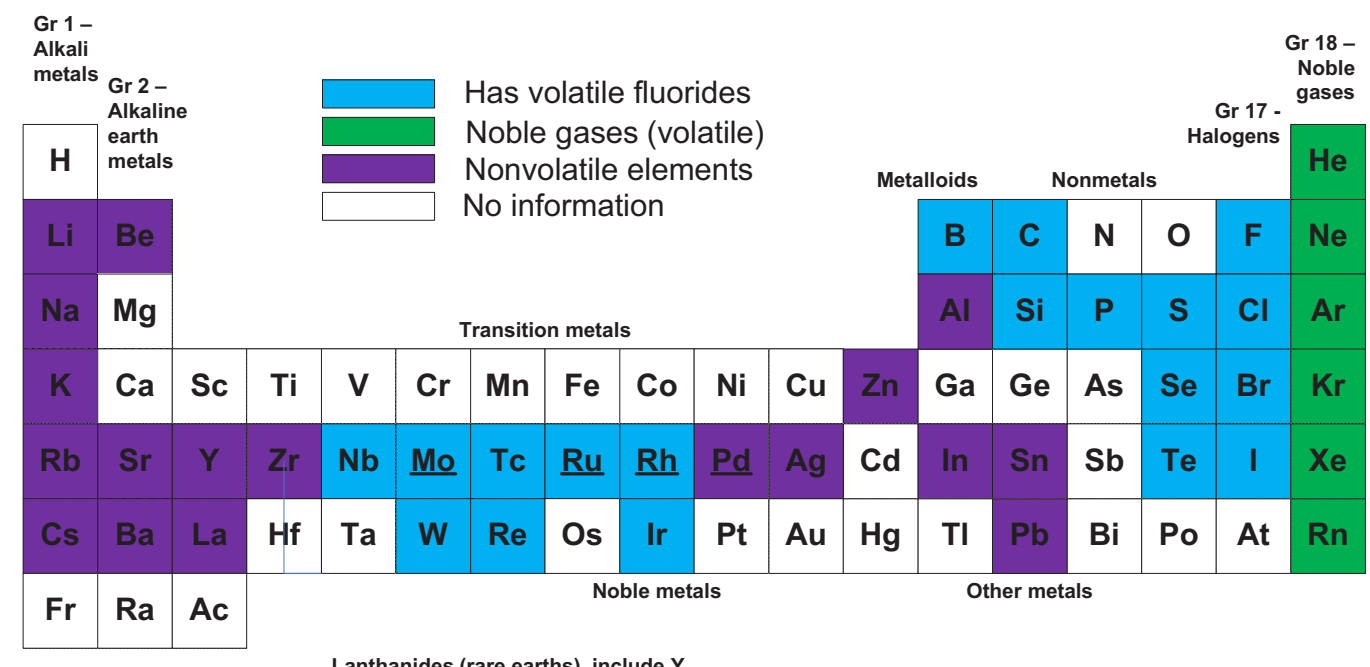

Lanthanides (rare earths), include $Y$

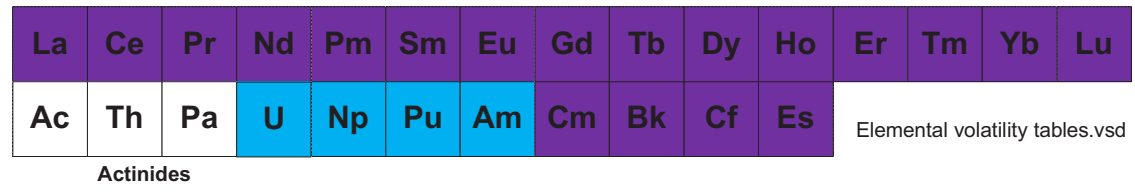

Figure 2-5. Periodic table indicating volatile fluorides (blue), nonvolatile elements (purple) and noble gases (green). 
Flowsheets for fluoride volatility processing vary in the literature and many alternatives have been considered. Figure 2-6 shows a proposed flowsheet from the 1970's.

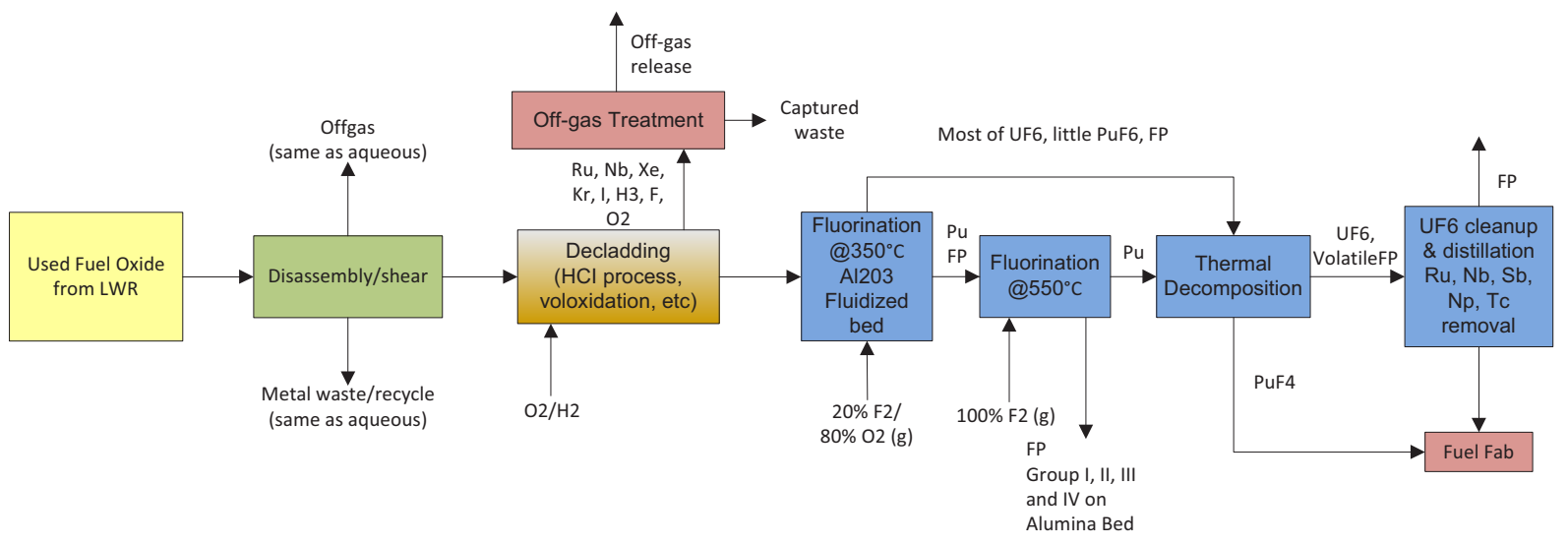

Innovative separations pfds.vsd

Figure 2-6. Reference fluoride volatility flowsheet [Kok 2009].

Uranium hexafluoride conversion was initially developed to produce feed for the gaseous diffusion process for uranium enrichment, and became routine on the multi-ton per day commercial scale. The final purification of the uranium from ore is usually by solvent extraction, and the recovered uranium oxide is reduced to the dioxide, hydrofluorinated with hot anhydrous hydrofluoride, and then fluorinated with fluorine from a nonaqueous electrolytic cell (Figure 2-7). The existing large-scale fluorination systems that are used in the preparation of pure $\mathrm{UF}_{6}$ from uranium ore for the redistribution of the $U$ isotopes in uranium enrichment plants obtain very good separation from most elements. There have been difficulties with the separation of the very small amounts of Mo, Tc, Np, and Pu that have been present in the feed. Tc progresses very slowly through the diffusion cascades and is a constant problem once the system is contaminated with it. Tungsten and molybdenum hexafluoride move readily in the diffusion plant and can also slightly contaminate the product [CGER 1996, Benedict 1981].

In another fluorination process that has been demonstrated, Pu residues were separated from other elements by fluorinating $\mathrm{PuO}_{2}$ in a fluidized bed reactor with fluorine at $400^{\circ} \mathrm{C}$ to form $\mathrm{PuF}_{6}$, which volatilizes from the non-volatile elements. After separation, the $\mathrm{PuF}_{6}$ was decomposed to $\mathrm{PuF}_{4}$ and $\mathrm{F}_{2}$ in a thermal decomposition column. This system worked but was not put into production. A development effort was also conducted through pilot plant testing to demonstrate the use of fluorine oxide, $\mathrm{O}_{2} \mathrm{~F}_{2}$ to convert $\mathrm{PuO}_{2}$ to $\mathrm{PuF}_{6}$ at ambient temperatures in simple reactor systems. According to this reference, isolation of $\mathrm{Pu}$ or $\mathrm{U}$ from bulk impurities or FPs by volatility methods has been demonstrated to be a practical approach that could be scaled to industrial levels [CGER 1996].

An evaluation completed in 1990 by Oak Ridge National Laboratory (ORNL) [Mallen 1990] indicated that $\mathrm{UF}_{6}$ obtained through fluorination processing of LWR UNF could be decontaminated adequately for direct feed to an enrichment plant. This evaluation included hydrofluorination with $\mathrm{HF}$ to produce $\mathrm{UF}_{4}$ and other fluorides. Then the dry fluorides would be fluorinated under strongly oxidizing conditions with compounds such as interhalogen fluoride compounds $\left(\mathrm{BrF}_{5}, \mathrm{ClF}_{3}, \mathrm{BrF}_{3}\right)$. This produces $\mathrm{UF}_{6}$ gas (along with small amounts of very few volatile FP fluorides) and leave nearly everything else (including most of the Pu and $\mathrm{Np}$ ) in the form of non-volatile/less volatile compounds. If elemental fluorine is used instead of the interhalogen fluorides, $\mathrm{Np}$ and $\mathrm{Pu}$ might be more volatile. It indicated though it is possible to volatilize $\mathrm{PuF}_{6}$ with elemental fluorine or $\mathrm{O}_{2} \mathrm{~F}_{2}$, it is a difficult reaction to accomplish, yields tend to be low, and it would require a fluidized bed and complex procedure. It is difficult to modify this process to produce purified $\mathrm{Pu}$ as it would still be substantially contaminated with some FP. This report seems to conflict somewhat with the some of the other 
references. The Mallen report also stated, "Major problems will involve heat-transfer and mechanical problems, such as formation of molten or "sticky" fluoride products."

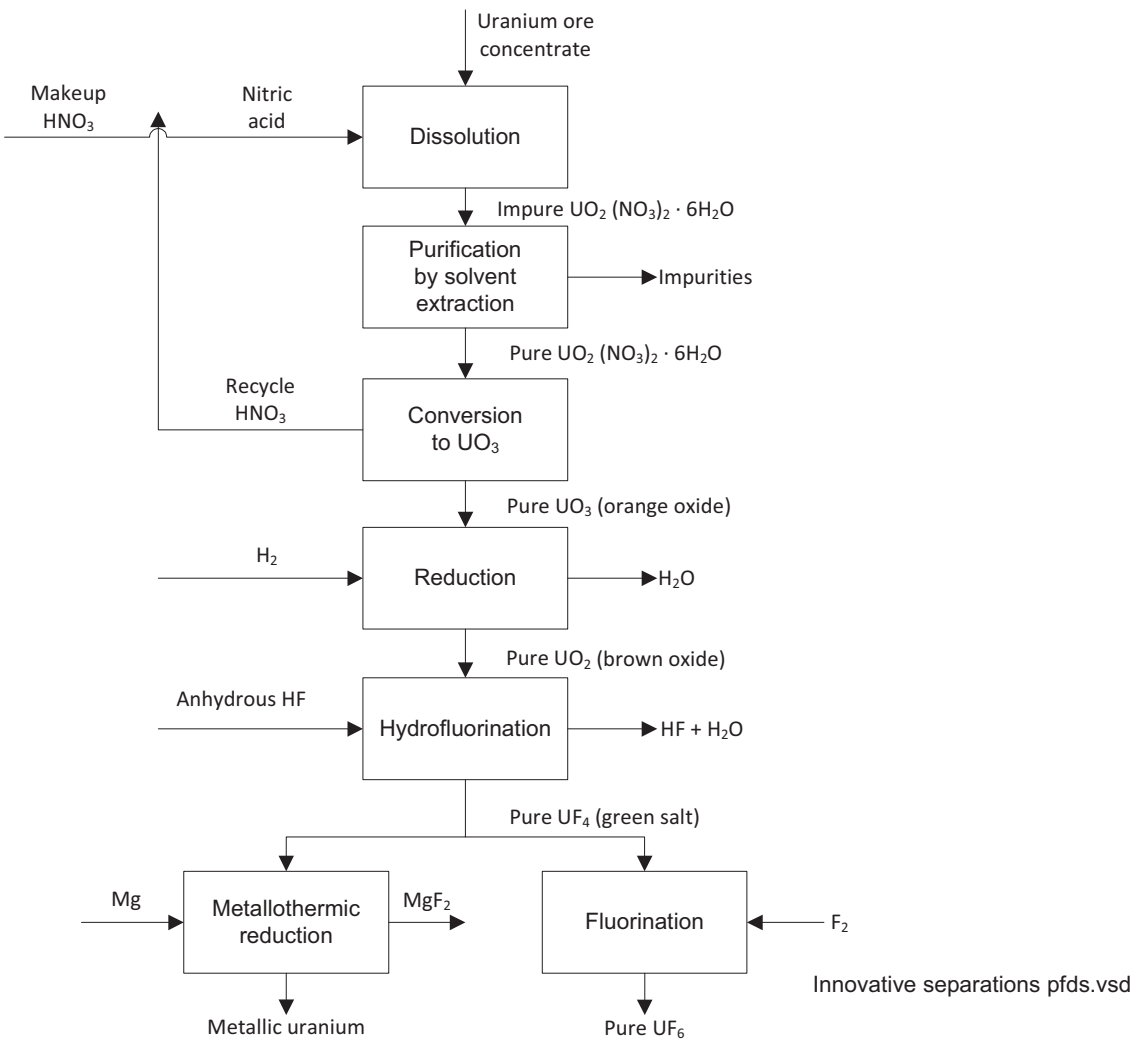

Figure 2-7. Steps in conventional uranium refining process [Benedict 1981].

Large scale fluoride volatility plants for UNF processing are feasible but none have been built and operated in western countries. A pilot plant utilizing fluoride volatility as a component of the overall plant system has reportedly been constructed in Dimitrograd, Russia for the processing of fast-reactor demonstration fuels but little information has been released on the utility of the facility or in the economics of volatility processing under the conditions imposed by spent fuel [CGER 1996].

In the Aquafluor process developed by the General Electric Company, U was separated from the Pu and FP (from LWR UNF) using aqueous solvent extraction and anion exchange. Then the final uranium separation and purification was to be conversion of impure uranyl nitrate to $\mathrm{UF}_{6}$, followed by removal of small amounts of $\mathrm{PuF}_{6}, \mathrm{NpF}_{6}$, and other volatile fluorides by adsorption on beds of $\mathrm{NaF}$ and $\mathrm{MgF}_{2}$ and a final fractional distillation. A plant to process $1 \mathrm{MT} /$ day was built but was never used for irradiated fuel because of inability to maintain on-stream, continuous operation even in runs on unirradiated fuel. The difficulties were believed to be more the fault of details in the design rather than being inherent in the process and are related to the attempt to carry out aqueous primary decontamination, denitration, fluorination, and distillation of intensely radioactive materials in a close-coupled, continuous process, without adequate surge capacity between the different steps and without sufficient spare, readily maintainable equipment [Benedict 1981].

The FLUOREX process has been proposed by Hitachi as a flexible method that can be adapted to produce fuels for light water reactors and future fast breeder reactors. This process combines elements of the fluoride volatility process with separation of some UNF elements using aqueous techniques similar to the PUREX process. The preparation and fluorination steps are similar to the fluoride volatility process. After the volatile fluorides are removed, the remaining non-volatile fluorides are converted to oxides using pyrohydrolysis which reacts the metal fluorides with steam to produce metal oxides and HF. The metal oxides are dissolved in 
nitric acid and undergo extraction with TBP similar to the aqueous processes. The advantage of the FLUOREX process compared to aqueous processes is that the fluoride volatization step significantly reduces the amount of material going through the aqueous process as most of the $\mathrm{U}$ (which is by far the largest component of the UNF) is removed prior to aqueous dissolution [Gray 2011, Kani 2009].

\subsubsection{Chloride Volatility Processes}

Many of the elements that form volatile high-valence fluorides will also form volatile high-valence chlorides. Chlorination and distillation is another possible method for separation and has even been proposed as a method for removing zirconium cladding from used fuel instead of mechanical decladding. Chlorides are likely easier than fluorides to later convert back to other compounds, such as oxides. However, the separation of volatilized $\mathrm{U}$ chlorides from structural material chlorides (such as $\mathrm{Zr}$ ) is more difficult due to overlapping vapor-pressure ranges. Most chloride compounds are soluble in water, and final recovery can be done using aqueous processing. None of the chlorination processes has been tested on a pilot-plant scale or with appreciable quantities of FPs.

\subsubsection{Waste Forms for Halide-laden Waste Streams}

Fluoride and chloride volatility processes introduce these halides into the waste streams produced when processing UNF. Halides generally have low solubilities in borosilicate glass (BSG), the reference waste form for FPs separated during the reference aqueous separations process. Three options are available, either (a) significantly lower the waste loading in BSG, (b) separate and recycle the halides, or (c) develop a waste form that can contain the halides at high enough concentrations so that the presence of the halides does not significantly reduce the waste loading. Options (b) or (c) are the presumed preferred options for this report, because a significant reduction in waste loading would substantially increase the waste mass and volume, adversely affecting treatment, packaging, shipping, and disposal costs.

Two potential halide-tolerant waste forms include ceramic waste forms and phosphate glass waste forms [Metcalfe 2004, Fong 2006, Donald 2007, Metcalfe 2009]. Ceramic waste forms such as Cl-laden sodalite, with and without glass bonding, has been considered the reference waste form for FPs separated during pyrochemical, or electrochemical, UNF processing. Research continues to develop and evaluate other ceramic waste forms for pyrochemical separations, including tellurite glasses [Riley 2011], a silica/alumina/phosphate waste (SAP) waste form, and zinc encapsulated titanium oxide (ZIT) [Frank 2011]. These waste forms, being developed and evaluated for containing Cl-laden waste streams from pyrochemical separations, may be adaptable for $\mathrm{Cl}$ and $\mathrm{F}$-laden waste streams from $\mathrm{Cl}$ and $\mathrm{F}$ volatility processes.

Glass-encapsulated calcium phosphate is another promising waste form for $\mathrm{Cl}$ and $\mathrm{F}$-laden waste streams [Metcalfe 2004, Fong 2007, Donald 2007, Metcalfe 2009]. FPs including the Ln will partition to the glass phase, while the halides and actinides partition to the ceramic phase. The ceramic phase is not expected to deplete the glass phase of its necessary constituents needed to produce a durable glass.

\subsection{Fuel Reuse Options}

The primary emphasis of UNF processing is the recovery and recycle of one or more of the elements in UNF in new fuel for further irradiation in reactors. The U.S. Department of Energy (DOE) has identified three general types of fuel cycle categories, shown in Figure 2-8. These general types of fuel cycles are summarized as:

- Once-Though (OT) fuel cycles, where fuel manufactured from ore is used once in a reactor and then the $\mathrm{UNF}$ is disposed. In OT fuel cycles, used fuel is not reprocessed so innovative separations technology is not generally relevant.

- Modified Open Cycle (MOC) fuel cycles, where UNF is reprocessed and one or more elements are recycled one or more times as part of new reactor fuel. The waste materials from processing are disposed. After a limited number of recycles, the used fuel is not processed but disposed. As a result, with MOC fuel cycles, both UNF and reprocessing wastes are disposed. 
- Full Recycle (FR) fuel cycles, where used fuel from reactors is never directly disposed, but is always processed to recover recyclable fuel materials. The recyclable materials (primarily actinides) are recycled into new reactor fuel, and the waste materials from UNF processing are disposed. In Full Recycle cases, UNF is never disposed, only processing wastes.

Since there is no recycling in OT fuel cycles, it is not expected that any of the innovative separations technologies described in this report would apply, although it is possible in principle that UNF could be processed for waste management purposes prior to disposal without any recycle. The primary technical challenge for applicability of these innovative separations technologies to MOC or Full Recycle fuel cycles is whether or not the separated product materials can be used in making new fuel. Even if the answer is yes, other technical and economic considerations may affect the applicability of these innovative technologies to MOC or Full Recycle options and need to be considered. The evaluation criteria discussed in this report review the technical and economic considerations.

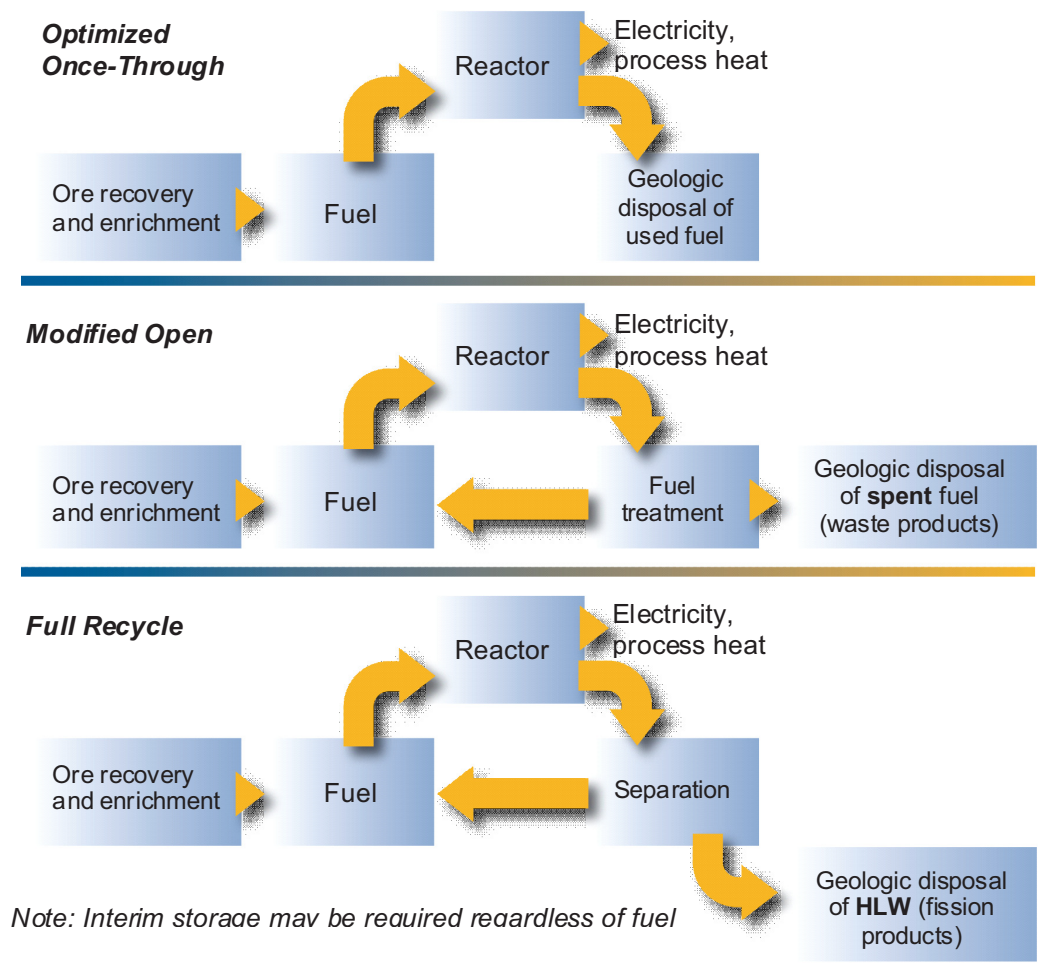

Figure 2-8. General nuclear fuel cycle categories [DOE 2010].

In general, the potentially reusable materials in UNF processing are the fertile and fissile actinides - uranium, thorium (in the case of a thorium / uranium fuel cycle), $\mathrm{Pu}$, and other TRU elements, either separately or in combinations. Some FPs such as Tc and iodine can also be recycled in transmutation targets and are a secondary consideration in this report. The challenges in making a viable fuel from recycled materials are similar to those for making fuel from natural ore - that is, to make a fuel with enough fissile material to be critical (i.e., sustain a nuclear fission chain reaction) in a reactor environment, which implies a sufficiently low concentration of impurities that either absorb neutrons, cause fuel performance problems, or both. But the amount of fissile material needed for criticality in a reactor varies for different reactor designs, and the limits on impurities vary too, depending on fuel and cladding type.

The concentration of fissile material in UNF from a non-breeder reactor will have generally been depleted to levels too low for sustainable criticality in a reactor. The consumption of fissile material in combination with the growth of FPs in the fuel is why the UNF is discharged from the reactor. UNF processing may enable recycle by removing FPs and other contaminants, and with increased fissile content from other sources, the 
recycled fuel can be a viable fuel material. The degree to which contaminants can be removed, and the amount of fissile material that needs to be added, determines how effectively the fuel can be recycled in MOC or Full Recycle fuel cycles.

It is essential to reduce the concentrations of neutron-absorbing FPs, particularly the rare earth FPs (lanthanides including $\mathrm{Gd}, \mathrm{Sm}, \mathrm{Eu}$, and $\mathrm{Nd}$ ) and the noble metal rhodium (in particular the $\mathrm{Rh}-103$ isotope). Other FPs which contribute to neutron absorption in the spent fuel include $\mathrm{Xe}, \mathrm{Kr}, \mathrm{I}, \mathrm{Cs}, \mathrm{Te}, \mathrm{Ru}$, and Mo. Cesium is also of interest because if not removed during reprocessing, it can vaporize during fuel pellet fabrication, possibly affecting pellet properties and complicating the sintering operation. Removal of Tc-99 may also be beneficial as it is very mobile in water transport mechanisms in repository operation. Of these, lanthanides and other fission products appear to be the main drivers with the broadest impact on separations, fuel fabrication costs and in fuel performance. Knowledge as to how much and to what degree the separation or removal can consistently treat FP from variable burn-up spent fuels is important for developing recycle fuel compositions within an acceptable and specified reactivity range [Christian 1999], and is important for evaluating the innovative separations technologies for suitability in MOC and FR fuel cycles.

While recycle of one or more actinide elements recovered from LWR and fast burner reactor UNF usually requires either uranium re-enrichment or additional fissile material in making new fuel, there are examples where uranium re-enrichment or the addition of new fissile to the recycled material is not necessary, such as some very limited recycle in CANada Deuterium Uranium (CANDU) reactors. CANDU reactors operate with heavy water (enriched in deuterium) instead of light water $\left(\mathrm{H}_{2} \mathrm{O}\right)$ for neutron moderation. With heavy water, the CANDU reactors can operate with lower levels of fissile material than is needed for other reactor types. Uranium and TRU elements separated from LWR or fast reactor UNF may be directly reusable in CANDU reactors as long as the lower requirement for fissile material content in the fuel is satisfied. However, analyses have shown that only very limited recycle is possible without providing additional fissile material.

A more flexible approach is the use of breeder reactors that breed excess fissile material from fertile material, i.e., producing more fissile material than they consume (fissile conversion ratio $(\mathrm{CR}) \geq 1$ ), and so can operate on recycled fuel without additional fissile material. Such reactors can create more fissile than is needed for recycle, making the excess fissile material available for use in other reactors. Breeder reactors can be designed using thorium (to breed U-233) and uranium (to provide fissile U-235) in thermal reactors, or with either thorium (to breed U-233), uranium (to provide fissile U-235 and/or breed Pu-239), and/or plutonium (to provide fissile $\mathrm{Pu}$-239) in fast reactors. As a result, while Full Recycle options that do not include breeder reactors avoid disposal of UNF, they dispose of large amounts of fertile materials, such as depleted uranium, uranium recovered from the UNF, and thorium in the case of thorium / uranium fuel cycles. Only breeder reactors can avoid the disposal of potentially large amounts of fertile materials.

The importance of this to the evaluation of innovative separations technologies is that the recovery of fissile material is one of the primary goals of MOC and FR fuel cycles. The ability to recover such fissile materials, and the amount of fissile material that is likely to be lost in processing, are key parts of the evaluation.

\section{INNOVATIVE SEPARATIONS CONCEPTS}

\subsection{Nitrogen Trifluoride for UNF Processing (PNNL)}

Nitrogen trifluoride $\left(\mathrm{NF}_{3}\right)$ reprocessing is being proposed as a fluoride volatility-based alternative to aqueous separations. The main distinction between this process and other fluoride volatility systems is the use of nitrogen trifluoride $\left(\mathrm{NF}_{3}\right)$ instead of $\mathrm{F}_{2}$ or other fluoridating reagents, for selectively fluorinating and volatilizing $U$ and some FPs. Figure 3-1 shows a potential diagram for this concept. Variations from this flowsheet are possible depending on different options for recycle fuel with either MOC or FR fuel cycles.

The process assumes UNF disassembly, shear, and voloxidation processes similar to those in the reference advanced aqueous system. However, instead of dissolving the resulting oxidized UNF powder in concentrated nitric acid, the powder, separated from the cladding, is fluorinated to convert uranium, various fission 
products, and other actinides to volatile and non-volatile fluorides. The difference in volatility of the fluorides is used to separate the uranium from the other UNF components, enabling the uranium to be recycled either after re-enrichment or addition of other fissile material. Unless a breeder reactor is being used as part of an FR fuel cycle, most or all of the recovered uranium is eventually discarded.

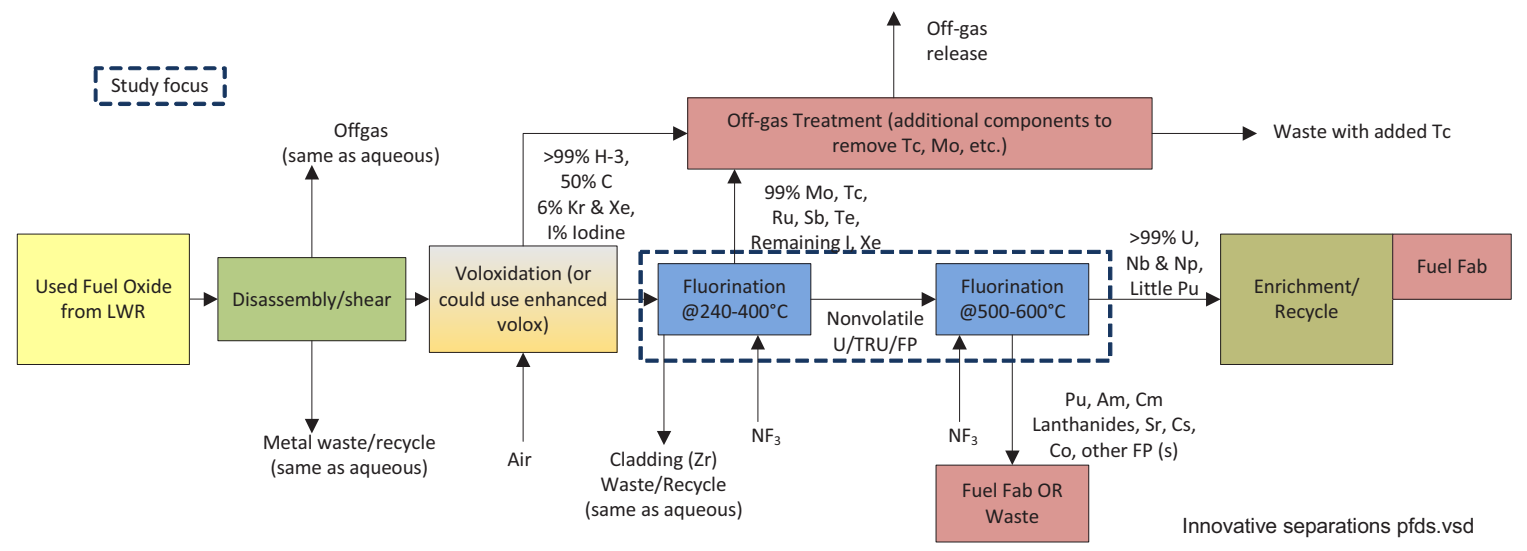

Figure 3-1. Potential nitrogen trifluoride UNF processing diagram.

The potential system steps include:

1. Disassemble and chop the fuel bundles.

2. Voloxidation similar to the reference advanced aqueous process to remove some of the volatile FP and separate the oxidized UNF powder from the cladding.

3. $\mathrm{NF}_{3}$ Treatment at $240-400^{\circ} \mathrm{C}$ to remove transition metal fluorides and remaining gaseous FPs.

4. $\mathrm{NF}_{3}$ Treatment of remaining U/TRU/FP at $500-600^{\circ} \mathrm{C}$ to fluorinate and volatilize the $\mathrm{U}, \mathrm{Nb}$, and $\mathrm{Np}$ and trace amounts of $\mathrm{Pu}$. This volatilized material is recovered for recycle in new fuel.

5. Depending on the goals of the MOC or FR fuel cycle, the remaining nonvolatilized TRU/FP is either considered as waste or can be further processed using aqueous or other separations technologies to separate the potentially re-useable TRU elements from the FPs.

Initial scoping studies at Pacific Northwest National Laboratory (PNNL) have indicated that $\mathrm{NF}_{3}$ is an effective thermally-sensitive fluorinator and oxidizer for converting uranium, various FPs, and other actinides present in spent nuclear fuel to volatile and non-volatile fluorides. In contrast to other commonly used fluorinating agents (e.g., $\mathrm{F}_{2}, \mathrm{ClF}_{3}$, and $\mathrm{HF}$ ), the lower reactivity of $\mathrm{NF}_{3}$ allows for "tuning" of its reactivity by controlling certain process parameters such as temperature and concentration. Because of its thermally tunable chemistry, in principle $\mathrm{NF}_{3}$ could be used to selectively fluorinate and volatilize FPs and minor actinides at temperatures other than that used for separating and recovering uranium. The tunable reactivity of the less hazardous $\mathrm{NF}_{3}$, as compared to other fluorinating species such as $\mathrm{F}_{2}$, can be used to selectively partition the fuel into streams containing potentially valuable elements (e.g., $\mathrm{U}, \mathrm{Pu}$ ) and elements that would be managed as waste, such as minor actinides and FPs, again depending on the fuel cycle goals, and may make $\mathrm{NF}_{3}$ an attractive candidate for application in either MOC or FR fuel cycles. Other potential applications may include 1) substituting use of $\mathrm{NF}_{3}$ to release volatile and semi-volatile FPs rather than using air or oxygen voloxidation, 2) use of $\mathrm{NF}_{3}$ to process carbon-based and silicon carbide TRISO fuels, 3) processing molten salt reactor fuels including recovery of bred U-233 from $\mathrm{Th}$, or 4) treatment of zirconium cladding after separation of fuel material to reduce or remove surface contamination.

Currently, thermal analytical ( $\mu \mathrm{g}$ scale) and laboratory scale experiments are being used to characterize the thermal reactivity of $\mathrm{NF}_{3}$ with oxides of the actinides $\mathrm{U}, \mathrm{Pu}$ and $\mathrm{Np}$, FPs which form volatile fluorides (including $\mathrm{Ru}, \mathrm{Mo}, \mathrm{Te}, \mathrm{Nb}, \mathrm{I}$ as $\mathrm{CsI}, \mathrm{Sb}$ ), FPs which form non-volatile fluorides such as the lanthanides, the "five-metal" phase, and mixed oxides of U and volatile FPs. 


\section{Proposed benefits}

According to the researchers, gas phase fluorination of UNF using $\mathrm{NF}_{3}$ has the potential to reduce the footprint in a UNF separations facility (compared to aqueous separations), and to reduce the hazard associated with other fluorinating agents used in fluorination processes. The $\mathrm{NF}_{3}$ gas is minimally-toxic and is not sensitive to shocks that could result in explosion as is the case with some other fluorinating agents. The transportation, storage, and installation requirements for $\mathrm{NF}_{3}$ are similar to those of oxygen. Proper engineering based on existing fluoride volatility prototypes should be able to reduce primary and off-gas emissions to low impact concentrations. Overall, according to the researchers, a fluoride volatility separation process based on $\mathrm{NF}_{3}$ will:

- Improve separations in the actinide fluoride volatility recycle flowsheet

- Reduce the overall size of the processing plant footprint compared to aqueous separations

- Reduce/relax process-requisite safeguards concerned with dissolver issues

- Reduce safeguards concerns with fissile material content in the hulls

- Reduce residual waste per processed batch to extremely low volume fluoride salts waste

- Increase plant safety by:

- reducing inadvertent tritium and fission gas release (controlled at the beginning)

$\circ$ reducing potential for metal catalyzed fire

\subsection{Reactive Fluoride Gas $\left(\mathrm{SF}_{6}\right)$ for UNF Processing (SRNL)}

Figure 3-2 shows a potential diagram for application of the work in this area. The main distinctions between this process and other fluoride volatility systems are (a) enhanced voloxidation using $N O_{x}$ as an oxidant, (b) the use of $\mathrm{SF}_{6}$ as the fluorinating reagent, and (c) the use of hydrolysis or pyrohydrolysis to condense and separate some of the volatilized materials from the still-gaseous $U_{4}$ and the fluorides of $U$, Pu, and $N p$.

The process assumes a UNF disassembly and shear process similar to that proposed for the advanced aqueous system. It also includes a voloxidation process but using an enhanced method with $\mathrm{NO}_{\mathrm{x}}$ gases to separate of Cs and Tc from the UNF materials as thermodynamic calculations conducted by Savannah River National Laboratory (SRNL) indicate that $\mathrm{CsNO}_{3}$ and $\mathrm{CsNO}_{2}$ should be volatile at $\mathrm{T}>800^{\circ} \mathrm{C}$ and $\mathrm{Tc}_{2} \mathrm{O}_{7}$ at $\mathrm{T}>300^{\circ} \mathrm{C}$. Then, instead of dissolving the resulting oxidized UNF powder in nitric acid, the powdered fuel would be exposed to a blend of mixed reactive gases at temperatures sufficient to selectively fluorinate the UNF elements to enable separation of the more volatile species such as $\mathrm{UF}_{6}, \mathrm{PuF}_{6}, \mathrm{NpF}_{6}, \mathrm{TcF}_{6}$ and $\mathrm{TeF}_{6}$ from the stable fluorinated solids (which includes the FP, lanthanides, etc.). SRNL in FY10 evaluated the potential use of three different alternate fluorinating agents $\left(\mathrm{SF}_{6}, \mathrm{XeF}_{2}\right.$, and $\left.\mathrm{NF}_{3}\right)$. Subsequent treatment with hydrogen containing gases such as $\mathrm{H}_{2}$ or $\mathrm{NH}_{3}$ are thermodynamically predicted to lead to selective de-fluorination and condensation which will lead to preferential concentration of gaseous U-F species and separation of $U$ from the other elements. In this step, the volatile $\mathrm{XF}_{6}$ gases (where $\mathrm{X}=\mathrm{U}, \mathrm{Pu}$, etc.) will react to form $\mathrm{XF}_{4}$ compounds and $\mathrm{HF}(\mathrm{g}) . \mathrm{UF}_{4}$ is a gas but $\mathrm{PuF}_{4}$ and others condense and separate from the gaseous $\mathrm{UF}_{4}$.

The primary focus of this process is fluorination to convert uranium, various FPs, and other actinides to volatile and non-volatile fluorides with the current specific emphasis on use of $\mathrm{SF}_{6}$. The relative volatility of the fluorides is used to achieve the required separations instead of an aqueous solvent extraction process. 


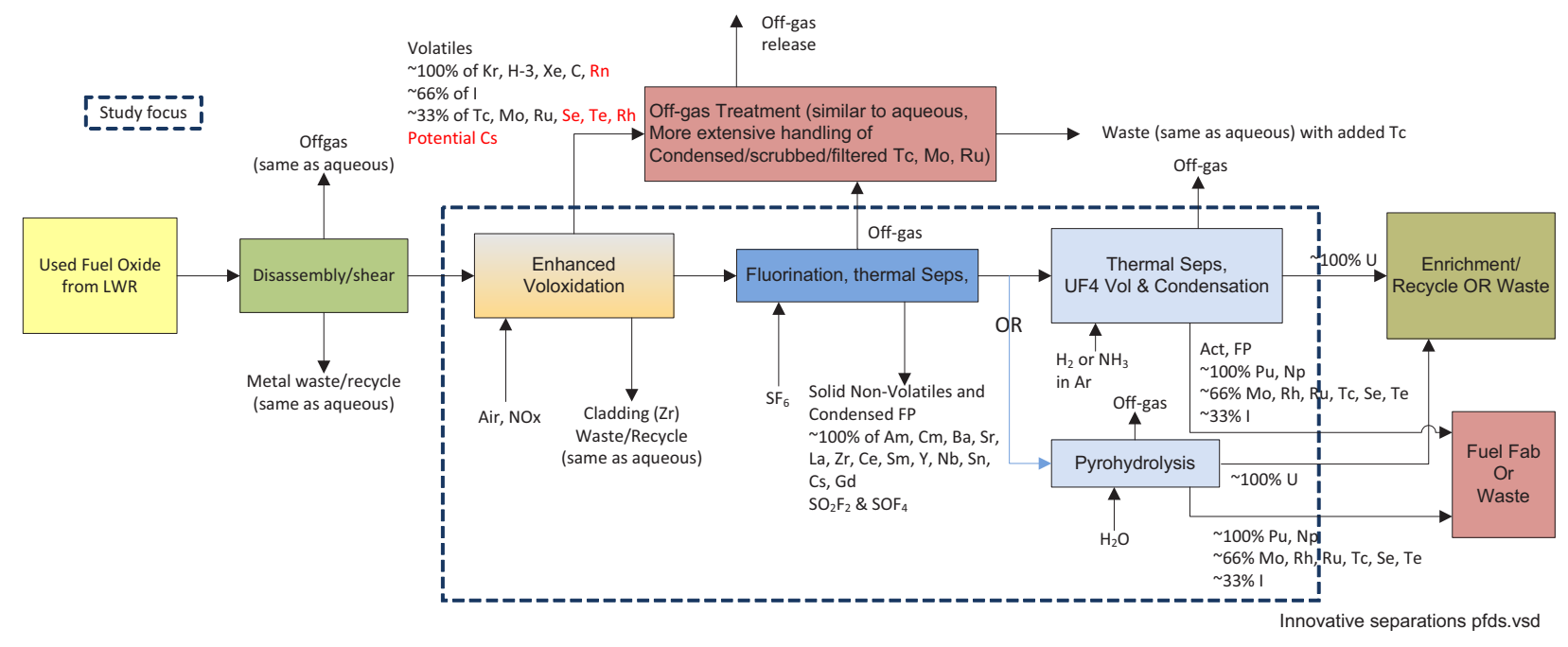

Figure 3-2. Potential $\mathrm{SF}_{6}$ fluorination diagram.

The potential system steps include:

1. Chop the fuel bundles.

2. Load the chopped pieces into a reactor (possibly rotary kiln), conduct an enhanced fuel oxidation process with $\mathrm{NO}_{\mathrm{x}}$ to oxidize the UNF resulting in a fine powder and to remove volatile $\mathrm{FP}$, some of the $\mathrm{Cs}$, Tc, and other semivolatile elements, and separate the powder from the cladding.

3. $\mathrm{SF}_{6}$ treatment at $>600^{\circ} \mathrm{C}$ to separate volatile and non volatile fluoride species resulting in $\mathrm{UF}_{6}, \mathrm{NpF}_{6}$, some $\mathrm{PuF}_{6}$, and some FP fluorides $(\mathrm{Nb}, \mathrm{Mo}, \mathrm{Te}, \mathrm{Tc})$ included in the volatilized product stream and separated from less volatile species of many of the FPs.

4. Hydrolyze the volatilized species, i.e., the gas stream in the previous step, to convert the remaining 6valent species to 4-valent species, which allows condensation and separation of the 4-valent (or less) $\mathrm{Pu}$, $\mathrm{Np}$, and trace FP fluoride species from $\mathrm{UF}_{4}$, which remains gaseous. Multiple passes are required for efficient separations. The separated $U$ can be re-enriched or otherwise processed into new fuel depending on the goals of the fuel cycle, and the stream containing the TRU and trace FPs can be processed into waste or further processed or separated to recycle the TRU, I, or Tc.

5. Alternatively, the volatilized stream can by pyrohydrolyzed as shown in Figure 3-2 to condense the volatilized species that are further processed into recycled product and waste streams.

6. Separate the $\mathrm{UF}_{4}$ from $\mathrm{HF} / \mathrm{SOF}_{4} / \mathrm{SO}_{2} \mathrm{~F}_{2}$ by condensation and recycle the reagents if possible.

As discussed in Chapter 2, the development of a process based on actinide fluoride formation had been previously studied for fuel cycles using fast breeder reactors. Final separation of the actinide species in this process was proposed using a molten salt separations technique. The research program for this innovative technology is proposing to leverage concepts previously developed for voloxidation and fluoride volatility, extending them to focus on the development of a fully "dry" technology process for the reprocessing of commercial spent nuclear fuels using combinations of mixed gases to cause the desired reactions and achieve the desired separations. The process will include a sequenced thermal treatment to separate the various product species via differences in volatility. It is asserted that the proposed dry process could be designed to efficiently separate the actinides $\mathrm{U}, \mathrm{Pu}$, and $\mathrm{Np}$ as a group so as to reduce proliferation concerns while at the same time making these resources available for recycle.

The recycled material can be a very high concentration $\mathrm{UF}_{6}$ stream $(>99 \%)$ that can be recycled, with reenrichment or with the addition of fissile material, in MOC or Full Recycle options. The high U purity can be achieved by using sodium and magnesium fluoride filters, selective for capturing impurities. In the worst case, rectification and distillation will be required to separate some of the highly volatile fluoride TRU and FP species from $\mathrm{UF}_{6}$. It is possible that some modification of the voloxidation head-end process could volatilize and separate some of the FPs that are otherwise difficult to separate from the U stream, in which case the need 
for rectification would be eliminated. However, in MOC fuel cycles, these contaminants may be tolerable in one or a few recycles, and thus the modified voloxidation and rectification steps might both be avoided. In this case, the stream to a MOC would be that typically seen in more traditional fluorination processes, comprising approximately $95-99 \% \mathrm{UF}_{6}$ with the balance representing other actinides and FP species which are known to volatilize $(\mathrm{Pu}, \mathrm{Np}, \mathrm{Mo}, \mathrm{Rh}, \mathrm{Ru}, \mathrm{I}, \mathrm{Tc}, \mathrm{Se}, \mathrm{Te})$. Regardless of whether a high purity or more contaminated $\mathrm{UF}_{6}$ stream is produced, and regardless of whether the used fuel is recycled in a MOC or Full Recycle, unless fissile material is added from some other source, or unless the uranium is recycled to a breeder reactor, most or all of the uranium may be eventually discarded.

The intended approach for the proposed work will focus on the evaluation of the thermodynamics of the various FP and actinide chemistries with respect to the simultaneous reaction in a mixed gas environment. Once the various stable chemistry forms are identified, an evaluation of technologies for capture and separation of volatile/semi-volatile FPs, oxides/hydroxides, fluorides, etc., will be performed and arranged into a conceptual system for this process development. An underlying approach will be to minimize the overall process temperature to less than $500^{\circ} \mathrm{C}$ so as to reduce process system complexity and to ensure balance of plant /materials of construction robustness. In addition, it is expected that capture of volatilized species during the separation treatment will be performed using as much commercially available technology as possible to minimize development of new equipment and capture technologies.

The proposed work will continue the identification of gaseous reactant streams that enable effective separations and capture of the UNF materials and will include the following tasks:

- Theoretical calculations will be extended to consider advanced fuel form materials such as metallic, carbide, and minor actinide-containing oxide fuel materials.

- Kinetic studies of mixed gas environmental reactors will be completed. The targeted bench scale experiments will be continued in-depth to evaluate the feasibility of effectively and efficiently separating and capturing key UNF materials. The experimental apparatus designed and initiated in FY10 will be used in FY11 to determine the realistic separation factors that are obtainable with off-gas product phase analysis capabilities (using $\mathrm{SF}_{6}$ as the fluorination gas). The set of conceptual process flow diagrams that had been proposed in FY10 based on then-current theoretical results of thermodynamic calculations will be refined to include process temperatures and pressures, reactant gas compositions and UNF material splits.

\section{Proposed Benefits}

According to the researchers, the benefits of this process include:

- Reduction in liquid waste compared to aqueous systems.

- Subsequent H-gas treatment would avoid use of solid metal fluoride filters to separate the U-species from the other volatile actinides.

- Potential to recycle the reagent gases by recovering by-products such as $\mathrm{SO}_{\mathrm{x}} \mathrm{F}_{\mathrm{y}}$ and $\mathrm{HF}$ gases.

\subsection{Dry Head-End Nitration Processing (ORNL)}

Figure 3-3 shows a potential diagram for application of the work in this area. The main distinctions between this process and other UNF separations flowsheets are (a) a relatively low temperature voloxidation process made feasible using $\mathrm{NO}_{2}$ gas, and (b) nitration of the powdered fuel meat using additional $\mathrm{NO}_{2}$, that nitrates the actinides ( $U, P u, N p, A m$, and $\mathrm{Cm}$ ) where the nitrates of these elements are soluble in TBP, so that an upfront acid dissolution step is unnecessary.

The process assumes a UNF disassembly and shear process similar to that proposed for the reference advanced aqueous system. A voloxidation process is also included but it is enhanced using strongly oxidizing $\mathrm{NO}_{2}$ and/or $\mathrm{O}_{2} / \mathrm{O}_{3}$ gases to volatilize and separate $\mathrm{Cs}$ and $\mathrm{Tc}$ from the fuel powder, and to nitrate the non-volatilized elements. Then, instead of dissolving the resulting oxidized UNF powder in nitric acid, the powdered actinide nitrates $(\mathrm{U}, \mathrm{Pu}, \mathrm{Np}, \mathrm{Am}$, and $\mathrm{Cm}$ ) nitrates are dissolved in TBP. As the majority of FPs and lanthanides are 
not soluble, they remain in the undissolved solids, and the separation of actinides from the nonsoluble FPs is achieved in this single step, eliminating the acid dissolution step used in the reference advanced aqueous separations process. The subsequent processing of the actinide-laden TBP can be similar to that of the reference advanced aqueous process.

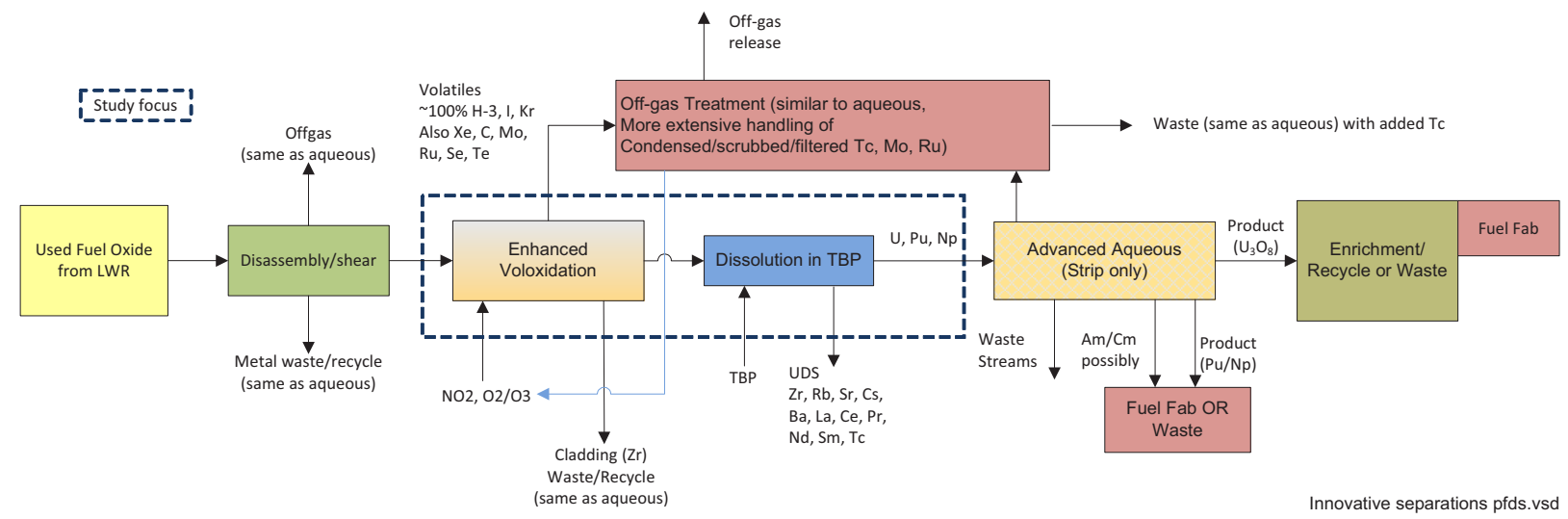

Figure 3-3. Potential dry head-end nitration diagram.

The potential system steps include:

1. Chop the fuel bundles.

2. Load the chopped pieces into a reactor (possibly rotary kiln), conducting voloxidation at $250-300^{\circ} \mathrm{C}$ using a mixture of $\mathrm{NO}_{2}$ and $10-15 \% \mathrm{O}_{2}$ to oxidize the UNF resulting in a fine powder, separating the volatile FP, and separating the powder from the cladding.

3. Contact the powder with $\mathrm{NO}_{2}\left(\mathrm{~N}_{2} \mathrm{O}_{4}\right)$ gas at room temperature to produce metal nitrate.

4. Dissolve the actinide nitrates in TBP.

5. Filter the solution to remove the undissolved solids.

6. Strip selective components from the TBP using multi-stage solvent extraction using a nitric acid solution, similar to the reference advanced aqueous process.

7. Dry/calcine the separated products for reuse, acid recovery from the remaining solution containing FP and minor actinide elements, and conversion of FP and minor actinides to vitrified waste forms.

As indicated above, the voloxidation process will be performed in a closed loop (no exhaust) where the fission gases and volatile/semivolatile FPs are trapped, and $\mathrm{NO}_{2}(\mathrm{~g})$ is recycled. The oxygen must be replenished as it is consumed. During the oxidation step, $\mathrm{UO}_{2}$ is oxidized to $\mathrm{UO}_{3}$, and the spent fuel is transformed into a finely divided powder.

All of the FP iodine, which is mostly present in the spent fuel as CsI, is expected to be released as $\mathrm{I}_{2}$ vapor under the proposed treatment conditions and can be removed from the off-gas using the reference iodine sorption process or other options suggested by the researchers such as molten alkaline hydroxides (e.g. $\mathrm{NaOH}$, $\mathrm{KOH}$ ) or a bed of heated copper-wool. Cold tests using uranium powders produced by $\mathrm{NO}_{2} / \mathrm{O}_{2}$ voloxidation mixed with CsI will be used to characterize and optimize the processing conditions. Small-scale tests with UNF would be used to validate the results.

The fine powder produced by reacting UNF with $\mathrm{NO}_{2} / \mathrm{O}_{2}$, containing the uranium, TRU, and non-volatile FP oxides, is cooled to near room temperature and then treated with pure $\mathrm{NO}_{2}\left(\mathrm{~N}_{2} \mathrm{O}_{4}\right)$ gas to produce metal nitrates. Cold tests using uranium powders mixed with rare earths, alkaline oxides, and noble metals will be used to characterize species and optimize the processing conditions. Small-scale tests with UNF would be used to validate the results.

The nitrated product should be directly dissolvable in the organic TBP solvent. Testing with a surrogate showed that greater than $99 \%$ of the U was dissolved along with $40-45 \%$ of the $\mathrm{Zr}$, and small amounts (less than about 3\%) of the Rb, Sr, Cs, La, Ce, Pr, Nd, Sm, and Em. Recent small-scale tests at ORNL using UNF 
from the Dresden reactor showed that all actinides ( $\mathrm{U}, \mathrm{Pu}, \mathrm{Np}, \mathrm{Am}$, and $\mathrm{Cm}$ ) could be nitrated, and then dissolved in a TBP solvent, along with some FPs. In this process, Tc is not extracted and remains insoluble with the majority of the other FPs.

The uranium and TRU elements could be recycled either with re-enrichment of the uranium or with the addition of other fissile material using either MOC or Full Recycle fuel cycles. Unless the uranium is recycled to a fast breeder reactor, most or all of the uranium may eventually be discarded. While most (perhaps greater than $97 \%$ ) of FPs may be removed from the materials intended for recycle, this amount of residual FPs may limit the number of times the materials recovered from processing the UNF can be recycled, and perhaps restrict this separations technology to only MOC options unless subsequent aqueous purification steps are added as shown in Figure 3-3. Cold testing will be used to characterize and optimize the system for selective stripping of the desired products $(\mathrm{U}, \mathrm{U} / \mathrm{Pu} / \mathrm{Np}, \mathrm{Am} / \mathrm{Cm})$. Small-scale tests with $\mathrm{UNF}$ would be used to validate the results.

\section{Proposed Benefits}

According to the researchers, the advantages listed below may enable major process simplification and cost reductions.

- Enhance the dry pyrochemical evolution of H-3 and I

- Reduce off-gas flowrates and treatment

- Eliminate time-consuming acid dissolution of fuel

- Reduce aqueous stream volume and number of solvent extraction process steps (as long as a more limited choice of separated waste streams are acceptable)

- Prevent Tc from entering aqueous stream

- Reduce amount of aqueous FP waste generated

- Can be integrated with direct use of spent LWR fuel in CANDU reactor (DUPIC) processes,

\subsection{Chlorination Processing of UNF (ORNL)}

Figure 3-4 shows a potential diagram for application of the work in this area. The main distinctions between this process and other separations flowsheets are (a) chlorination of FPs and minor actinides in the fuel following voloxidation, which enables separation of these elements by water dissolution from the $U$, $P u$, and $N p$, and (b) oxychlorination of the U, enabling it to be dissolved in water and separated from the insoluble Pu and $N p$.

The process assumes a UNF disassembly and shear process similar to that proposed for the reference advanced aqueous system. It also includes a similar voloxidation process, possibly enhanced to release additional FPs as in the ORNL head-end nitration process described in Section 3.3. Then, instead of dissolving the powdered UNF in nitric acid, the powdered UNF would be exposed to dry chlorine gas to transform minor actinides and most of the FPs to water-soluble chlorinated species. These species are subsequently dissolved in water and separated from the insoluble $\mathrm{U}, \mathrm{Pu}, \mathrm{Np}$, and $\mathrm{Zr}$ oxides that remain as solids. Uranium can be separated from the $\mathrm{U} / \mathrm{Pu} / \mathrm{Np}$ material by further processing in an advanced aqueous process or treated with a mixture of $\mathrm{HCl} / \mathrm{O}_{2}$ to convert a large fraction of the $\mathrm{U}$ to soluble forms, while leaving the $\mathrm{Pu}$ and $\mathrm{Np}$ as insoluble oxides. This soluble $\mathrm{U}$ can be removed by water washing. 


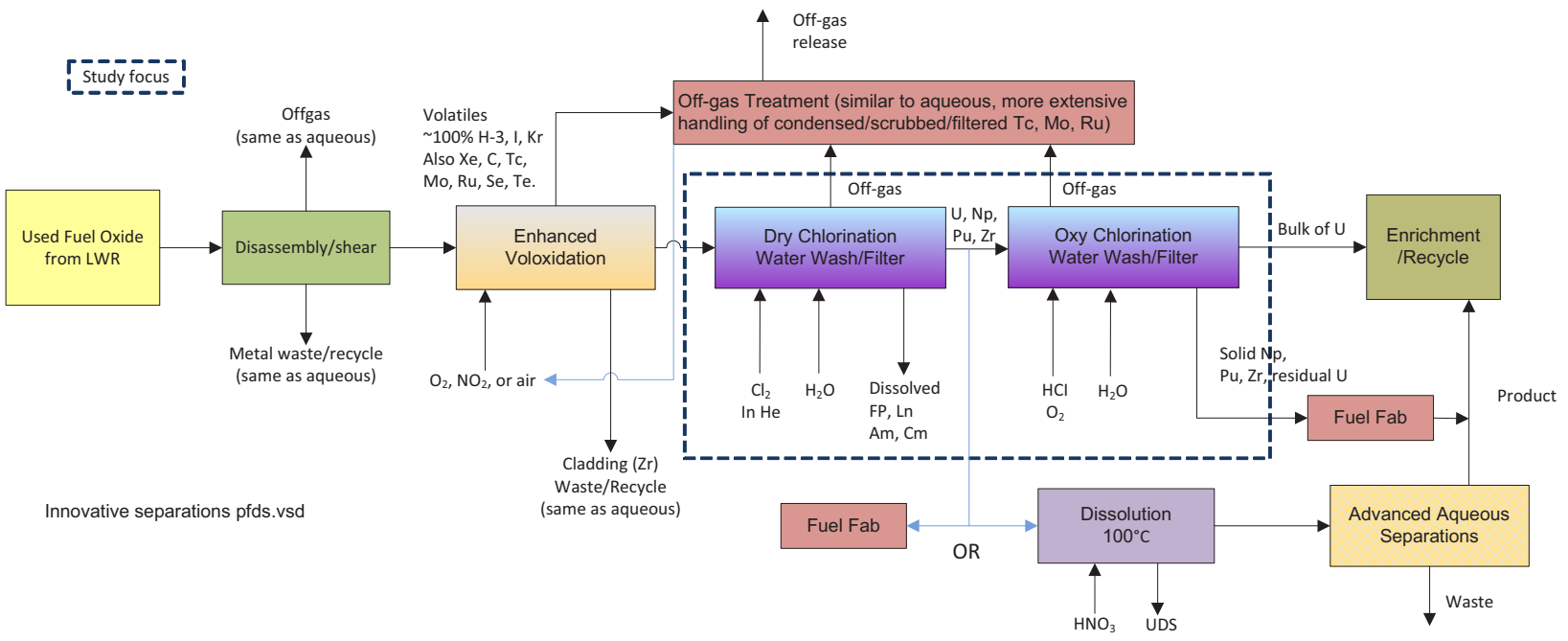

Figure 3-4. Potential chlorination diagram.

The potential system steps include:

1. Chop the fuel bundles.

2. Load the chopped pieces into a reactor (possibly rotary kiln), conducting a closed loop voloxidation to oxidize the UNF to a fine powder and to remove volatile FP, separating the powder from the cladding.

3. Contact the UNF powder with dry chlorine gas at $350^{\circ} \mathrm{C}$, which chlorinates $\mathrm{Ln}$ and other FPs, Am, and $\mathrm{Cm}$.

4. Dissolve Ln and other FPs, Am, Cm in water.

5. Filter the solution to remove undissolved solids.

6. Recover the undissolved $\mathrm{U} / \mathrm{Pu} / \mathrm{Np} / \mathrm{Zr}$ oxides.

OR

7. Further separate this stream using an advanced aqueous dissolution and separation process. OR

8. Further separate this stream using an oxychlorination step (with $\left.\mathrm{HCl} / \mathrm{O}_{2}\right)$ to make $\mathrm{U}$ soluble $\left(\mathrm{UO}_{2} \mathrm{Cl}_{2}\right.$ ) and wash $\mathrm{U}$ out of solids with water. The $\mathrm{Pu}, \mathrm{Np}$, and $\mathrm{Zr}$ remain as insoluble oxides.

9. Send products separated using advanced aqueous or oxychlorination separations to fuel fabrication or waste.

The uranium and TRU elements could be recycled either with re-enrichment of the uranium or with the addition of other fissile material using either MOC or Full Recycle fuel cycles. Unless the uranium is recycled to a fast breeder reactor, most or all of the uranium may eventually be discarded. This separations process would only be viable for Full Recycle fuel cycles if the efficiency of separating FPs, especially the lanthanides, is high enough to avoid the gradual increase of these FPs with each recycle, possibly reaching levels too high to make acceptable fuel.

Standard voloxidation (air or oxygen-rich) of LWR UNF separates fuel from cladding while removing H-3 and a significant fraction of $\mathrm{C}, \mathrm{Kr}$ and $\mathrm{Xe}$. Additional treatment with $\mathrm{NO}_{2} / \mathrm{O}_{2}$ would remove iodine. The separated fuel product is a fine powder. Treatment of the powder with dry chlorine gas at elevated temperatures should transform several of the FPs and minor actinides into oxychlorides and chlorides. U, Np and Pu oxides should remain unreacted under a reasonably wide range of conditions. A preliminary test performed on $10 \mathrm{~g}$ of voloxidized $\mathrm{U}_{3} \mathrm{O}_{8}$ powder showed that $\mathrm{U}_{3} \mathrm{O}_{8}$ remains mostly unreacted $(0.42 \%$ washed out $)$ while all of the $\mathrm{Cs}$ and $81 \%$ of the Sr can be washed out completely with distilled water, and most importantly, it appears that a significant fraction of the rare earths $(45.6 \% \mathrm{Gd}, 43.2 \% \mathrm{Sm})$ could be removed by additional water washing. 
Detailed thermodynamic analysis of the expected behavior of all species in spent fuel under a wide range of conditions (temperature, $\mathrm{Cl}_{2}$ concentration, $\mathrm{Cl}_{2} / \mathrm{O}_{2}$ mixtures, etc.) is being conducted to determine the optimum reaction conditions. Experimental testing using cold surrogates and uranium oxide obtained by voloxidation will be completed to fully characterize the species produced under favorable conditions and to optimize the treatment. Optimization of the leaching conditions using cold surrogates to determine the best media to maximize the selective removal of FPs, particularly lanthanides and alkaline metals will also be investigated. Possible separation schemes to isolate the minor actinides from the leachates will be addressed. Small scale tests with UNF would be used to validate the results.

\section{Proposed Benefits}

According to the researchers, the benefits of this process include:

- Selective separations using much less aggressive media than concentrated nitric acid.

- Dry chlorination can also be used for decladding of the fuel by formation of volatile $\mathrm{ZrCl}_{4}$ amenable for purification and reuse.

- Reduces the number of separation steps.

- Supports limited separations by recovering U, Pu and $\mathrm{Np}$ together, unless further processed to separate the uranium.

- $\mathrm{Am} / \mathrm{Cm}$ remain with FP waste.

\subsection{Enhanced Oxidation/Chlorination Processing of UNF (INL)}

Figure 3-5 shows a potential diagram for application of the work in this area. The main distinctions between this process and other separations flowsheets are (a) a high temperature advanced oxidation process in place of the reference voloxidation process, to remove gaseous and semivolatile FPs, and (b) separation of the remaining Ln by chlorination using a strongly reductive chlorinating agent such as $\mathrm{NH}_{4} \mathrm{Cl}$.

The process assumes a UNF disassembly and shear process similar to that proposed for the reference advanced aqueous process. It also includes an advanced oxidation step based on the AIROX system previously described. The resulting UNF powder will be reacted at around $425^{\circ} \mathrm{C}$ with a strongly reductive chlorinating agent such as $\mathrm{NH}_{4} \mathrm{Cl}$, which chlorinates the relatively nonvolatile rare earths that are not volatilized in the oxidation step. The $\mathrm{U}$ and $\mathrm{Pu}$ oxides should not be chlorinated by the $\mathrm{NH}_{4} \mathrm{Cl}$. The $\mathrm{Ln}$ chlorides are then volatilized by increasing the temperature to $1100^{\circ} \mathrm{C}$. The remaining solid $\mathrm{UO}_{2}, \mathrm{PuO}_{2}$, and other actinides are ready for processing into new fuel or additional separations using aqueous dissolution/separations processes.

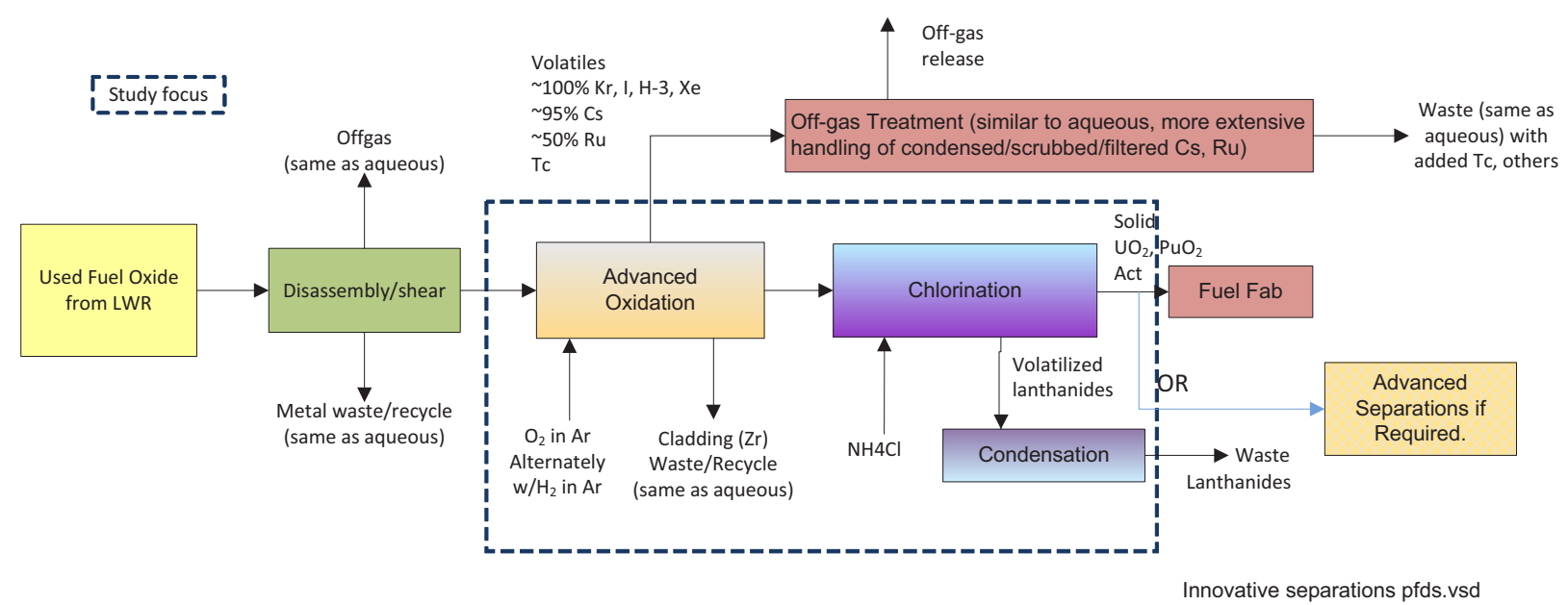

Figure 3-5. Potential enhanced oxidation/chlorination diagram. 
The potential system steps include:

1. Chop the fuel bundles.

2. Load the chopped pieces into a reactor (possibly rotary kiln) conducting an advanced oxidation process (alternating cycles of $\mathrm{O}_{2}$ in $\mathrm{Ar}$ at $400^{\circ} \mathrm{C}$ and $\mathrm{H}_{2}$ in $\mathrm{Ar}$ at $600^{\circ} \mathrm{C}$ ) to oxidize the $\mathrm{UNF}$ to fine powder and to remove volatile FP, separating the powder from the cladding. (One reference indicated that an initial voloxidation at $500^{\circ} \mathrm{C}$ would be conducted first to separate the UNF powder from the cladding followed by the oxidation/reduction cycles above [KAERI 2007]).

3. Contact the fuel powder with $\mathrm{NH}_{4} \mathrm{Cl}$ (or another strongly reductive chlorinating agent) to convert remaining $\mathrm{Ln}$ into chlorides. The actinides remain as oxides.

4. Increase the temperature to $1100^{\circ} \mathrm{C}$ to volatilize the chlorinated lanthanides. The actinide oxides remain.

5. Condense the lanthanide stream for waste.

6. Recover solids for processing and new fuel fabrication.

An advanced oxidative process is capable of nearly complete removal of $\mathrm{Kr}, \mathrm{C}, \mathrm{Cs}, \mathrm{Tc}$, and I, thus enhancing the ability to decrease FP accumulation with recycle of the UNF. The nearly complete separation of these FPs is achieved by controlling the thermal and oxidative conditions of the process. Despite these advances, the rare earth FPs remain and would still be of concern in terms of suitability for new fuel.

Rare earth FPs that form during irradiation are present in solid solution as oxides with $\mathrm{UO}_{2}$. During the advanced oxidative process, the rare earth oxides segregate to a rare earth enriched fluorite phase that forms nodules on the $\mathrm{U}_{3} \mathrm{O}_{8}$ particles due to solubility differences. Although the nodules are easily pulverized, separation of the rare earths using a mechanical process would be difficult given their particle size; on the order of 1 micron. The inter-particle electrostatic forces characteristic of these fines would likely render dry techniques, such as air classification and magnetic separation, improbable. Thus, a chemical process to remove the rare earth nodules seems warranted [Westphal 2010].

A strongly reducing chlorinating agent could be utilized that converts the rare earth oxides to chlorides, thus allowing their removal via vaporization. Similar reactions have been performed for rare earth mineral and scrap recovery operations although they have yet to be applied to nuclear fuel reprocessing. Considering the stabilities of the oxides and chlorides of uranium and the rare earths, uranium oxide should not be affected by the chlorination process but would be reduced back to $\mathrm{UO}_{2}$.

As envisioned, all four phases (oxidation, initial FP removal, chlorination, and final FP removal) of the process would be performed in a single piece of equipment capable of oxidative as well as reducing conditions and temperatures not to exceed $1100^{\circ} \mathrm{C}$. The choice of technology for this process would be a rotary kiln which similar to those that have been well developed industrially, and currently utilized for the conversion of $\mathrm{UF}_{6}$ to $\mathrm{UO}_{2}$ on a production scale.

The four phase oxidation/chlorination process proposed would allow the removal of volatile FPs in order to recycle used LWR fuel multiple cycles without neutronic interferences. In addition, the process renders no separation of minor actinides from uranium thus reducing proliferation risks.

The uranium/TRU stream could be recycled either with re-enrichment of the uranium or with the addition of other fissile material using either MOC or Full Recycle fuel cycles if the FP content is low enough. Unless it is recycled to a fast breeder reactor, most or all of the uranium may eventually be discarded. This separations process would likely only be viable for Full Recycle fuel cycles if the rare earth FPs are separated to avoid buildup with each recycle. Evaluations of separation efficiencies are still in progress.

The research, development, and demonstration aspects of this technology are in various states of progress. Collaborative research on the advanced oxidative process is nearly complete (September 2010) under a three year INERI program with the Idaho National Laboratory, DOE and the Republic of Korea (KAERI). Research and development of the rare earth chlorination has not yet been performed and is the emphasis of initial experimentation at the lab-scale with surrogate materials. Uranium oxide will be doped with a combination of rare earth oxides that represent their individual formation quantities in used fuel in order to demonstrate their 
individual distributions to the segregated fluorite phase and subsequent chlorination. Concurrent with the segregation and chlorination experiments, a rotary kiln capable of oxidative, reducing, and vaporization conditions would be developed for demonstration testing of the technology. Demonstration experiments include using simulated high burnup LWR fuel (SIMFUEL) and LWR UNF for the oxidation/chlorination process followed by volatile FP removal.

\section{Proposed Benefits}

According to the researchers, the current proposal addresses the four criteria of the DOE's MOC fuel cycle for a sustainable fuel cycle in the following ways.

- Used LWR fuel can be recycled multiple times with the proposed technology such that uranium resource needs are significantly decreased.

- The quantity of long-lived FPs, such as I-129 and Tc-99, in the final disposed fuel is reduced via periodic removals for recycle.

- The system for the current technology is quite simple; a chopping step followed by one process step for the oxidation/chlorination process in which volatiles are removed with a rotary kiln.

- The process does not separate plutonium.

\section{ASSESSMENT APPROACH AND RESULTS}

The assessment of the innovative separations techniques considered several major areas, including:

- Separations

- Engineering issues

- Safety/Environmental

- Waste management

- Used fuel disposal/suitability for recycle

- Economics/Footprint reduction

- Resource Sustainability

- Proliferation risk and physical protection

\subsection{Comparison}

In this section, the characteristics of each of the innovative processes are compared to both the reference advanced aqueous process and to existing processes using the same separations principles. Given that all of the innovative processes use gas phase processing, and that there are commonalities among them, the performance of each of the innovative processes may be very similar to one another in at least some areas. To be comprehensive for each innovative technology, the following detailed discussions may be repetitive where these commonalities occur, but the details are included for clarity of the analysis of each technology, since the comparison is to the applicable reference cases and not necessarily to each other at this time.

\subsubsection{Nitrogen Trifluoride for UNF Processing}

Table 4-1 provides a comparison of the product and waste streams out of the proposed process to those for the advanced aqueous case and the reference fluoride volatility case. 
Table 4-1. Product and waste stream comparison for nitrogen trifluoride system.

\begin{tabular}{|c|c|c|c|}
\hline Process & $\begin{array}{c}\text { Reference Case: } \\
\text { Advanced Aqueous w/Voloxidation }\end{array}$ & $\begin{array}{l}\text { Reference Fluoride } \\
\text { Volatility }\end{array}$ & $\mathrm{NF}_{3}$ \\
\hline \begin{tabular}{|l|} 
UNF Dis- \\
assembly and \\
Chopping
\end{tabular} & $\begin{array}{ll}\text { 1. } & \text { Metal fuel assembly parts (activated and/or } \\
\text { contaminated) } \\
\text { 2. } \\
\text { 3. } \\
\text { Offopped fuel elements } \\
\text { other FP) }\end{array}$ & $\begin{array}{l}\text { Same as reference } \\
\text { aqueous case }\end{array}$ & $\begin{array}{l}\text { Same as reference } \\
\text { aqueous case }\end{array}$ \\
\hline \begin{tabular}{|l|} 
Fuel \\
Oxidation / \\
Voloxidation
\end{tabular} & $\begin{array}{l}\text { 1. Zr cladding contaminated with FPs and actinides } \\
\text { (when voloxidation is not used to separate cladding } \\
\text { from fuel, the cladding is separated during } \\
\text { dissolution). } \\
\text { 2. Off-gas : }>99 \% \mathrm{H}-3,6 \% \mathrm{Kr}, 6 \% \mathrm{Xe}, 50 \% \mathrm{C}, 1 \% \mathrm{I} \text {, } \\
\mathrm{Br},<0.2 \% \mathrm{Ru}, \mathrm{Sb}, \mathrm{Cs} \text { at moderate temps } / \mathrm{rxn} \text { times }\end{array}$ & $\begin{array}{l}\text { Same as reference } \\
\text { aqueous case }\end{array}$ & $\begin{array}{l}\text { Same as reference } \\
\text { aqueous case }\end{array}$ \\
\hline \begin{tabular}{|l|} 
Dissolution \& \\
Filtration
\end{tabular} & $\begin{array}{l}\text { 1. Undissolved solids (can be combined with FP in } \\
\text { glass, or with Tc, SS, and Zircaloy in melted MWF) } \\
\text { 2. Off-gas [w/ no volox : all remaining Kr, } 90 \% \text { of the } \\
\text { I, some C-14, some H-3] } \\
\text { 3r cladding (contaminated with FPs and actinides) } \\
\text { when voloxidation is not used to separate fuel from } \\
\text { cladding }\end{array}$ & NA & NA \\
\hline Separation & $\begin{array}{l}\text { Several options are possible depending on if all TRU are } \\
\text { recycled or if separate waste management pathways for } \\
\text { different FPs are desired: } \\
\text { Product streams } \\
\text { 1. Uranium } \\
\text { 2. TRU, possibly with uranium } \\
\text { 3. Pu, Np, Am, Cm, \& other TRU, either separately } \\
\text { or in groups } \\
\text { Primary waste streams } \\
\text { 1. FP in HLW glass- includes raffinate from 1st cycle, } \\
\text { Tank waste, and UDS (vitrified) } \\
\text { 2. Tc in } \mathrm{Zr} / \mathrm{SS} / \mathrm{Tc} / \mathrm{UDS} \text { MWF, if the Tc is separated } \\
\text { from other FPs and if the UDS is placed into MWF } \\
\text { instead of glass. } \\
\text { 3. Cs/Sr/Rb/Ba in mineral waste form if separated } \\
\text { from other FPs } \\
\text { 4. Np, Am, Cm, and other TRU if separated for } \\
\text { disposal instead of recycle. }\end{array}$ & \begin{tabular}{|l} 
Product streams: \\
1. UF ${ }_{6}+$ small \\
amount Pu and Np \\
and contamination \\
by volatile FP \\
fluorides. \\
2. PuF Pul $_{4}$ small \\
amount of U, Np, \\
and contamination \\
by volatile FP \\
fluorides. \\
Primary Waste \\
streams: \\
1. Non volatile FP \\
on alumina bed \\
(vitrified using \\
BSG or \\
phosphate glass) \\
2. Volatile FP from \\
distillation and \\
absorbers (Mo, \\
Np, Tc, Ru, Nb, \\
Sb) (vitrified \\
using BSG or \\
phosphate glass)
\end{tabular} & 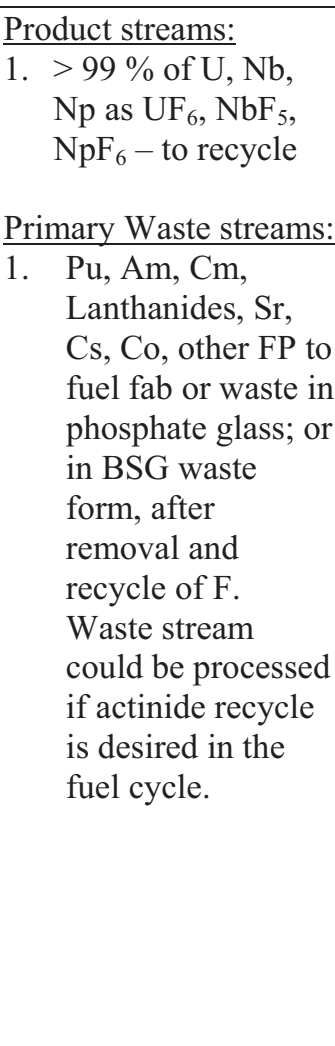 \\
\hline
\end{tabular}




\begin{tabular}{|c|c|c|c|}
\hline Process & $\begin{array}{c}\text { Reference Case: } \\
\text { Advanced Aqueous w/Voloxidation }\end{array}$ & $\begin{array}{c}\text { Reference Fluoride } \\
\text { Volatility }\end{array}$ & $\mathrm{NF}_{3}$ \\
\hline $\begin{array}{l}\text { Off-gas } \\
\text { control } \\
\text { systems }\end{array}$ & $\begin{array}{l}\text { The reference gaseous FP waste forms are: } \\
\text { 1. H-3 in HTO in grouted waste form } \\
\text { 2. I-129 in glass-bonded silver zeolite waste form } \\
\text { 3. C-14 in } \mathrm{CO}_{2} \text { grouted waste form } \\
\text { 4. Kr- } 85 \text { (with or without nonradioactive Xe) in } \\
\text { compressed gas cylinders. } \\
\text { Particulate matter formed from entrained dust and } \\
\text { condensed semi-volatile matter in the head end and } \\
\text { dissolver off-gas systems is filtered in cleanable filters } \\
\text { and recycled to the dissolver. Particulate matter in the } \\
\text { process gas streams is recycled or solidified into a } \\
\text { separate waste form. Particulate matter captured on } \\
\text { HEPA filters is disposed with the filters, although it } \\
\text { could also be removed from the filters (via filter } \\
\text { leaching) and combined with the separated FP waste } \\
\text { stream. }\end{array}$ & $\begin{array}{l}\text { Same gaseous FP } \\
\text { waste streams as } \\
\text { reference aqueous } \\
\text { case. } \\
\text { Particulate matter } \\
\text { may have some } \\
\text { fluoride species; } \\
\text { combined with the } \\
\text { FP waste streams. }\end{array}$ & $\begin{array}{l}\text { Same gaseous FP waste } \\
\text { streams. } \\
\text { Particulate matter may } \\
\text { have some fluoride } \\
\text { species; combined with } \\
\text { the FP waste streams. }\end{array}$ \\
\hline
\end{tabular}

\subsubsection{Separations}

This separation method, as proposed, does not attempt to achieve the same degree of separation achievable with an advanced aqueous process. It provides a separated $\mathrm{U}$ stream which also contains some of the $\mathrm{Nb}$ and $\mathrm{Np}$, and a small portion of the Pu. The other separated stream contains most of the TRU and the FPs.

It is expected to recover more than $99 \%$ of the uranium stream which contains a small amount of $\mathrm{Nb}, \mathrm{Np}$ and $\mathrm{Pu}$. The amount of FP remaining in the $\mathrm{U}$ stream has not yet been determined. The proposed process is attempting to volatilize $\mathrm{Mo}, \mathrm{Tc}, \mathrm{Ru}, \mathrm{Sb}, \mathrm{Te}, \mathrm{I}$ and $\mathrm{Xe}$ at a low temperature, prior to volatilization of the $\mathrm{U}$ at a slightly higher temperature. Testing completed to date on this project indicates that $\mathrm{NF}_{3}$ oxidizes and fluorinates $\mathrm{UO}_{2}$ to $\mathrm{UF}_{6}$ near $550^{\circ} \mathrm{C}_{\text {, }} \mathrm{TcO}_{2}$ to volatile $\mathrm{TcF}_{6}$ near $350^{\circ} \mathrm{C}$, and $\mathrm{RuO}_{2}$ to volatile $\mathrm{RuF}_{5}$ and $\mathrm{RuF}_{6}$ at $<500^{\circ} \mathrm{C}$. It does not convert $\mathrm{Rh}_{2} \mathrm{O}_{3}$ to the volatile $\mathrm{RhF}_{5}$ or $\mathrm{RhF}_{6}$ at temperatures up to $550^{\circ} \mathrm{C}$. It can oxidize and fluorinate $\mathrm{NpO}_{2}$ to volatile $\mathrm{NpF}_{6}$ when heated to $580^{\circ} \mathrm{C}$. It will oxidize and fluorinate a $25 \% \mathrm{Pu} / \mathrm{U}$ mixed oxide and effectively separate the $U$ from the mixed oxide. However, there have not been tests conducted yet with a simulated fuel to determine how the various FP interact with the U.

This separation method claims to have the potential to improve separations compared to the actinide fluoride volatility recycle system due to the "tunability" of the $\mathrm{NF}_{3}$ process versus a process conducted with fluorine gas. The use of the more strongly oxidizing fluorine gas will form $\mathrm{PuF}_{6}$, although literature indicates that $\mathrm{PuF}_{6}$ is very unstable compared to $\mathrm{UF}_{6}$ and will decompose to $\mathrm{PuF}_{4}$ under a variety of conditions. As this process is using the two fluorination steps to achieve the separation of volatile fluoride FP from $\mathrm{U}$ and then $\mathrm{U}$ from $\mathrm{Pu}$ it is important to realize that complete separations may be difficult to control under normal fluorinating conditions.

The separation of the $\mathrm{U}, \mathrm{Pu}$, and some FP relies on the differential abilities of these elements for forming higher-order volatile fluorides with fluorine, as well as on the different reactivities of the $\mathrm{UF}_{6}$ and $\mathrm{PuF}_{6}$. Uranium dioxide becomes involved more readily in the interaction with fluorine, to form a higher-order fluoride, than does plutonium dioxide. The resulting $\mathrm{UF}_{6}$ is more inert in its chemical activity than $\mathrm{PuF}_{6}$, which acts as a more vigorous fluorinating agent than fluorine under certain conditions. Since many FPs capable of interacting with $\mathrm{PuF}_{6}$ are in $\mathrm{UNF}$, and lower valence $\mathrm{U}$ compounds are also present, the $\mathrm{PuF}_{6}$ is capable of oxidizing the later, and becoming reduced to a tetrafluoride in the process. The combination of these two differences in the properties of $\mathrm{U}$ and $\mathrm{Pu}$ in a fluorine medium is what constitutes the prerequisite for separation of $\mathrm{U}$ and $\mathrm{Pu}$ in the fluorination process. Some experiments documented in literature confirmed that $\mathrm{U}$ could be separated from $\mathrm{Pu}$ by fluorination in a dilute inert gas (Volume ratio 1:1) [Veryatin 1972]. 
Work done by Hitachi [Kani 2009] indicates that a small amount of Pu and some FPs are volatilized and accompany $\mathrm{UF}_{6}$ in a fluorination process completed in a flame reactor using $\mathrm{F}_{2}$ gas although the reactor was designed with a $\mathrm{PuF}_{6}$ decomposition chamber. About $94-98 \%$ of $\mathrm{U}$ supplied was volatilized as $\mathrm{UF}_{6}$ (amount depended on $\mathrm{F}_{2}$ stoichiometric ratio, $\mathrm{F}_{2}$ concentration, $\mathrm{F}_{2}$ feed rate and grain size of fuel powder) and some of the $\mathrm{Pu}(<5 \%)$ was measured as $\mathrm{PuF}_{6}$ in the reaction gas even though it had gone through the decomposition chamber. They were considering a trapping recovery system for the trace amount of $\mathrm{Pu}$ gas remaining with the $\mathrm{UF}_{6}$. The $\mathrm{UF}_{6}$ in their process is further purified by rectification and/or passing through absorbents such as $\mathrm{NaF}$. Additional supporting data for the separation of $\mathrm{U}$ from $\mathrm{Pu}$ in the literature included the fluorination of a mixture of uranium dioxide and plutonium dioxide corresponding the composition of the fuel in a fast reactor core showed that as a result of fluorination at $350^{\circ} \mathrm{C}$, the $\mathrm{U}$ goes over completely to the vapor phase in the form of $\mathrm{UF}_{6}$, while the $\mathrm{Pu}$ remains in the solid precipitate as $\mathrm{PuF}_{4}$ [Veryatin 1972].

The fluorides of a few other elements are sufficiently volatile that their separation from uranium fluoride can cause some problems, notably these elements are $\mathrm{Nb}, \mathrm{Ru}, \mathrm{Tc}, \mathrm{Te}$, and Mo. Some of these may be primarily or partially removed by an initial fuel oxidation step, but additional work is needed to determine if the initial fluorination step will be able to remove these volatile fluorides without volatilizing the uranium. Even if this initial separation is successful to a degree, some of these FP may be carried into the $\mathrm{UF}_{6}$ stream and additional decontamination of this stream be required (as noted in the Hitachi work) for direct feed to an enrichment plant.

Some possibilities for removing this "additional decontamination" of the $\mathrm{UF}_{6}$ stream include rectification and absorption. $\mathrm{TcF}_{6}$ and $\mathrm{NpF}_{6}$ cannot be separated by distillation, since they have volatilities very close to those of $\mathrm{UF}_{6}$ and $\mathrm{PuF}_{6}$. These materials can be removed by sorption methods using solid $\mathrm{MgF}_{2}$. Purification of $\mathrm{UF}_{6}$ by sorption-desorption on $\mathrm{NaF}$ is most useful in processing high enrichment fuels where the bulk of the fuel element is $\mathrm{Al}$ or $\mathrm{Zr}$ and the total amount of $\mathrm{U}$ is relatively small (so NaF sorption beds are of reasonable size). For low-enrichment fuels where the quantity of $U$ processed is large, the distillation purification method may be needed [Szulinski 1966].

The fluorides of elements such as $\mathrm{Cs}, \mathrm{Sr}, \mathrm{Ce}$ and others whose vapor pressures indicate they are not volatile at the fluorination temperature, may be present in the vapor phase in the form of aerosols and dust. Filters, such as sintered metal filters, are capable of removing the dust and aerosols; however, plugging of the filters can be an issue [Veryatin 1972].

Per the proposed system, the remaining Pu is not separated from the lanthanides, Cs, Sr, or other FP. The lanthanide/FP concentration will likely limit the number of times this type of product can be recycled. If this product is used as is to make fuel, Cs could affect pellet properties when it volatilizes during pellet sintering [Christian 1999].

Consideration could be given to a secondary process (such as an aqueous process or pyrochemical process) which could be conducted on the FP/Actinide stream to complete further separations on this stream. The advantage would be this secondary process would be much smaller as the majority component of the fuel, the uranium (which is $\sim 93 \%$ of the total mass of the used fuel meat), has already been removed. This work will continue to obtain details on the separation factors obtainable, especially with simulated or actual spent fuel. Interaction of the various components in the UNF can significantly affect the results over the results for a pure compound.

\subsubsection{Engineering/Operational Issues}

Direct reactions between the fuel and gaseous fluorinating reagents require control of reaction rates and temperatures because of the heat generated in the highly exothermic gas-solid reactions involved and the low heat capacity of the gaseous effluents. Accordingly, one method suggested in literature [Reilly 1963] to deal with the problem is the use of a fluidized bed of inert granular solids, which by virtue of its heat capacity and heat transfer properties, enables such reactions to be carried out under controlled conditions. The heat produced in the reaction is transferred to the bed and from there to the walls of the reactor where it is removed 
by an external coolant. One of the key problems is that the fluidized bed might break down because of sintering of the particles if the temperature is not well controlled [Veryatin 1972] or through attrition, even with adequate temperature control. If a fluidized bed reactor is used with fuel having a high heat load, decay heat will be a problem if fluidization should be stopped or caking could occur as it will cause a temperature rise in the reactor [Vogel 1968].

Another literature source [Uhlir 2009] suggests that direct flame fluorination as the most promising unit operation for future industrial application but at a higher temperature than desired for the proposed system as the temperature in the flame can reach the range of $1500-1700^{\circ} \mathrm{C}$. This method of fluorination was used in the 1980s and is under development by Hitachi Ltd in Japan and by the Nuclear Research Institute Rez plc in the Czech Republic. Another method mentioned is a rotary kiln. One concern on this type of device would be ensuring that the fuel particles avoid clumping to allow all surfaces contact with the reaction gas. Preparing a uniform powder by voloxidation of required granularity for subsequent fluorination is difficult [Uhlir 2009]. If the particle size is too large then reaction times will be slowed or reactions will be less complete due to less surface area. Work will be required to determine optimum fuel particle sizes, if it is possible to consistently obtain these particles in a fuel oxidation process, and which type of reactor will allow the necessary reaction control while providing a robust process that is not easily upset.

Filtering of the dusts/aerosols will be important. Gaseous fluorination testing in the Soviet Union with cermet filters associated with the fluidized beds, showed they plugged rapidly and would not fully be regenerated in a process [Veryatin 1972]. In addition, though fluoride volatility processes have been done on a industrial scale, these processes have been done in the absence of high radiation levels and radioactive contamination. Remote maintenance of this sort of equipment under plant conditions with irradiated fuels will present additional problems. Remote control of processes, valve operation, moving parts and other components of equipment in a fluorine base flowsheet is more complicated than in an aqueous based system [Veryatin 1972]. In addition, the need for moving dry materials through the process by pneumatic methods is needed.

At least one case has shown that a fluidized bed process with dry pneumatic handling of highly radioactive materials is feasible. At the Idaho Chemical Processing Plant (ICPP) at the INL, fluidized bed calciners were successfully operated from 1962 through 2000 to solidify high level wastes. Though this process was different than that proposed, it showed that a fluidized bed could be operated in a hot cell environment and that removal of the dust/aerosols is possible. Fine particles were produced in the fluidized bed reaction and an off-gas particle removal and cleanup system was required. This consisted of a primary cyclone to remove the majority of the fines, a venturi scrubber to remove most of the remaining entrained fines, a scrubber separator and mist eliminators to remove aerosols, $\mathrm{Ru}$ adsorbers, and HEPA filters. The fines removed from the system along with the solidified waste were pneumatically transported to storage bins. Operating parameters had to be controlled to maintain an average particle size large enough to prevent excessive carry-over of particles and small enough to maintain adequate fluidization.

Volatility processes have the disadvantage in that they generally operate at elevated temperature, where corrosion problems must be carefully considered. In addition, uranium and plutonium hexafluorides are powerful fluorinating agents that require use of non-reactive materials of construction including nickel or alloys containing $\geq 60 \%$ nickel (Monel, Inconel), and certain copper and aluminum alloys. The rates of corrosion of nickel by fluorine gas, anhydrous $\mathrm{HF}$ and volatile fluorides are acceptable up to $600-650^{\circ} \mathrm{C}$. Although pure nickel exhibits very good corrosion resistance, it is difficult to weld so high-nickel-content alloys are used instead. The Portsmouth gaseous diffusion plant used nickel coated steel for much of its piping. Shaft seals and packing glands also pose significant problems, for which fully fluorinated hydrocarbon polymers must be used.

One of the problems at gaseous diffusion plants is significant deposits of uranium and plutonium compounds in the equipment. These deposits are the result of accidental occurrences, usually the leakage of moist air into the equipment or water permeation of elastomer gaskets or seals, causing the formation of crusts of solid uranium (and $\mathrm{Tc}^{99}$ compounds from some DOE fuels sent through the process) and a fairly thin coating of 
uranyl fluoride and uranium-fluoride-metal reaction products on the inside surfaces of the operating equipment. $\mathrm{UO}_{2} \mathrm{~F}_{2}$ is the primary solid material along with other uranium oxyfluorides $\left(\mathrm{U}_{\mathrm{n}} \mathrm{O}_{2 \mathrm{n}-1} \mathrm{~F}_{2 \mathrm{n}+2}\right)$. Solid $\mathrm{UF}_{4}$ and $\mathrm{UF}_{5}$ can also be formed from the reaction of $\mathrm{UF}_{6}$ with internal metal surfaces. This experience with gaseous diffusion plant suggests that the same kind of problem could occur in a dry fluorination process for used fuel separations. This kind of problem could be worsened by the potential for the solidification of compounds of elements such as ${ }^{99} \mathrm{Tc}$ and $\mathrm{Pu}$. The elemental ${ }^{99} \mathrm{Tc}$ present can sorb tightly to metal surfaces, and volatile $\mathrm{PuF}_{6}$ can readily be converted to nonvolatile $\mathrm{PuF}_{4}$.

\subsubsection{Safety/Environmental}

The prospect of handling fluorine, interhalogen compounds and volatile fluorides at high temperatures is daunting; however, these materials, with the exception of $\mathrm{PuF}_{6}$, are not new to industry. Fluorine and $\mathrm{UF}_{6}$ have been produced in multi-ton quantities at gaseous diffusion plants for years. The presence of compounds of other elements such as TRU elements and FPs could present new safety and environmental challenges. $\mathrm{NF}_{3}$ is a non-flammable gas which is less toxic and considered less hazardous than $\mathrm{F}_{2}(\mathrm{~g})$ or HF that is typically used in fluoride volatility flowsheets. More innocuous $\mathrm{F}$ compounds such as $\mathrm{NF}_{3}$ have been proposed in part to replace the more hazardous $\mathrm{F}_{2}$ and $\mathrm{HF}$ compounds with safer ones. Table 4-2 summarizes hazard parameters for the various gases considered in this fluoride volatility process and reference processes.

Table 4-2. Hazard parameter comparison for $\mathrm{NF}_{3}$ process versus reference process.

\begin{tabular}{|l|l|c|l|l|}
\hline Compound & $\begin{array}{c}\text { IDLH limit, } \\
\text { ppmv }\end{array}$ & $\begin{array}{c}\text { NFPA } \\
\text { ratings }\end{array}$ & Flammability & \multicolumn{1}{|c|}{ Comments } \\
\hline $\mathrm{F}_{2}$ & 25 & $4,0,4$, none & None & $\begin{array}{l}\text { The most powerful oxidizing agent } \\
\text { known. }\end{array}$ \\
\hline $\mathrm{HF}$ & 30 & $4,0,1$, none & None & \\
\hline $\mathrm{NF}_{3}$ & 1,000 & $\begin{array}{c}1,0,0, \\
\text { oxidizer }\end{array}$ & None & $\begin{array}{l}\mathrm{NF}_{3} \text { is a greenhouse gas that is } \\
17200 \text { times worse than } \mathrm{CO}_{2} .\end{array}$ \\
\hline $\mathrm{HNO}_{3}$ & 25 & $\begin{array}{c}4,0,3, \\
\text { corrosive }\end{array}$ & None & \\
\hline $\mathrm{O}_{2}$ & None & $\begin{array}{c}0,0,0, \\
\text { oxidizer }\end{array}$ & $\begin{array}{l}\text { None; } \\
\text { supports } \\
\text { combustion }\end{array}$ & \\
\hline $\mathrm{O}_{3}$ & 5 & $\begin{array}{c}4,0,4, \\
\text { oxidizer }\end{array}$ & $\begin{array}{l}\text { None; } \\
\text { supports } \\
\text { combustion }\end{array}$ & \\
\hline
\end{tabular}

\subsubsection{Waste management}

The gaseous radioactive FP (iodine, carbon-14, tritium, and krypton) capture technologies, waste streams, and waste forms are expected to be no different from the reference aqueous separations case, except that the presence of fluorine/fluoride may contaminate, and cause increased amounts of the iodine waste form. There may also be larger amounts of particulate matter in the off-gas systems, with larger amounts of fluoride species, and this particulate matter may exhibit different flow and handling properties. The particulate matter could be separately processed into a waste form, but combining this material with the waste stream that contains most of the rest of the FPs is likely to be the preferred option.

The best disposal option for the $\mathrm{Pu} / \mathrm{Am} / \mathrm{Cm} / \mathrm{FP}$ waste stream is a durable, long-lived waste form, which is a borosilicate glass in the reference aqueous case. Fluoride species are expected to contaminate this waste stream in this nitrogen trifluoride case. Halogens are not very soluble in borosilicate glass. To avoid what might be a necessarily low waste loading in borosilicate glass, other waste forms such as a ceramic, glassceramic, or phosphate glass, tailored to retain the FPs and residual actinides and also contain fluoride, might achieve higher waste loadings. Alternatively, the fluorides could be removed and recycled, which could 
enable this waste stream to be vitrified into a BSG or ceramic waste form. Research and development of suitable waste form options for high fluoride waste streams is a key area of research that is needed to advance this separation technology.

\subsubsection{Used fuel disposal/suitability for recycle}

There are current limitations on the amount of contaminants (FPs, etc.) allowed in the fuel fabrication process. The advanced aqueous reference method can meet the current contaminant limits. It is anticipated that these limits may change in the future due to development of "impurity-tolerant fuels" to allow fuel fabrication with FPs and some other contaminants. Regardless, contamination of waste elements in the recycle fuel material must be limited such that the impurity limits are met for whatever fuel technology and performance levels are established. One the main concerns with this proposed system is that the lanthanides are not separated from the Pu stream. Lanthanides, as well as other fission products, are a potential problem in the fuel for a number of reasons, including fuel performance and neutron capture.

The radiological hazard of fuels made with products from the aqueous separations process depends on what is being recycled. The same is true for this process. If only recovered uranium is used in the new fuel, the fuel may be radiologically clean enough that a hot cell environment for the fuel fabrication would not be required although contamination control will still be needed. However, if the Pu product from the $\mathrm{NF}_{3}$ process was recycled, it would require a fully-remote fuel fabrication process due to FP contamination. The question of fuel tolerance to impurities is currently being investigated in the FCR\&D Fuels campaign, and would determine to what extent recycle is practical given such impurities in the products from processing.

Some of the key issues for utility acceptance of recycled fuel include [Christian 1999]:

- Fuel cost in comparison to fresh fuel.

- New capital and/or equipment costs for receiving, inspecting, and handling the fuel.

- Low fuel defects (Is this achievable using a fully remote manufacturing and inspection process?).

- Worker exposure and safety.

- New waste streams.

- Impacts to safety analysis due to higher source term, lower beta fraction, fuel temperature coefficient.

- Accountability issues.

The viability of this separations process depends in part on how pure the recovered uranium is, and if the recovered uranium can meet applicable fuel purity limits.

\subsubsection{Economics/Footprint reduction}

The overall cost difference in producing a relatively dirty $U$ product and a clean product might be relatively small as $\mathrm{U}$ is the main material by weight in an LWR reprocessing plant. It is typically reported in the literature that a dry reprocessing scheme will reduce the overall recycle plant's footprint (especially in cell space); however, quantitative data supporting this has not been developed. A separation scheme such as that proposed would likely require less space but it also does not obtain the same amount of separation.

Investigation into additional off-gas cleanup space/costs also needs to be considered.

Some differences in the proposed system which would affect the footprint include:

- No dissolver and no liquid storage tanks, so a smaller footprint is expected for those things compared to aqueous.

- $\quad$ Staging and storage for reagents changes - no nitric acid, but added $\mathrm{NF}_{3}$. Analyses need to be done to determine how reagent transport, receiving, and storage are impacted by eliminating nitric acid and organic solvents vs added $\mathrm{NF}_{3}$.

- Since the recovered uranium contains other contaminants including $\mathrm{Nb}$ and $\mathrm{Np}$, the recovered uranium is less pure than recovered uranium from the reference aqueous process. This has several implications that 
could reduce or eliminate and potential savings that are achieved by using a non-aqueous process [Mallen 1990]:

- With more FP impurities, the recovered uranium may require remote handling inside a hot cell, while the aqueous $U$ stream generally requires only contamination control efforts.

- Due to remote handling requirements, costs and footprint for recovered uranium handling, packaging, processing for fuel fabrication, and the fuel fabrication itself will be higher.

0 If the recovered uranium is to be re-enriched, then higher purity recovered uranium may be required by the enrichment process

- Current regulations require that if UNF is reprocessed, the waste must be treated, solidified, and packaged shortly after being generated. It is relatively easy in a technical, economic and regulatory context to store clean recovered uranium, but long-term storage of contaminated recovered uranium faces major unknowns.

- If the recovered uranium is eventually determined to be a waste, then the levels of TRU contamination may cause it to be classified as a TRU-contaminated waste with the associated high waste storage and disposal costs.

\subsubsection{Resource Sustainability}

$\mathrm{NF}_{3}$ separations will not increase the conservation of uranium resources compared to the aqueous separations reference case, because the reference aqueous case already can recover and recycle the actinides (which is one way to increase uranium conservation). The conservation of uranium resources also depends on the degree to which natural uranium is consumed to produce power. Fuel cycles in which depleted uranium is used and not discarded, and in which $\mathrm{U}$ and TRU in used fuel is recycled, maximize uranium utilization. In $\mathrm{NF}_{3}$ separations, uranium utilization can be maximized if the recovered $U$ is used in CANDU or breeder reactors, and if the TRU in the waste stream is also recovered for recycle.

\subsubsection{Proliferation risk and physical protection}

The researchers have suggested that this separations approach:

- Reduces safeguards requirements that are needed when used fuels are dissolved.

- Increases proliferation resistance, as the Pu stream will contain some amount of FP so that it can be selfprotecting.

- Increases difficulty of safeguards sampling during fuel fabrication.

A number of factors, some of which are technical in nature, determine proliferation risk. One of the main technical issues is whether or not safeguards can be effectively implemented in a facility using the innovative technology, where the goal of safeguards is timely detection of misuse of or diversion from the facility. In this respect, the reference advanced aqueous process has the benefit of decades of safeguards experience on commercial processing plants, especially in France. Assessment of the relative ease or difficulty of applying effective safeguards for this technology involves consideration of product stream contents and characteristics that may hinder implementation of safeguards technologies, including non-destructive assay, material control and accountability (MC\&A), and sampling.

The target material in this process is likely to be the plutonium in the UNF. Based on the diagram in Fig. 3-1, several characteristics of the product streams may introduce difficulties in implementing the safeguards technologies, including the presence of elements with higher radiation than plutonium which complicates or even eliminates indirect measurement of plutonium. It should be noted that this same difficulty may occur with advanced aqueous processes that propose to recover more than just the uranium and plutonium. MC\&A begins with an assay of the incoming UNF, usually performed in an accountancy tank located immediately after the dissolver for an aqueous process. In this process, sampling of the oxidized powder after the voloxidation step might provide equivalent data for initializing MC\&A analyses, although it would not appear that safeguards requirements would be reduced during this stage as compared to the dissolution step of aqueous processes. The contaminants in the recovered plutonium should not pose a problem for chemical 
analysis of process samples. Overall, it appears that the ability to apply safeguards to this technology is generally similar to those for the advanced aqueous process.

The radiation hazard of the product streams can have an impact on physical protection, in that radiation may provide some deterrence to theft. At this time it is not known if the FP and minor actinide contamination would provide sufficient radiation for the plutonium bearing waste stream as shown in Figure 3-1 to render it unattractive.

\subsubsection{Summary}

Fuel cycle options where $\mathrm{NF}_{3}$ separations could apply mainly include MOC and FR fuel cycles where the uranium in UNF is recovered for re-enrichment. Based on Fig. 3-1, where the plutonium is considered to be part of the waste stream, recovery of plutonium for recycle would require additional processing to separate it from minor actinides and FPs.

Differentiators of the proposed $\mathrm{NF}_{3}$ system compared to aqueous separations include:

- The dissolver, liquid tank storage, and nitric acid and organic solvent reagents can be eliminated, so footprint and equipment needed inside and outside hot cells for these things can be eliminated; but the addition of $\mathrm{NF}_{3}$ reagent adds footprint and equipment outside the hot cells for receiving and storing $\mathrm{NF}_{3}$.

- Off-gas particulate matter capture and management needs to be more extensive to handle the expectedly larger amounts of dust and condensed materials that likely contain $\mathrm{F}$ species.

- Recycle of $\mathrm{Pu}, \mathrm{Am}$, and $\mathrm{Cm}$ may not be possible without further separation of these TRU elements from FPs, especially the lanthanides.

- Organic solvent degradation products, waste acid, and waste water are eliminated in waste streams.

- Waste streams will contain fluorides which will necessitate the need to either develop a new waste form such as phosphate glass or mineral waste form, or remove and recycle the F, enabling the use of BSG.

Differentiators compared to reference fluoride volatility separations include:

- Use of safer and less corrosive $\mathrm{NF}_{3}$, but if the $\mathrm{F}$ is recovered and recycled, then other $\mathrm{F}$ species that may be more hazardous and corrosive than $\mathrm{NF}_{3}$ may also be present in the system.

- Tunable separations that might enable more efficient separations of some FPs from the U and TRU streams.

Research and development information that is still needed to further evaluate this technology in the context of MOC and FR fuel cycles includes:

- More complete determination of separation factors for the fuel into the product/waste streams and determination if the separation achievable will allow a fuel to be fabricated that can be used in reactors.

- Mass balances needed to assess process flow and equipment size requirements, amount of reagents needed, etc.

- More complete process definition - such as F recycling or not, operating temperatures, corrosion and equipment degradation, handling of solids materials, and process performance

- Development and demonstration of waste form concepts.

\subsubsection{Reactive Fluoride Gas $\left(\mathrm{SF}_{6}\right)$ for UNF Processing}

Table 4-3 provides a comparison of the product and waste streams out of the proposed process to those for the advanced aqueous case and the reference fluoride volatility case. 
Table 4-3. Product and waste stream comparison for reactive fluoride gas $\left(\mathrm{SF}_{6}\right)$ system.

\begin{tabular}{|c|c|c|c|}
\hline Process & $\begin{array}{c}\text { Reference Case: } \\
\text { Advanced Aqueous w/Basic Voloxidation }\end{array}$ & $\begin{array}{l}\text { Reference Fluoride } \\
\text { Volatility }\end{array}$ & $\mathrm{SF}_{6}$ \\
\hline \begin{tabular}{|l} 
UNF \\
Disassembly \\
and Chop
\end{tabular} & $\begin{array}{l}\text { 1. Metal fuel assembly parts (activated and/or } \\
\text { contaminated) } \\
\text { 2. Chopped fuel elements } \\
\text { 3. Off-gas - Up to } 10 \% \mathrm{Kr}, \mathrm{Xe} \text {, (some C, H-3, and } \\
\text { other FP) }\end{array}$ & $\begin{array}{l}\text { Same as reference } \\
\text { aqueous case }\end{array}$ & $\begin{array}{l}\text { Same as reference } \\
\text { aqueous case }\end{array}$ \\
\hline $\begin{array}{l}\text { Fuel } \\
\text { Oxidation / } \\
\text { Voloxidation }\end{array}$ & $\begin{array}{l}\text { 1. Zr cladding contaminated with FPs and actinides } \\
\text { (when voloxidation is not used to separate } \\
\text { cladding from fuel, the cladding is separated } \\
\text { during dissolution). } \\
\text { 2. Off-gas : }>99 \% \mathrm{H}-3,6 \% \mathrm{Kr}, 6 \% \mathrm{Xe}, 50 \% \mathrm{C}, 1 \% \\
\text { I, } \mathrm{Br},<0.2 \% \mathrm{Ru}, \mathrm{Sb}, \mathrm{Cs} \text { at moderate temps } / \mathrm{rxn} \\
\text { times }\end{array}$ & $\begin{array}{l}\text { Same as reference } \\
\text { aqueous case }\end{array}$ & $\begin{array}{l}\text { 1. Zr cladding: } \\
\text { Same as reference } \\
\text { volox } \\
\text { 2. Off-gas- } \\
\text { increased semi- } \\
\text { volatiles over } \\
\text { reference volox: } \\
100 \% \mathrm{Kr}, \mathrm{H}-3, \mathrm{Xe}, \mathrm{C} \text {, } \\
\mathrm{Rn} ; 66 \% \mathrm{I} ; 33 \% \mathrm{Tc}, \\
\text { Mo, Ru, Se, Te, Rh: } \\
\text { Potential Cs }\end{array}$ \\
\hline $\begin{array}{l}\text { Dissolution / } \\
\text { Filtration }\end{array}$ & $\begin{array}{l}\text { 1. Undissolved solids (can be combined with FP in } \\
\text { glass, or with Tc, SS, and Zircaloy in melted } \\
\text { metal waste form) } \\
\text { 2. Off-gas [w/ no volox:all remaining } \mathrm{Kr}, 90 \% \text { of } \\
\text { the I, some C-14, some H-3] } \\
\text { 3. Zr cladding (contaminated with FPs and } \\
\text { actinides) when voloxidation is not used to } \\
\text { separate fuel from cladding }\end{array}$ & $\mathrm{NA}$ & $\mathrm{NA}$ \\
\hline Separation & $\begin{array}{l}\text { Several options are possible depending on whether all } \\
\text { TRU are recycled or if separate waste management } \\
\text { pathways for different FPs are desired: } \\
\text { Product streams } \\
\text { 1. Uranium } \\
\text { 2. TRU, possibly with uranium } \\
\text { 3. Pu, Np, Am, Cm, \& other TRU, either separately } \\
\text { or in groups } \\
\text { Primary waste streams } \\
\text { 1. FP in HLW glass- includes raffinate from 1st } \\
\text { cycle, Tank waste, and UDS (vitrified) } \\
\text { 2. Tc in } \mathrm{Zr} / \mathrm{SS} / \mathrm{Tc} / \mathrm{UDS} \text { MWF, if the Tc is } \\
\text { separated from other FPs and if the UDS is } \\
\text { placed into MWF instead of glass. } \\
\text { 3. } \mathrm{Cs} / \mathrm{Sr} / \mathrm{Rb} / \mathrm{Ba} \text { in mineral waste form if separated } \\
\text { from other FPs } \\
\text { 4. Np, Am, Cm, and other TRU if separated for } \\
\text { disposal instead of recycle. }\end{array}$ & $\begin{array}{l}\text { Product streams: } \\
\text { 1. UF }+ \text { small amount } \\
\text { Pu and Np and } \\
\text { contamination by } \\
\text { volatile FP fluorides. } \\
\text { 2. PuF } 4 \text { small } \\
\text { amount of U, Np, and } \\
\text { contamination by } \\
\text { volatile FP fluorides. } \\
\text { 1. Primary Waste } \\
\text { streams: Non volatile FP } \\
\text { on alumina bed (vitrified } \\
\text { using BSG or phosphate } \\
\text { glass) } \\
\text { 2. Volatile FP from } \\
\text { distillation and absorbers } \\
\text { (Mo, Np, Tc, Ru, Nb, } \\
\text { Sb) (vitrified using BSG } \\
\text { or phosphate glass) }\end{array}$ & $\begin{array}{l}1 . \quad 100 \% \text { of } \mathrm{U}, \text { as } \\
\mathrm{UF}_{6},(\text { maybe some } \\
\mathrm{Nb} \text { and } \mathrm{Np} \text { as } \mathrm{NbF}_{5} \\
\mathrm{NpF}_{6} \text { ) }- \text { to recycle or } \\
\text { waste } \\
2 . \quad 100 \% \mathrm{Pu}, \mathrm{Np} \\
66 \% \mathrm{Mo}, \mathrm{Rh}, \mathrm{Ru}, \mathrm{Tc}, \\
\mathrm{Se}, \mathrm{Te} ; 33 \% \mathrm{I} \text { to fuel } \\
\text { fab or waste } \\
3 . \quad 100 \% \mathrm{Am}, \mathrm{Cm}, \\
\mathrm{Ba}, \mathrm{Sr}, \mathrm{La}, \mathrm{Zr}, \mathrm{Ce}, \\
\mathrm{Sm}, \mathrm{Y}, \mathrm{Nb}, \mathrm{Sn}, \mathrm{Cs}, \\
\mathrm{Gd}, \mathrm{SO}_{2} \mathrm{~F}_{2} \& \mathrm{SOF}_{4} \text { to } \\
\text { waste } \\
\end{array}$ \\
\hline
\end{tabular}




\begin{tabular}{|c|c|c|c|}
\hline Process & $\begin{array}{c}\text { Reference Case: } \\
\text { Advanced Aqueous w/Basic Voloxidation }\end{array}$ & $\begin{array}{l}\text { Reference Fluoride } \\
\text { Volatility }\end{array}$ & $\mathrm{SF}_{6}$ \\
\hline $\begin{array}{l}\text { Off-gas } \\
\text { control } \\
\text { systems }\end{array}$ & $\begin{array}{l}\text { The reference gaseous FP waste forms are: } \\
\text { 1. H-3 in HTO in grouted waste form } \\
\text { 2. I-129 in glass-bonded silver zeolite waste form } \\
\text { 3. C-14 in } \mathrm{CO}_{2} \text { grouted waste form } \\
\text { 4. Kr-85 (with or without nonradioactive Xe) in } \\
\text { compressed gas cylinders. } \\
\text { Particulate matter formed from entrained dust and } \\
\text { condensed semi-volatile matter in the head end and } \\
\text { dissolver off-gas systems is filtered in cleanable } \\
\text { filters and recycled to the dissolver. Particulate } \\
\text { matter in the process gas streams is recycled or } \\
\text { solidified into a separate waste form. Particulate } \\
\text { matter captured on HEPA filters is disposed of with } \\
\text { the filters, although it could also be removed from } \\
\text { the filters (via filter leaching) and combined with the } \\
\text { separated FP waste stream. }\end{array}$ & $\begin{array}{l}\text { Same gaseous FP waste } \\
\text { streams as reference } \\
\text { aqueous case. } \\
\text { Particulate matter may } \\
\text { have some fluoride } \\
\text { species; combined with } \\
\text { the FP waste streams. }\end{array}$ & $\begin{array}{l}\text { Same gaseous FP } \\
\text { waste streams as } \\
\text { reference aqueous } \\
\text { case. } \\
\text { Particulate matter } \\
\text { may have some } \\
\text { fluoride species; } \\
\text { combined with the } \\
\text { FP waste streams. }\end{array}$ \\
\hline
\end{tabular}

\subsubsection{Separations}

This separation method, as proposed, does not attempt to achieve the same degree of separation achievable with an advanced aqueous process as it leaves the Pu with some of the FP. The simplified process steps proposed in the $\mathrm{SF}_{6}$ system produce a purified uranium product, a $\mathrm{Pu} /$ actinide oxide product which will contain some $\mathrm{FP}$, and a waste stream that contains the majority of the lanthanides, $\mathrm{Cs}, \mathrm{Sr}, \mathrm{Am}$, and $\mathrm{Cm}$. According to the researchers, it is expected to recover more than $99 \%$ of the uranium stream. It is also expect to recover more than $99 \%$ of the $\mathrm{Pu}$ and $\mathrm{Np}$ with some $\mathrm{FP}$. The amount of contaminants in the $\mathrm{U}$ and $\mathrm{Pu} / \mathrm{Np}$ streams is projected but has not yet been experimentally determined.

\section{Oxidation Step:}

The first step of the proposed process uses an enhanced voloxidation of the fuel to remove additional volatile components ( $\mathrm{Rn}, \mathrm{Se}, \mathrm{Te}, \mathrm{Rh}$ and potentially $\mathrm{Cs}$ ). They are proposing use of $\mathrm{NO}_{\mathrm{x}}$ gases instead of just $\mathrm{O}_{2}$ or air to separate some of the $\mathrm{Cs}$ and Tc. Thermodynamic calculations conducted by $\mathrm{SRNL}$ indicate that $\mathrm{CsNO}_{3}$ and $\mathrm{CsNO}_{2}$ should be volatile at $\mathrm{T}>800^{\circ} \mathrm{C}$ and $\mathrm{Tc}_{2} \mathrm{O}_{7}$ at $\mathrm{T}>300^{\circ} \mathrm{C}$ [Gray 2010]. The proposal is to remove $100 \%$ of the $\mathrm{Kr}, \mathrm{H}-3, \mathrm{Xe}, \mathrm{C}, \mathrm{Rn}, 66 \%$ of the I, $33 \%$ of the Tc, Mo, Ru, Se, Te, Rh, and some Cs using $\mathrm{NO}_{\mathrm{x}}$ and higher temperatures.

A cursory review of the literature shows a variety of voloxidation process conditions and amounts of FP volatilized. There are some differences in published data on FP removal achieved using the typical voloxidation $\left(\sim 500^{\circ} \mathrm{C}\right)$ and the AIROX type process. Some of the results reported are listed in Table 4-4. During this quick review, no information was found in the general literature on voloxidation with $\mathrm{NO}_{\mathrm{x}}$ as the oxidizing gas. One potential issue is that aggressive voloxidation may affect plutonium solubility depending on many factors such as reaction temperature, time, etc [ORNL 2009, Johnson 1980]. 
Table 4-4. Some voloxidation/AIROX results listed in literature.

\begin{tabular}{|l|l|l|l|l|}
\hline & $\begin{array}{l}\text { Volox @ } \\
480^{\circ} \mathrm{C} \& 4 \mathrm{hr} \\
{[\text { ORNL 2009] }}\end{array}$ & $\begin{array}{l}500^{\circ} \mathrm{C} \text { in } \mathrm{O}_{2} \text { or } \\
\text { air } \\
\text { [Johnson1980] }\end{array}$ & $\begin{array}{l}500^{\circ} \mathrm{C} \text { in air \& 5-10 } \\
\text { hrs } \\
\text { [KAERI 2007] }\end{array}$ & $\begin{array}{l}500^{\circ} \mathrm{C} \text { in air then 3 cycles } \\
500^{\circ} \mathrm{C} \text { in air followed by } \\
700^{\circ} \mathrm{C} \text { in } 4 \% \mathrm{H}_{2}, \mathrm{Ar} \\
{[\text { KAERI 2007] }}\end{array}$ \\
\hline $\mathrm{H}-3$ & & $100 \%$ & $99 \%$ (typical) & $99 \%$ \\
\hline $\mathrm{C}-14$ & $\sim 50 \%$ & $17-22 \%$ & $7.5-15 \%$ (measured) & Up to $89 \%$ \\
\hline $\mathrm{Kr}$ & $6 \%$ & $<17 \%$ & $7-18 \%$ (measured) & Up to $90.1 \%$ \\
\hline $\mathrm{Xe}$ & $6 \%$ & & & \\
\hline $\mathrm{I}, \mathrm{Br}$ & $1 \%$ & & $<8 \%$ (typical) & $@ 1200^{\circ} \mathrm{C} 86-99 \%$ \\
\hline $\mathrm{Ru}, \mathrm{Sb}, \mathrm{Cs}$ & $0.2 \%$ & & & \\
\hline $\mathrm{Cs}$ & & & & $91500^{\circ} \mathrm{C}$ up to $95 \%$ \\
\hline
\end{tabular}

Another important factor will be the powder size distribution formed which also depends on the temperature (typically voloxidation forms particles less than $20 \mu \mathrm{m}$ ) [ORNL 2009]. Some literature has indicated that preparing a uniform powder by voloxidation of required granularity for subsequent fluorination is difficult [Uhlir 2009].

These references indicate that the success of the voloxidation step in the proposed process is contingent not only on the gas used, but also on the temperature, the pressure, the UNF burn-up and other factors. If the initial laboratory tests using surrogate materials looks successful, it will be important to test with actual spent fuel.

\section{Fluorination:}

The second step of the proposed process is fluorination with $\mathrm{SF}_{6}$ at $>600^{\circ} \mathrm{C}$ to separate the volatile and nonvolatile fluoride species, resulting in $\mathrm{UF}_{6}, \mathrm{NpF}_{6}$, some $\mathrm{PuF}_{6}$, some FP fluorides $(\mathrm{Nb}, \mathrm{Mo}, \mathrm{Te}, \mathrm{Tc})$ in the gas stream and the rest of the FP (including $\mathrm{Am}, \mathrm{Cm}, \mathrm{Sr}, \mathrm{Cs}$, and lanthanides) in the remaining solids.

The separation of the $\mathrm{U}, \mathrm{Pu}$, and some FP relies on the differential abilities of these elements for forming higher-order volatile fluorides, as well as on the different reactivities of the $\mathrm{UF}_{6}$ and $\mathrm{PuF}_{6}$. Uranium dioxide more readily reacts with fluorine to form a higher-order fluoride, than does plutonium dioxide. The resulting $\mathrm{UF}_{6}$ is more inert in its chemical activity than $\mathrm{PuF}_{6}$, which acts as a more vigorous fluorinating agent than fluorine under certain conditions. Since many FPs capable of interacting with $\mathrm{PuF}_{6}$ are in $\mathrm{UNF}$, and lower valence $\mathrm{U}$ compounds are also present, the $\mathrm{PuF}_{6}$ is capable of oxidizing the later, and becoming reduced to a tetrafluoride in the process. Literature indicates that $\mathrm{PuF}_{6}$ is very unstable compared to $\mathrm{UF}_{6}$ and will decompose to $\mathrm{PuF}_{4}$ under a variety of conditions. As this step in the proposed process is using the fluorination to achieve the separation of non-volatile fluoride FP from volatile $\mathrm{U}$ and $\mathrm{Pu}$ it is important to realize that complete separations (especially of the $\mathrm{Pu}$ ) may be difficult to control. The fluorides of a few other elements are sufficiently volatile that they will likely be present with the uranium fluoride. These include $\mathrm{Nb}, \mathrm{Ru}, \mathrm{Tc}$, Te, and Mo. Some of these may be primarily or partially removed by an initial fuel oxidation step.

Studies of the behavior of $\mathrm{Pu}$ when U-Pu fuel containing simulated FP is fluorinated showed that the presence of elements such as $\mathrm{Cs}, \mathrm{Sr}, \mathrm{Ba}$, and rare earths, contribute to Pu retention in the fluorination residue because they form strong complexes with plutonium fluoride [Veryatin 1972]. The Mallen report indicated that the recovery by fluoride volatility of a significant fraction of the $\mathrm{Pu}$ as a clean product is probably not practical and certainly would not be easy. Although $\mathrm{Pu}$ can be volatilized as a fluoride under carefully controlled conditions, it is a difficult reaction to accomplish, yields tend to be low, and in any case, it would still be substantially contaminated with some FPs [Mallen 1990].

According to another source, while the fluorination of $\mathrm{U}$ to the volatile hexavalent form is spontaneous, $\mathrm{PuF}_{6}$ is thermally unstable and can be obtained only at a considerable excess of fluorine gas. In addition, $\mathrm{PuF}_{6}$ is susceptible to internal radiolysis with a significant decomposition rate to non-volatile $\mathrm{PuF}_{4}$ and $\mathrm{F}_{2}$. The 
reaction is reversible, and in a closed system could result in an equilibrium composition dependent on pressure and temperature. Therefore, the means to refluorinate the $\mathrm{PuF}_{4}$ residue must be built into any system handling $\mathrm{PuF}_{6}$ in quantity. Past fluoride volatility studies indicated controlling the amount of $\mathrm{Pu}$ volatilized will require careful control of the process. Studies in the Czech Republic using a flame fluorinator with $\mathrm{F}_{2}$ gas achieved 95-99.5\% U recovery, 98-99.5\% Pu, 60-70\% Np, and verified that Am, Cm, FPs formed non-volatile fluorides (and thus were individually inseparable without further processing). The behavior of $\mathrm{Np}$ varied in these studies. The thermal stability of $\mathrm{NpF}_{6}$ is substantially higher than of $\mathrm{PuF}_{6}$ so the thermal decomposition of $\mathrm{NpF}_{6}$ is less. $\mathrm{MoF}_{6}, \mathrm{TcF}_{6}, \mathrm{IF}_{5}$, and $\mathrm{SbF}_{5}$ tend to accompany $\mathrm{UF}_{6}$ through the system [Uhlir 2009].

The fluorides of elements such as $\mathrm{Cs}, \mathrm{Sr}, \mathrm{Ce}$, and others, whose vapor pressures indicated are not volatile at the fluorination temperature, may be present in the vapor phase in the form of aerosols and dust. Filters, such as sintered metal filters, are capable of removing the dust and aerosols, however, plugging of the filters can be an issue [Veryatin 1972].

\section{Hydrolization:}

In the third step of the proposed process, the U/Pu containing gas stream is then hydrolyzed (with $\mathrm{H}_{2}$ or $\mathrm{NH}_{3}$ at $>1000^{\circ} \mathrm{C}$ ) to convert the 6 -valent species to 4 -valent species, which allows condensation and separation of the 4-valent (or less) $\mathrm{Pu}, \mathrm{Np}$, and trace FP fluoride species from $\mathrm{UF}_{4}$, which remains gaseous. The separated $\mathrm{U}$ can be enriched or otherwise processed into new fuel; the stream containing the TRU and trace FPs can be processed into waste/fuel or further processed or separated to recycle the TRU, I, or Tc.

This work will continue to obtain details on the separation factors obtainable, especially with simulated or actual spent fuel.

\subsubsection{Engineering Issues}

Direct reaction between the fuel and gaseous fluorinating reagents requires control of reaction rates and temperatures because of the heat generated in the highly exothermic gas-solid reactions involved and the low heat capacity of the gaseous effluents. Accordingly, one method suggested in literature [Reilly 1963] to deal with the problem is the use of a fluidized bed of inert granular solids, which, by virtue of its heat capacity and heat transfer properties, enables such reactions to be carried out under controlled conditions. The heat produced in the reaction is transferred to the bed and from there to the walls of the reactor where it is removed by an external coolant. One of the key problems is that the fluidized bed might break down because of sintering of the particles if the temperature is not well controlled [Veryatin 1972], and through attrition even with adequate temperature control. If a fluidized bed reactor is used with fuel having a high heat load, decay heat will be a problem if fluidization should be stopped. Caking could occur as it will cause a temperature rise in the reactor [Vogel 1968].

Another literature source [Uhlir 2009] suggests that direct flame fluorination is the most promising unit operation for future industrial application, but at a higher temperature than desired for the proposed system, as the temperature in the flame can reach the range of $1500-1700^{\circ} \mathrm{C}$. This method of fluorination was used in the 1980s and is under development by Hitachi Ltd in Japan and by the Nuclear Research Institute Rez plc in the Czech Republic. Another method mentioned is a rotary kiln. One concern on this type of device would be ensuring that the fuel particles avoid clumping to allow all surfaces contact with the reaction gas. Preparing a uniform powder by voloxidation of required granularity for subsequent fluorination is difficult [Uhlir 2009]. If the particle size is too small the fines may elutriate from the vessel. If the particle size is too large then reaction times will be slowed or reactions will be less complete due to less surface area. Work will be required to determine optimum fuel particle sizes, if it is possible to consistently obtain these particles in a fuel oxidation process, and which type of reactor will allow the necessary reaction control while providing a robust process that is not easily upset.

Filtering of the dusts/aerosols will be important. Gaseous fluorination testing in the Soviet Union with cermet filters associated with the fluidized beds, showed they plugged rapidly and would not fully be regenerated in a process [Veryatin 1972]. In addition, though fluoride volatility processes have been done on a industrial scale, 
these processes have been done in the absence of high radiation levels and radioactive contamination. Remote maintenance of this sort of equipment under plant conditions with irradiated fuels will present additional problems. A source [Veryatin] found that remote control of processes, valve operation, moving parts and other components of equipment in a fluorine base flowsheet is more complicated than in an aqueous based system. In addition, the need for moving dry materials through the process by pneumatic methods is needed [Veraytin 1972].

At least one case has shown that a fluidized bed process with dry pneumatic handling of highly radioactive materials is feasible. At the ICPP at the INL, fluidized bed calciners were successfully operated from 1962 through 2000 to solidify high level wastes. Though this process was different than that proposed, it showed that a fluidized bed could be operated in a hot cell environment and that removal of the dust/aerosols is possible. Fine particles were produced in the fluidized bed reaction and an off-gas particle removal and cleanup system was required. This consisted of a primary cyclone to remove the majority of the fines, a venturi scrubber to remove most of the remaining entrained fines, a scrubber separator and mist eliminators to remove aerosols, Ru adsorbers, and HEPA filters. The fines removed from the system along with the solidified waste were pneumatically transported to storage bins. Operating parameters had to be controlled to maintain an average particle size large enough to prevent excessive carry-over of particles and small enough to maintain adequate fluidization.

Volatility processes have the disadvantage that they generally operate at elevated temperature, where corrosion problems must be carefully considered. In addition, uranium and plutonium hexafluorides are powerful fluorinating agents that require use of non-reactive materials of construction including nickel or alloys containing $\geq 60 \%$ nickel (Monel, Inconel), and certain copper and aluminum alloys. The rates of corrosion of nickel by fluorine gas, anhydrous $\mathrm{HF}$ and volatile fluorides are acceptable up to $600-650^{\circ} \mathrm{C}$. Although pure nickel exhibits very good corrosion resistance, it is difficult to weld, so high-nickel-content alloys are used instead. The Portsmouth gaseous diffusion plant used nickel coated steel for much of its piping. Shaft seals and packing glands also pose significant problems, for which fully fluorinated hydrocarbon polymers must be used.

One of the problems at gaseous diffusion plants is significant deposits of uranium and plutonium compounds and FPs in the equipment. These deposits are the result of accidental occurrences, usually the leakage of moist air into the equipment or water permeation of elastomer gaskets or seals, causing the formation of crusts of solid uranium (and $\mathrm{Tc}^{99}$ compounds from some DOE uranium sent through the process) and a fairly thin coating of uranyl fluoride and uranium-fluoride-metal reaction products on the inside surfaces of the operating equipment. $\mathrm{UO}_{2} \mathrm{~F}_{2}$ is the primary solid material, along with other uranium oxyfluorides $\left(\mathrm{U}_{\mathrm{n}} \mathrm{O}_{2 \mathrm{n}-1} \mathrm{~F}_{2 \mathrm{n}+2}\right)$. Solid $\mathrm{UF}_{4}$ and $\mathrm{UF}_{5}$ can also be formed from the reaction of $\mathrm{UF}_{6}$ with internal metal surfaces. Any ${ }^{99} \mathrm{Tc}$ present can sorb tightly to metal surfaces. $\mathrm{PuF}_{6}$ can decompose when bombarded by its intrinsic $\alpha$-radiation, and potentially deposit on the walls of the process equipment. This contributes to eventual equipment plugging and also causes Pu losses and accountability problems in the equipment, piping and valves [Veryatin 1972].

\subsubsection{Safety/Environmental}

The thought of handling fluorine, interhalogen compounds and volatile fluorides at high temperatures is daunting; however, these materials, with the exception of $\mathrm{PuF}_{6}$, are not new to industry. Fluorine and $\mathrm{UF}_{6}$ have been produced in multi-ton quantities at gaseous diffusion plants for years. The presence of compounds of other elements such as TRU elements and FPs could present new safety and environmental challenges. $\mathrm{SF}_{6}$ is a non-flammable gas which is considered less toxic and hazardous than $\mathrm{F}_{2}(\mathrm{~g})$ or HF that is typically used in fluoride volatility flowsheets. Table 4-5 summarizes hazard parameters for this proposed system and other gases considered standard in fluoride volatility processes. 
Table 4-5. Hazard parameter comparison for $\mathrm{SF}_{6}$ process versus reference the fluoride volatility process.

\begin{tabular}{|c|c|c|c|c|}
\hline Compound & $\begin{array}{l}\text { IDLH limit, } \\
\text { ppmv }\end{array}$ & $\begin{array}{l}\text { NFPA } \\
\text { ratings }\end{array}$ & Flammability & Comments \\
\hline $\mathrm{F}_{2}$ & 25 & $4,0,4$, none & None & $\begin{array}{l}\text { The most powerful oxidizing agent } \\
\text { known. }\end{array}$ \\
\hline $\mathrm{HF}$ & 30 & $4,0,1$, none & None & \\
\hline $\mathrm{NO}_{2}$ & 20 & $4,0,0$, none & None & \\
\hline $\mathrm{SF}_{6}$ & Not established & $0,0,0$, none & None & $\begin{array}{l}\text { Greenhouse gas } 22800 \text { times worse than } \\
\mathrm{CO}_{2} \text {. }\end{array}$ \\
\hline $\mathrm{HNO}_{3}$ & 25 & $\begin{array}{l}4,0,3, \\
\text { corrosive }\end{array}$ & None & \\
\hline $\mathrm{O}_{2}$ & None & $\begin{array}{l}0,0,0 \\
\text { oxidizer }\end{array}$ & $\begin{array}{l}\text { None; } \\
\text { supports } \\
\text { combustion }\end{array}$ & \\
\hline $\mathrm{O}_{3}$ & 5 & $\begin{array}{l}4,0,4, \\
\text { oxidizer }\end{array}$ & $\begin{array}{l}\text { None; } \\
\text { supports } \\
\text { combustion }\end{array}$ & \\
\hline
\end{tabular}

\subsubsection{Waste management}

The gaseous fission product capture, waste streams, and waste forms are expected to be no different from the reference aqueous separations case, except that the presence of fluorine/fluoride may contaminate, and cause increased amounts of, the iodine waste form. There may also be larger amounts of particulate matter in the off-gas systems, with larger amounts of fluoride species, and this particulate matter may exhibit different flow and handling properties. The particulate matter could be separately processed into a waste form, but combining this material with the waste stream that contains most of the rest of the FPs is likely to be the preferred option.

The best disposal option for the Am, Cm, and FP waste stream that will contain relatively high decay heat and radiotoxicity is a durable, long-lived waste form such as a ceramic, glass-ceramic, or phosphate glass, tailored to retain the FPs and residual actinides and also contain fluoride. Alternatively, the fluorides could be removed and recycled, which could enable this waste stream to be vitrified into a BSG or ceramic waste form.

The output stream containing the $\mathrm{Pu}, \mathrm{Np}$, and various amounts of FPs will be a waste stream unless further processing is done to separate and recycle the $\mathrm{Pu}$ and $\mathrm{Np}$. This waste stream may also contain fluorides, and so could require treatment similar to, or be combined with, the $\mathrm{Am} / \mathrm{Cm} / \mathrm{FP}$ waste stream.

Research and development of suitable waste form options for high fluoride waste streams is a key area of research that is needed to advance this separation technology.

\subsubsection{Used fuel disposal/suitability for recycle}

The issues for recycling fuel materials recovered from processing UNF are basically the same for this process as for the nitrogen trifluoride processing discussed in the previous section, as follows. There are current limitations on the amount of contaminants (FPs, etc.) allowed in the fuel fabrication process. The advanced aqueous reference method can meet the current contaminant limits. It is anticipated that these limits may change in the future due to development of "impurity-tolerant fuels" to allow fuel fabrication with FPs and some other contaminants. Either way, contamination of waste elements in the recycle fuel material must be limited such that the impurity limits are met for whatever fuel technology and performance levels are established.

The radiological hazard of fuels made with products from this process depends on what is being recycled. If only the recovered uranium stream is used in the new fuel, the fuel may be radiologically clean enough that a 
hot cell environment for the fuel fabrication would not be required although contamination control will still be needed. If the uranium stream contains too many FP then it is likely to require further processing or a fullyremote fuel fabrication process. For the $\mathrm{Pu}$ stream to be recycled, it would require further processing and possibly a fully-remote fuel fabrication process depending on any residual FP contamination. The question of fuel tolerance to impurities is currently being investigated in the FCR\&D Fuels campaign, and would determine to what extent recycle is practical given such impurities in the products from processing.

Some of the key issues for utility acceptance of recycled fuel include [Christian 1999]:

- Fuel cost in comparison to fresh fuel.

- New capital and/or equipment costs for receiving, inspecting, and handling the fuel.

- Low fuel defects (Is this achievable using a fully remote manufacturing and inspection process?).

- Worker exposure and safety.

- New waste streams.

- Impacts to safety analysis due to higher source term, lower beta fraction, fuel temperature coefficient.

- Accountability issues.

The viability of this separations process depends in part on how pure the recovered uranium is, and if the recovered uranium can meet applicable fuel purity limits.

\subsubsection{Economics/Footprint reduction}

The overall cost difference in producing a relatively dirty $\mathrm{U}$ product and a clean product might be relatively small since $U$ is the main material by weight in an LWR reprocessing plant. It is typically reported in the literature that a dry reprocessing scheme will reduce the overall recycle plant's footprint (especially in cell space); however, quantitative data supporting this has not been developed. A separation scheme such as that proposed would likely require less space but it also does not obtain the same amount of separation.

Investigation into additional off-gas cleanup space/costs also needs to be considered.

Some differences in the proposed system which would affect the footprint include:

- No dissolver and no liquid storage tanks, so a smaller footprint is expected for those things compared to aqueous.

- Staging and storage for reagents changes - no nitric acid, but added $\mathrm{SF}_{6}$. Analyses need to be done to determine how reagent transport, receiving, and storage are impacted by eliminating nitric acid and organic solvents vs added $\mathrm{SF}_{6}$.

- Since the recovered uranium may contain other contaminants including $\mathrm{Nb}$ and $\mathrm{Np}$, the recovered uranium could be less pure than recovered uranium from the reference aqueous process. This has several implications that could result in reduced or eliminated savings that are achieved by using a non-aqueous process [Mallen 1990]:

- With more FP impurities, the recovered uranium may require remote handling inside a hot cell, while the aqueous $U$ stream generally requires only contamination control efforts.

- Due to remote handling requirements, costs and footprint for recovered uranium handling, packaging, processing for fuel fabrication, and for the fuel fabrication itself will be higher.

0 If the recovered uranium is to be re-enriched, then higher purity recovered uranium may be required by the enrichment process.

- Current regulations require that if used fuel is reprocessed, the waste must be treated, solidified, and packaged shortly after being generated. It is relatively easy in a technical, economic and regulatory context to store clean recovered uranium. But long-term storage of highly contaminated recovered uranium faces major unknowns.

- If the recovered uranium is eventually determined to be a waste, then the levels of TRU contamination may cause it to be classified as a TRU-contaminated waste with the associated high waste storage and disposal costs. 


\subsubsection{Resource Sustainability}

$\mathrm{SF}_{6}$ separations will not increase the conservation of uranium resources compared to the aqueous separations reference case, because the reference aqueous case already can recover and recycle the actinides. The conservation of uranium resources depends on the degree to which natural uranium is consumed to produce power (which is one way to increase uranium conservation). The conservation of uranium resources also depends on the degree to which natural uranium is consumed to produce power. Fuel cycles in which depleted uranium is used and not discarded, and in which $U$ and TRU in used fuel is recycled, maximize uranium utilization. In $\mathrm{SF}_{6}$ separations, uranium utilization can be maximized if the recovered $\mathrm{U}$ is used in CANDU or breeder reactors, and if the TRU in the waste stream is also recovered for recycle.

\subsubsection{Proliferation resistance and physical protection}

The diagram in Fig. 3-2 shows products and waste streams that are different from those of the nitrogen trifluoride approach discussed in the previous section. The target material in this process is again likely to be the plutonium in the UNF. The same general comments apply concerning the nature of proliferation risk and the focus on the ability to effectively implement safeguards for timely detection of misuse and diversion. In this case though, the product stream containing $\mathrm{Pu}$ and $\mathrm{Np}$ is in the presence of other fission products, while the other minor actinides are in a different waste stream.

\subsubsection{Summary}

Fuel cycle options where $\mathrm{SF}_{6}$ separations could apply mainly include MOC and FR fuel cycles where the uranium in UNF is recovered for re-enrichment. Based on Fig. 3-2, recovery of plutonium for recycle would require additional processing to separate it from minor actinides and FPs.

Differentiators of the proposed $\mathrm{SF}_{6}$ system compared to aqueous separations include:

- The dissolver, liquid tank storage, and nitric acid and organic solvent reagents can be eliminated, so footprint and equipment needed inside and outside hot cells for these things can be eliminated; but the addition of $\mathrm{SF}_{6}$ reagent adds footprint and equipment outside the hot cells for receiving and storing $\mathrm{SF}_{6}$.

- Off-gas particulate matter capture and management needs to be more extensive to handle the expectedly larger amounts of dust and condensed materials that likely contain F species.

- Recycle of the Pu stream or the Am and Cm stream may not be possible without further separation of these elements from FPs.

- Organic solvent degradation products, waste acid, and waste water are eliminated in waste streams.

- Waste streams will contain fluorides which will necessitate the need to either develop a new waste form such as phosphate glass or mineral waste form, or remove and recycle the F, enabling the use of BSG.

Differentiators compared to reference fluoride volatility separations include:

- Use of safer and less corrosive $\mathrm{SF}_{6}$, but if the $\mathrm{F}$ is recovered and recycled, then other $\mathrm{F}$ species that may be more hazardous and corrosive than $\mathrm{SF}_{6}$ may also be present in the system.

Research and development information that is still needed to further evaluate this technology in the context of MOC and FR fuel cycles includes:

- More complete determination of separation factors for the fuel into the product/waste streams and determination if the separation achievable will allow a fuel to be fabricated that can be used in reactors.

- Mass balances needed to assess process flow and equipment size requirements, amount of reagents needed, etc.

- More complete process definition - such as F recycling or not, operating temperatures, corrosion and equipment degradation, handling of solids materials, and process performance

- Development and demonstration of waste form concepts. 


\subsubsection{Dry Head-End Nitration Processing}

Table 4-6 compares the product and waste streams of the proposed process to those for the basic voloxidation process and the advanced aqueous case.

Table 4-6. Product and waste stream comparison for dry head-end nitration system.

\begin{tabular}{|c|c|c|}
\hline Process & $\begin{array}{c}\text { Reference Case: Advanced Aqueous w/ Basic } \\
\text { Voloxidation }\end{array}$ & Dry Head-end Nitration \\
\hline $\begin{array}{l}\text { Disassemble } \\
\text { and Chop }\end{array}$ & $\begin{array}{ll}\text { 1. } & \text { Metal fuel assembly parts (activated and/or } \\
\text { contaminated) } \\
\text { 2. }\end{array}$ & Same as reference aqueous case \\
\hline \begin{tabular}{|l|} 
Fuel \\
Oxidation
\end{tabular} & $\begin{array}{l}\text { 1. Zr cladding contaminated with FPs and } \\
\text { actinides (when voloxidation is not used to } \\
\text { separate cladding from fuel, the cladding is } \\
\text { separated during dissolution). } \\
\text { 2. Off-gas : }>99 \% \mathrm{H}-3,6 \% \mathrm{Kr}, 6 \% \mathrm{Xe}, 50 \% \mathrm{C}, 1 \% \\
\text { I, } \mathrm{Br},<0.2 \% \mathrm{Ru}, \mathrm{Sb}, \mathrm{Cs} \text { at moderate temps } / \mathrm{rxn} \\
\text { times }\end{array}$ & $\begin{array}{l}\text { 1. } \text { Zr cladding: Same as base volox } \\
\text { 2. } \text { Off-gas: increased volatiles over } \\
\text { base volox: } 100 \% \mathrm{H}-3 \text {, I; Unspecified } \\
\% \mathrm{Kr}, \mathrm{Xr}, \mathrm{C}, \mathrm{Tc}, \mathrm{Mo}, \mathrm{Ru}\end{array}$ \\
\hline \begin{tabular}{|l|} 
Dissolution/ \\
Filtration
\end{tabular} & $\begin{array}{l}\text { 1. Undissolved solids (can be combined with FP in } \\
\text { glass, or with Tc, SS, and Zircaloy in melted } \\
\text { metal waste form) } \\
\text { 2. Off-gas [w/ no volox:all remaining Kr, 90\% of } \\
\text { the I, some C-14, some H-3] } \\
\text { 3. Zr cladding (contaminated with FPs and } \\
\text { actinides) when voloxidation is not used to } \\
\text { separate fuel from cladding }\end{array}$ & $\begin{array}{l}\text { 1. Undissolved solids with } \mathrm{Zr}, \mathrm{Rb} \text {, } \\
\mathrm{Sr}, \mathrm{Cs}, \mathrm{Ba}, \mathrm{La}, \mathrm{Ce}, \mathrm{Pr}, \mathrm{Nd}, \mathrm{Sm}, \mathrm{Tc} \\
\text { 2. Off-gas } \\
\text { 3. TBP with actinides (U, Pu, Np, } \\
\mathrm{Am}, \mathrm{Cm} \text { ) }\end{array}$ \\
\hline Separation & 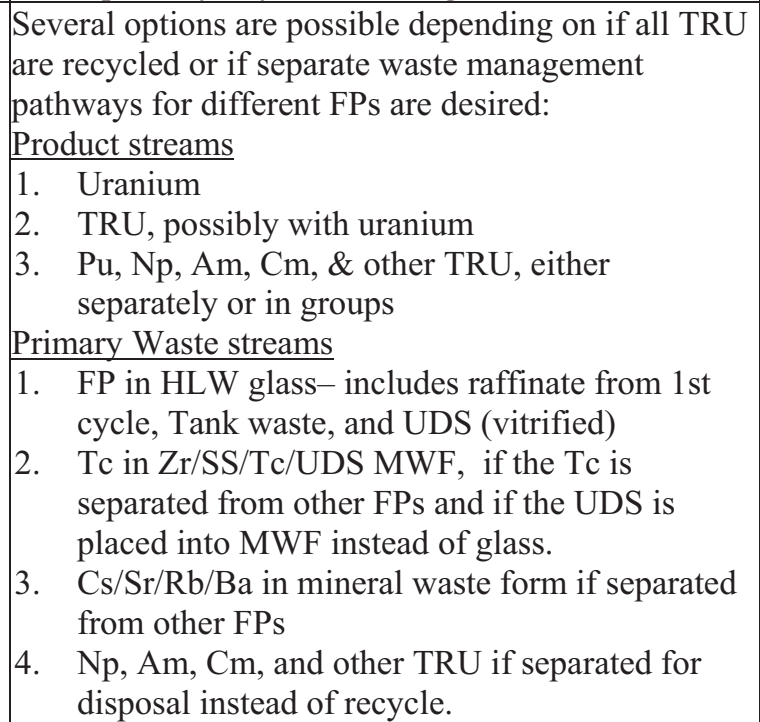 & $\begin{array}{ll}\text { Product streams: } \\
\text { 1. } \\
\text { 2. } \\
\text { 3. } \\
\text { Possibly Pu \& Np } \\
\text { Waste streams: } \\
\text { 1. } \\
\text { 2. } & \text { Undissolved fission products } \\
\text { Um \& Cm } \\
\end{array}$ \\
\hline
\end{tabular}




\begin{tabular}{|c|c|c|}
\hline Process & $\begin{array}{l}\text { Reference Case: Advanced Aqueous w/ Basic } \\
\text { Voloxidation }\end{array}$ & Dry Head-end Nitration \\
\hline $\begin{array}{l}\text { Off-gas } \\
\text { control } \\
\text { systems }\end{array}$ & $\begin{array}{l}\text { The reference gaseous FP waste forms are: } \\
\text { 1. H-3 in HTO in grouted waste form } \\
\text { 2. I-129 in glass-bonded silver zeolite waste form } \\
\text { 3. C-14 in } \mathrm{CO}_{2} \text { grouted waste form } \\
\text { 4. Kr-85 (with or without nonradioactive Xe) in } \\
\text { compressed gas cylinders. } \\
\text { Particulate matter formed from entrained dust and } \\
\text { condensed semi-volatile matter in the head end and } \\
\text { dissolver off-gas systems is filtered in cleanable } \\
\text { filters and recycled to the dissolver. Particulate } \\
\text { matter in the process gas streams is recycled or } \\
\text { solidified into a separate waste form. Particulate } \\
\text { matter captured on HEPA filters is disposed with the } \\
\text { filters, although it could also be removed from the } \\
\text { filters (via filter leaching) and combined with the } \\
\text { separated FP waste stream. }\end{array}$ & Same as reference aqueous case. \\
\hline
\end{tabular}

\subsubsection{Separations}

This proposed separation method is essentially a version of the head-end voloxidation process with subsequent aqueous separations so the separation factors achieved would be similar to those for the advanced aqueous reference process. The main difference in separations would be the removal of more of the FP in the volatile stream (additional I, $\mathrm{Kr} \mathrm{Tc}, \mathrm{Cs}$, etc.) for recovery from the off-gas treatment system so that removal in the aqueous portion of the process is eliminated or simplified. In addition, instead of nitric acid dissolution, the actinides from the voloxidation process would be dissolved directly in a TBP solution, leaving the majority of FPs and lanthanides in the undissolved solids. This would eliminate the nitric acid dissolution step and the first cycle extraction process (separation of actinides from FP) from the advanced aqueous process.

During this review, no information was found in the general literature on voloxidation with $\mathrm{NO}_{\mathrm{x}} / \mathrm{O}_{2}$. ORNL completed some studies in FY2010 [DelCul 2010] which have shown that a mixture of $\mathrm{NO}_{2}$ and $10-15$ vol\% $\mathrm{O}_{2}$ converted $\mathrm{UO}_{2}$ pellets to $\mathrm{U}_{3} \mathrm{O}_{8}$ at $\sim 350^{\circ} \mathrm{C}$ faster than reactions for air or oxygen at temperatures over $450^{\circ} \mathrm{C}$. Oxidation with the same mixture during cooling at temperatures below $300^{\circ} \mathrm{C}$ readily and completely converted the oxide powder into $\mathrm{UO}_{3}$. Room temperature nitration of $\mathrm{U}_{3} \mathrm{O}_{8}$ or $\mathrm{UO}_{3}$ powders readily produced a yellow powder determined to be Uranyl Nitrosyl Nitrate $\left(\mathrm{UO}_{2}\left(\mathrm{NO}_{3}\right)_{3}\right.$ which is soluble in water and TBP. In addition, the I, which is mostly present in the spent fuel as CsI, is released as I vapor by:

$$
\mathrm{CsI}+\mathrm{xNO}_{2}(\mathrm{~g}) \rightarrow \mathrm{CsOx}+\mathrm{NO}(\mathrm{g})+0.5 \mathrm{I}_{2}(\mathrm{~g})(\mathrm{x}=0.5,1 \text { or } 2)
$$

A small batch of surrogate U fuel with simulated FP (Rb, Sr, Y, Zr, Cs, La, Ce, Pr, Nd, Sm, Eu, Ba and I) was nitrated with $\mathrm{NO}_{2}$ and contacted it with $30 \%$ TBP. The sample readily dissolved, leaving behind a small amount of solid residue. Over $99 \%$ of the U was extracted, $\mathrm{Zr}$ was partially extracted (40-50\%), and only 0 $3 \%$ of the rare earths, alkaline and alkaline earth species were dissolved. ORNL also completed a nitration of voloxidized Dresden Fuel with $\mathrm{NO}_{2}$ at room temperature for about 6 hours. The material formed was water soluble and TBP soluble. This test showed that all actinides ( $\mathrm{U}, \mathrm{Pu}, \mathrm{Np}, \mathrm{Am}$ and $\mathrm{Cm}$ ) readily dissolved in TBP along with rare earths and some $\mathrm{Sr}$ and $\mathrm{Ba}$. The Tc was not soluble in TBP.

Voloxidation was originally designed for tritium removal but it was determined it was also possible to remove some portion of the $\mathrm{C}, \mathrm{Kr}, \mathrm{Xe}$, and I. A cursory review of the literature showed a variety of voloxidation process conditions and amounts of FP volatilized. There are some differences in published data on FP removal achieved using the typical voloxidation $\left(\sim 500^{\circ} \mathrm{C}\right.$ with air or $\left.\mathrm{O}_{2}\right)$. Some of the results reported are listed in Table 4-7. 
Table 4-7. Some voloxidation results listed in literature.

\begin{tabular}{|l|l|l|l|}
\hline & $\begin{array}{l}\text { Volox @ } \\
480^{\circ} \mathrm{C} \mathrm{\&} \mathrm{4} \mathrm{hr} \\
{[\text { ORNL, 2009] }}\end{array}$ & $\begin{array}{l}500^{\circ} \mathrm{C} \text { in } \mathrm{O}_{2} \text { or } \\
\text { air } \\
\text { [Johnson, 1980] }\end{array}$ & $\begin{array}{l}500^{\circ} \mathrm{C} \text { in air \& 5-10 } \\
\text { hrs } \\
\text { [KAERI, 2007] }\end{array}$ \\
\hline $\mathrm{H}-3$ & & $100 \%$ & $99 \%$ (typical) \\
\hline $\mathrm{C}-14$ & $\sim 50 \%$ & $17-22 \%$ & $7.5-15 \%$ (measured) \\
\hline $\mathrm{Kr}$ & $6 \%$ & $<17 \%$ & $7-18 \%$ (measured) \\
\hline $\mathrm{Xe}$ & $6 \%$ & & \\
\hline $\mathrm{I}, \mathrm{Br}$ & $1 \%$ & & $<8 \%$ (typical) \\
\hline $\mathrm{Ru}, \mathrm{Sb}, \mathrm{Cs}$ & $0.2 \%$ & & \\
\hline
\end{tabular}

Basic voloxidation does not remove all of the $\mathrm{C}$ and $\mathrm{I}$ which are subsequently released in the nitric acid dissolution of the fuel in the reference advanced aqueous process, while the proposed head-end process may remove a larger percentage. Several FP such as Ru, Cs, Mo, and Tc would potentially be removed from the $\mathrm{U} / \mathrm{Pu}$ stream in the proposed process. These FP cause issues in the reference aqueous system as outlined below:

- The behavior of long-lived fission products I-129 and Tc-99 in the PUREX process cause concerns as they may enter the environment via waste streams. Also Tc decreases Zr-95 decontamination factors and the stability of hydrazine containing partitioning reagents [Sood 1996].

- Technetium: in the reference aqueous process Tc is present as pertechnetate in the feed entering the extraction process. This form of Tc co-extracts with $U$ into TBP. A separate partitioning step in the aqueous process is then required to remove the Tc from the $\mathrm{U}$ product stream. The Tc must be removed as it has a high mobility in the environment.

- Iodine-129: There is an extremely low tolerance concentration of radioiodine (relatively high biological toxicity) so it must be removed from reprocessing effluents. Also, radioiodine remaining in the dissolvedfuel solution extracts readily and reacts with the organic extracting solvents. In the reference aqueous system most of the radioiodine vapors ( $>99 \%$ ) are released into the off-gas during dissolution and captured during off-gas cleanup. The remainder goes into the organic phases, is removed only partially in the solvent washing, and may accumulate in the recycled solvent [Sood 1996]. In the proposed process, all of the FP iodine, which is mostly present in the spent fuel as CsI, is expected to be released as $\mathrm{I}_{2}$ in the headend step prior to the TBP dissolution. If I-129 can be removed prior to dissolution/solvent extraction, it would facilitate its trapping and removal.

- Cesium: one of the main contributors to radioactivity and the heat load for waste going to a repository initially. Up-front removal may reduce the need for shielding in downstream processes. In the reference aqueous system, the Cs and Sr may be removed in a separate partitioning step to form a separate waste stream which could be stored in monitored waste storage until the $\mathrm{Cs} / \mathrm{Sr}$ have decayed to a low level.

The initial removal of these FPs in the proposed head-end nitration process could reduce the operating cost and radioactivity level in the subsequent processes.

The success of the voloxidation step in the proposed process is contingent not only on the gas used, but also on the temperature, the pressure, the UNF burn-up, and other factors. If the initial laboratory tests using surrogate materials looks successful, it will be important to test with actual spent fuel.

\subsubsection{Engineering Issues}

As the initial step is a dry process, filtering of the dusts/aerosols will be important. Remote maintenance of this type of equipment under plant conditions with irradiated fuels will present additional problems. A Soviet Union study [Veryatin 1972] found that remote control of processes, valve operation, moving parts and other components of equipment in a dry reprocessing system is more complicated than in an aqueous based system. In addition, the need for moving dry materials through the process by pneumatic methods is needed. 
At least one case has shown that capture of dusts/aerosols and dry pneumatic handling of highly radioactive materials is feasible. At the ICPP at INL, fluidized bed calciners were successfully operated from 1962 through 2000 to solidify high level wastes. These calciners required an extensive off-gas cleanup system to remove particulate as well as volatilized $\mathrm{Ru}$. Fine particles were removed with a primary cyclone to remove the majority of the fines, a venturi scrubber to remove most of the remaining entrained fines, a scrubber separator and mist eliminators to remove aerosols, Ru adsorbers, and HEPA filters. The fines removed from the system along with the solidified waste were pneumatically transported to storage bins. Operating parameters in the reaction vessel had to be controlled to maintain an average particle size large enough to prevent excessive carry-over of particles.

Volatility processes have the disadvantage that they generally operate at elevated temperature, where corrosion problems must be carefully considered.

\subsubsection{Safety/Environmental}

Table 4-8 summarizes hazard parameters for this proposed system and other gases considered standard in voloxidation processes.

Table 4-8. Hazard parameter comparison for dry head-end process versus reference process.

\begin{tabular}{|l|l|l|l|l|}
\hline Compound & $\begin{array}{l}\text { IDLH limit, } \\
\text { ppmv }\end{array}$ & $\begin{array}{l}\text { NFPA } \\
\text { ratings }\end{array}$ & Flammability & Comments \\
\hline $\mathrm{NO}_{2}$ & 20 & $4,0,0$, none & None & \\
\hline $\mathrm{HNO}_{3}$ & 25 & $\begin{array}{l}4,0,3, \\
\text { corrosive }\end{array}$ & None & \\
\hline $\mathrm{O}_{2}$ & None & $\begin{array}{l}0,0,0, \\
\text { oxidizer }\end{array}$ & $\begin{array}{l}\text { None; } \\
\text { supports } \\
\text { combustion }\end{array}$ & \\
\hline $\mathrm{O}_{3}$ & 5 & $\begin{array}{l}4,0,4, \\
\text { oxidizer }\end{array}$ & $\begin{array}{l}\text { None; } \\
\text { supports } \\
\text { combustion }\end{array}$ & \\
\hline
\end{tabular}

IDLH $=$ immediate danger to life and health

NFPA $=$ National Fire Protection Act

NFPA ratings order: health, fire, instability, special; scale from 0 (no hazard) to 4 (most severe hazard)

\subsubsection{Waste management}

The gaseous FP capture, waste streams, and waste forms are expected to be no different from the reference aqueous separations case. However, there may also be larger amounts of particulate matter in the off-gas systems, with larger amounts of nitrated species, and this particulate matter may exhibit different flow and handling properties. The particulate matter could be separately processed into a waste form, but combining this material with the waste stream that contains most of the rest of the FPs is likely to be the preferred option.

The separations process waste streams will be similar to those of the reference aqueous separations case. These waste streams may include a single stream that contains all the undissolved FPs, which, like the FPs from the reference aqueous separations case, should be processed into a BSG or glass-ceramic waste form. Additional, smaller, waste streams of FP and Am/Cm may also be produced. These should be combined with the FP waste stream for processing in to a BSG.

\subsubsection{Used fuel disposal/suitability for recycle}

There are current limitations on the amount of contaminants (FPs, etc.) allowed in the fuel fabrication process. Losses of waste elements into fuel must be such that the impurity limits are met for whatever fuel technology and performance levels are established. It is noted that the advanced aqueous method, and thus the proposed method, would meet the current contaminant limits.

The radiological hazard of fuels made with products from the aqueous separations process depends on what is being recycled. If the recovered uranium and plutonium are used in the new fuel, the fuel is likely to be 
radiologically clean enough that a hot cell environment for the fuel fabrication would not be required although contamination control will still be needed. The question of fuel tolerance to impurities is currently being investigated in the FCR\&D Fuels campaign, and would determine to what extent recycle is practical given such impurities in the products from processing.

\subsubsection{Economics/Footprint reduction}

Some differences in the proposed system which would affect the footprint include:

- No nitric acid dissolver and elimination of first cycle extraction, elimination of Tc partitioning step, potential elimination of $\mathrm{Cs}$ partitioning step, so a smaller footprint is expected over the reference aqueous system.

- Potential for additional off-gas cleanup space costs needs to be evaluated.

- $\quad$ Staging and storage for reagents changes - no nitric acid for dissolution (still needed in stripping processes), but added $\mathrm{NO}_{\mathrm{x}}$ - analyses need to be done to determine if transport, receiving, and storage for reagents is impacted.

\subsubsection{Resource Sustainability}

Dry Head-end Nitration separations will not increase the conservation of uranium resources compared to the aqueous separations reference case, because the reference aqueous case already can recover and recycle the actinides. The conservation of uranium resources depends on the degree to which natural uranium is consumed to produce power (which is one way to increase uranium conservation). The conservation of uranium resources also depends on the degree to which natural uranium is consumed to produce power. Fuel cycles in which depleted uranium is used and not discarded, and in which $U$ and TRU in used fuel is recycled, maximize uranium utilization. In Dry Head-end Nitration, uranium utilization can be maximized if the recovered $\mathrm{U}$ is used in CANDU or breeder reactors, and if the recovered TRU is also recycled.

\subsubsection{Proliferation resistance and physical protection}

The head-end nitration process is shown in Fig. 3-3 as essentially being added on to the front of an advanced aqueous reprocessing approach. The system shows processing, products and waste streams that are similar in many cases to the reference advanced aqueous process. In this respect, it is anticipated that the proliferation risk would be comparable, and the target material in this process is again likely to be the plutonium in the UNF. Also, the ability to implement safeguards should not be adversely affected by the addition of the headend nitration process. However, there may be some concern with the proposed $\mathrm{Pu}$ and $\mathrm{Np}$ stream, since this is effectively the same as separated plutonium, but that is a feature of the advanced aqueous process to which the head-end nitration is connected and is not an issue with the use of head-end nitration.

\subsubsection{Summary}

Head-end nitration processing should be adaptable to many advanced aqueous processes such as those in the UREX+ group. The applicability of the head-end nitration process to MOC and FR fuel cycles is dependent on the capabilities of the subsequent aqueous process.

Differentiators of the proposed dry head-end system compared to reference aqueous separations include:

- Eliminate of the nitric acid dissolver, first cycle extraction, as well as potential elimination of Tc and Cs partitioning steps, so footprint and equipment needed inside outside hot cells for these things can be eliminated; but the addition of $\mathrm{NO}_{2}$ adds footprint and equipment outside the hot cells for receiving and storing $\mathrm{NO}_{2}$.

- Off-gas particulate matter capture and management needs to be more extensive to handle the expectedly larger amounts of dust and condensed materials.

- A reduction in liquid waste streams as the raffinate from the first cycle extraction (separation of $\mathrm{U} / \mathrm{Pu}$ from FP) is eliminated. Also potential reduction in liquid wastes from Tc and Cs partitioning steps. 
Research and development information that is still needed to further evaluate this technology in the context of MOC and FR fuel cycles includes:

- More complete determination of separation factors for the fuel during the head-end treatment and determination if the separation will allow elimination of various aqueous processing steps.

- Mass balances needed to assess process flow and equipment size requirements, amount of reagents needed, etc.

- More complete process definition - such as operating temperatures, corrosion and equipment degradation, handling of solids materials, and process performance.

- Development and demonstration of waste form concepts.

\subsubsection{Chlorination Processing of UNF}

Table 4-9 compares the product and waste streams of the proposed process to those for the reference advanced aqueous process.

Table 4-9. Product and waste stream comparison for Chlorination/Oxychlorination system.

\begin{tabular}{|c|c|c|}
\hline Process & $\begin{array}{l}\text { Reference Case: Advanced Aqueous w/ Basic } \\
\text { Voloxidation }\end{array}$ & Chlorination/Oxychlorination \\
\hline $\begin{array}{l}\text { Disassemble } \\
\text { and Chop }\end{array}$ & $\begin{array}{ll}\text { 1. } & \text { Metal fuel assembly parts (activated and/or } \\
\text { contaminated) } \\
\text { 2. } \\
\text { 3. } \\
\begin{array}{l}\text { Off-gapped fuel - elements } \\
\text { and other FP) }\end{array}\end{array}$ & Same as reference aqueous case \\
\hline $\begin{array}{l}\text { Fuel } \\
\text { Oxidation }\end{array}$ & $\begin{array}{l}\text { 1. Zr cladding contaminated with FPs and } \\
\text { actinides (when voloxidation is not used to } \\
\text { separate cladding from fuel, the cladding is } \\
\text { separated during dissolution). } \\
\text { 2. Off-gas : }>99 \% \mathrm{H}-3,6 \% \mathrm{Kr}, 6 \% \mathrm{Xe}, 50 \% \mathrm{C} \text {, } \\
1 \% \mathrm{I}, \mathrm{Br},<0.2 \% \mathrm{Ru}, \mathrm{Sb}, \mathrm{Cs} \text { at moderate } \\
\text { temps/rxn times }\end{array}$ & $\begin{array}{l}\text { 1. Zr Cladding: Same as aqueous } \\
\text { 2. Off-gas: increased volatiles over } \\
\text { base volox } \\
\text { 100\% H-3, I; Unspecified \% Kr, Xr, } \\
\text { C, Tc, Mo, Ru }\end{array}$ \\
\hline $\begin{array}{l}\text { Dissolution/ } \\
\text { Filtration }\end{array}$ & $\begin{array}{l}\text { 1. Undissolved solids (can be combined with } \\
\text { FP in glass, or with Tc, SS, and Zircaloy in } \\
\text { melted metal waste form) } \\
\text { 2. Off-gas [w/ no volox:all remaining } \mathrm{Kr}, 90 \% \\
\text { of the I, some C-14, some H-3] } \\
\text { 3. } \begin{array}{l}\text { Zr cladding (contaminated with FPs and } \\
\text { actinides) when voloxidation is not used to } \\
\text { separate fuel from cladding }\end{array}\end{array}$ & $\begin{array}{l}\text { After } 1^{\text {st }} \text { chlorination step } \\
\text { 1. Dissolved FP, } \mathrm{Ln}, \mathrm{Am}, \mathrm{Cm} \text {, } \\
\text { chloride } \\
\text { 2. Undissolved } \mathrm{U}, \mathrm{Np}, \mathrm{Pu}, \mathrm{Zr} \text { to } \\
\text { oxy/chlorination, advanced aqueous } \\
\text { separations, or fuel fab }\end{array}$ \\
\hline
\end{tabular}




\begin{tabular}{|c|c|c|}
\hline Process & $\begin{array}{l}\text { Reference Case: Advanced Aqueous w/ Basic } \\
\text { Voloxidation }\end{array}$ & Chlorination/Oxychlorination \\
\hline Separation & $\begin{array}{l}\text { Several options are possible depending on if all } \\
\text { TRU are recycled or if separate waste } \\
\text { management pathways for different FPs are } \\
\text { desired: } \\
\text { Product streams } \\
\text { 1. Uranium } \\
\text { 2. TRU, possibly with uranium } \\
\text { 3. Pu, Np, Am, Cm, \& other TRU, either } \\
\text { separately or in groups } \\
\text { Primary waste streams } \\
\text { 1. FP in HLW glass - includes raffinate from } \\
\text { 1st cycle, Tank waste, and UDS (vitrified) } \\
\text { 2. Tc in } \mathrm{Zr} / \mathrm{SS} / \mathrm{Tc} / \mathrm{UDS} \text { MWF, if the Tc is } \\
\text { separated from other FPs and if the UDS is } \\
\text { placed into MWF instead of glass. } \\
\text { 3. Cs/Sr/Rb/Ba in mineral waste form if } \\
\text { separated from other FPs } \\
\text { 4. Np, Am, Cm, and other TRU if separated } \\
\text { for disposal instead of recycle. }\end{array}$ & $\begin{array}{l}\text { After } 2^{\text {nd }} \text { (oxychlorination) step } \\
\text { 1. Dissolved } \mathrm{U} \text { (with } \mathrm{Cl} \text { ) to fuel fab } \\
\text { 2. Solid } \mathrm{Np}, \mathrm{Pu}, \mathrm{Zr} \text { oxides and } \\
\text { residual } \mathrm{U} \text { to fuel fab } \\
\text { After advanced aqueous separations: } \\
\text { 1. Same recycle } \mathrm{U} \text { and } \mathrm{U} / \mathrm{TRU} \\
\text { product streams as in aqueous } \\
\text { reference case } \\
\text { 2. Separated waste stream of } \mathrm{Zr} \\
\text { and } \mathrm{Cl}\end{array}$ \\
\hline $\begin{array}{l}\text { Off-gas } \\
\text { control } \\
\text { systems }\end{array}$ & $\begin{array}{l}\text { The reference gaseous FP waste forms are: } \\
\text { 1. H-3 in HTO in grouted waste form } \\
\text { 2. I-129 in glass-bonded silver zeolite waste } \\
\text { form } \\
\text { 3. } \mathrm{C}-14 \text { in } \mathrm{CO}_{2} \text { grouted waste form } \\
\text { 4. } \mathrm{Kr}-85 \text { (with or without nonradioactive Xe) } \\
\text { in compressed gas cylinders. } \\
\text { Particulate matter formed from entrained dust } \\
\text { and condensed semi-volatile matter in the head } \\
\text { end and dissolver off-gas systems is filtered in } \\
\text { cleanable filters and recycled to the dissolver. } \\
\text { Particulate matter in the process gas streams is } \\
\text { recycled or solidified into a separate waste } \\
\text { form. Particulate matter captured on HEPA } \\
\text { filters is disposed with the filters, although it } \\
\text { could also be removed from the filters (via filter } \\
\text { leaching) and combined with the separated FP } \\
\text { waste stream. }\end{array}$ & Same as in aqueous reference case \\
\hline
\end{tabular}

\subsubsection{Separations}

This separation method, as proposed including the oxychlorination step, does not attempt to achieve the same degree of separation achievable with an advanced aqueous process as it leaves the $\mathrm{Pu}$ with $\mathrm{Zr}$ and $\mathrm{Np}$. An advanced aqueous process separates $U$ and Pu products and a fraction containing trivalent actinides (Am, $\mathrm{Cm}$ ) and rare earths from the other FPs. Np can be put into one of these products or withdrawn separately, depending on valence control, although it is generally assumed to go primarily with the Pu product.

This proposed separation method includes an enhanced voloxidation process to release additional FPs (per previously described ORNL head-end process). Then, instead of nitrating and dissolving the resulting UNF powder in a TBP solution, the powdered fuel would be exposed to dry chlorine gas to transform minor actinides and most of the FP to water-soluble chlorinated species which are subsequently dissolved in water and separated from the insoluble $\mathrm{U}, \mathrm{Pu}$, and $\mathrm{Np}$. U, $\mathrm{Np} \mathrm{Pu}$ and $\mathrm{Zr}$ oxides remain in the undissolved solids. $\mathrm{The} \mathrm{U} / \mathrm{Pu} / \mathrm{Np} / \mathrm{Zr}$ stream can be processed for fuel fabrication, processed via advanced aqueous separations to separate the $\mathrm{U}, \mathrm{Pu}, \mathrm{Np}$, and $\mathrm{Zr}$, or processed via oxychlorination and water-washed to dissolve and separate most of the $\mathrm{U}$ from the remaining $\mathrm{Pu}, \mathrm{Np}$, and $\mathrm{Zr}$. 
During this review, no information was found in the general literature on voloxidation with $\mathrm{NO}_{\mathrm{x}} / \mathrm{O}_{2}$. ORNL completed some studies in FY2010 [DelCul 2010] which have shown that a mixture of $\mathrm{NO}_{2}$ and $10-15$ vol\% $\mathrm{O}_{2}$ converted $\mathrm{UO}_{2}$ pellets to $\mathrm{U}_{3} \mathrm{O}_{8}$ at $\sim 350^{\circ} \mathrm{C}$ faster than reactions for air or oxygen at temperatures over $450^{\circ} \mathrm{C}$. Oxidation with the same mixture during cooling at temperatures below $300^{\circ} \mathrm{C}$ readily and completely converted the oxide powder into $\mathrm{UO}_{3}$.

Voloxidation was originally designed for tritium removal but it was determined it was also possible to remove some portion of the $\mathrm{C}, \mathrm{Kr}, \mathrm{Xe}$, and I. A cursory review of the literature showed a variety of voloxidation process conditions and amounts of FP volatilized. There are some differences in published data on FP removal achieved using the typical voloxidation $\left(\sim 500^{\circ} \mathrm{C}\right.$ with air or $\left.\mathrm{O}_{2}\right)$. Some of the results reported are listed in Table 4-10.

Table 4-10. Some voloxidation results listed in literature.

\begin{tabular}{|l|l|l|l|}
\hline & $\begin{array}{l}\text { Volox @ } \\
480^{\circ} \mathrm{C} \mathrm{\&} \mathrm{4} \mathrm{hr} \\
{[\text { ORNL, 2009] }}\end{array}$ & $\begin{array}{l}500^{\circ} \mathrm{C} \text { in } \mathrm{O}_{2} \text { or } \\
\text { air } \\
\text { [Johnson, 1980] }\end{array}$ & $\begin{array}{l}500^{\circ} \mathrm{C} \text { in air \& 5-10 } \\
\text { hrs } \\
\text { [KAERI, 2007] }\end{array}$ \\
\hline $\mathrm{H}-3$ & & $100 \%$ & $99 \%$ (typical) \\
\hline $\mathrm{C}-14$ & $\sim 50 \%$ & $17-22 \%$ & $7.5-15 \%$ (measured) \\
\hline $\mathrm{Kr}$ & $6 \%$ & $<17 \%$ & $7-18 \%$ (measured) \\
\hline $\mathrm{Xe}$ & $6 \%$ & & \\
\hline $\mathrm{I}, \mathrm{Br}$ & $1 \%$ & & $<8 \%$ (typical) \\
\hline $\mathrm{Ru}, \mathrm{Sb}, \mathrm{Cs}$ & $0.2 \%$ & & \\
\hline
\end{tabular}

These references indicate that the success of the voloxidation step in the proposed process is contingent not only on the gas used, but also on the temperature, the pressure, the UNF burn-up and other factors. If the initial laboratory tests using surrogate materials looks successful, it will be important to test with actual spent fuel.

After the voloxidation process, the fuel oxides will go through a dry chlorination step. As previously noted many of the elements that form volatile high-valence fluorides will also form high-valence chlorides. Much of the work with chloride volatility in the past has been on gas-solid chlorination reactions to remove $\mathrm{Zr}$ cladding (Zircex process). This process can be used to separate and recover $U$ from other structural materials. This process removes $\mathrm{Zr}$ cladding by reaction with $\mathrm{HCl}$ gas at a temperature above the sublimation point of $\mathrm{ZrCl}_{4}$ $\left(331^{\circ} \mathrm{C}\right)$, leaving the declad $\mathrm{UO}_{2}$ and $\mathrm{PuO}_{2}$. However, the proposed process is not attempting to volatilize anything with the $\mathrm{Cl}_{2}$ gas but just convert oxides to chlorides.

Preliminary experiments were conducted in FY2010 by ORNL on the dry chlorination step of the process. Previous computations using HSC and SolGasMix indicated that $\mathrm{U}, \mathrm{Np}, \mathrm{Pu}$ and $\mathrm{Zr}$ would remain as oxides (i.e. not water soluble) over a range of $\mathrm{Cl}_{2}$ partial pressures and temperatures while the FPs would be chlorinated ( $\mathrm{Ln}$ to $\mathrm{LnOCl}$ or $\mathrm{LnCl}_{3}$, alkali metals to $\mathrm{XCl}$, alkaline metals to $\mathrm{YCl}_{2}$, and transition metals to either chlorides or oxychlorides). They exposed a $\mathrm{U}_{3} \mathrm{O}_{8}$ powder mixed with surrogate $\mathrm{FP}$ species $\mathrm{SrO}, \mathrm{Cs}_{2} \mathrm{O}, \mathrm{ZrO}_{2}, \mathrm{Gd}_{2} \mathrm{O}_{3}$, $\mathrm{Sm}_{2} \mathrm{O}_{3}$ and ground "noble metal alloy" containing $\mathrm{Pd}, \mathrm{Mo}, \mathrm{Ru}, \mathrm{Rh}$, and $\mathrm{Re}$ to $\mathrm{Cl}_{2}$ gas $\left(50 \% \mathrm{v} / \mathrm{v} \mathrm{Cl} \mathrm{Cl}_{2} \mathrm{He}\right)$ at $360-390^{\circ} \mathrm{C}$. The subsequent powder was washed with water. This experiment found that $\mathrm{U}$ and $\mathrm{Zr}$ remained generally insoluble as predicted by thermodynamic calculations (a very small amount of $U$ dissolved). Noble metals were also insoluble which disagreed with thermodynamic calculations. Lanthanides were soluble, in agreement with thermodynamic calculations. Some of the separation was incomplete probably due to incomplete reactions as no stirring was done.

Subsequent experiments were done with $\mathrm{U}_{3} \mathrm{O}_{8}$ and $\mathrm{UO}_{3}$ (3:2 ratio) powder with $\mathrm{CsI}, \mathrm{SrO}, \mathrm{BaO}, \mathrm{Rb}_{2} \mathrm{O}, \mathrm{Na}_{2} \mathrm{O}$, $\mathrm{Ln}_{2} \mathrm{O}_{3}$ (included $\mathrm{La}, \mathrm{Ce}, \mathrm{Pr}, \mathrm{Nd}, \mathrm{Sm}, \mathrm{Eu}$, and $\mathrm{Gd}$ ) using a laboratory scale rotary calciner. The feed was exposed to temperatures from $300-450^{\circ} \mathrm{C}$ with $\mathrm{Cl}_{2}$ feed concentration of $25-75 \% \mathrm{v} / \mathrm{v}$ in a carrier gas and a 
reaction time of 0.6 to 6 hours. These experiments found no volatile $U$ was produced and that the powders agglomerated at $\mathrm{T} \sim 450^{\circ} \mathrm{C}$. Table 4-11 summarizes the results from one of the runs [ORNL 2010].

Table 4-11. Results from Run \#6- exposure of surrogate fuel to $350^{\circ} \mathrm{C}$ and $1: 1 \mathrm{Cl}_{2}: \mathrm{He}$ for $120 \mathrm{~min}$.

\begin{tabular}{|c|c|c|c|}
\hline Element & $\%$ of residue dissolved by water & $\%$ remaining in residue & $\begin{array}{l}\text { Solubility of chloride in cold water } \\
\text { [CRC] }\end{array}$ \\
\hline $\mathrm{U}$ & 1 & 99 & $\begin{array}{c}\text { Uranium chlorides are soluble or } \\
\text { decompose* }\end{array}$ \\
\hline I & 14 & 86 & $\mathrm{ICl}$ decomposes or is soluble \\
\hline $\mathrm{Rb}$ & 95 & 5 & $\mathrm{RbCl}-77 \mathrm{~g} / 100 \mathrm{cc}$ \\
\hline $\mathrm{Sr}$ & 98 & 2 & $\mathrm{SrCl}_{2}-53.8 \mathrm{~g} / 100 \mathrm{cc}$ \\
\hline $\mathrm{Y}$ & 92 & 8 & $\mathrm{YCl}_{2}-78 \mathrm{~g} / 100 \mathrm{cc}$ \\
\hline \multicolumn{4}{|l|}{$\mathrm{Zr}$} \\
\hline $\mathrm{Cs}$ & 98 & 2 & CsCl-162 g/100cc \\
\hline $\mathrm{Ba}$ & 37 & 63 & $\mathrm{BaCl}_{2}-37 \mathrm{~g} / 100 \mathrm{cc}$ \\
\hline $\mathrm{La}$ & 98 & 2 & $\mathrm{LaCl}_{3}-$ very soluble \\
\hline $\mathrm{Ce}$ & 1 & 99 & $\mathrm{CeCl}_{3}-100 \mathrm{~g} / 100 \mathrm{cc}$ \\
\hline $\operatorname{Pr}$ & 98 & 2 & $\mathrm{PrCl}_{3}-104 \mathrm{~g} / 100 \mathrm{dd}$ \\
\hline $\mathrm{Nd}$ & 98 & 2 & $\mathrm{NdCl}_{3}-97 \mathrm{~g} / 100 \mathrm{cc}$ \\
\hline $\mathrm{Sm}$ & 97 & 3 & $\mathrm{SmCl}_{3}-92 \mathrm{~g} / 100 \mathrm{cc}$ \\
\hline $\mathrm{Eu}$ & 97 & 3 & $\mathrm{EuCl}_{3}-$ soluble \\
\hline
\end{tabular}

* the low amount of $\mathrm{U}$ dissolved supports modeling done with HSC and SolGasMix which indicates $\mathrm{U}, \mathrm{Np}, \mathrm{Pu}$ and $\mathrm{Zr}$ remain as oxides over a range of $\mathrm{Cl} 2$ partial pressures (it requires pressurized $\mathrm{Cl}_{2}$ to convert $\mathrm{U}$ to Uranyl chloride).

Therefore this process seems to allow separation of the majority of the lanthanides except for Ce. Most of the $\mathrm{Cs}, \mathrm{Sr}, \mathrm{Y}$, and $\mathrm{Rb}$ and about a third of the $\mathrm{Ba}$ from the $\mathrm{U}$ were separated. This work does not show $\mathrm{Zr}$ in the water or the undissolved solids so the disposition of the $\mathrm{Zr}$ is unknown.

Laboratory work on the oxychlorination step to separate the $\mathrm{U}$ from the remaining residuals is being conducted in FY2011. Modeling indicates that $\mathrm{UO}_{2} \mathrm{Cl}_{2}$ can be formed and this compound would be water soluble. In this case, the reference case dissolution and subsequent solvent extraction process would be eliminated. The bulk of the uranium would be sent to enrichment and the residual stream with $\mathrm{Pu}, \mathrm{Np}$, and other contaminants could be sent to waste or purified as needed and used in a fuel fabrication process. The separation efficiencies for this process are still being determined.

The chloride contamination levels of the off-gas, product, and waste streams need to be determined. The current oxide fuel fabrication $\mathrm{F} / \mathrm{Cl}$ limit is $60 \mathrm{ppm}$ [Piet 2010]. It is not known if there is flexibility in this limit, but as both halogens can cause very corrosive conditions, it is anticipated that the contamination level in the products going to recycle will have to be low.

An alternative to the oxychlorination step is to send the residual solids from the initial dry

chlorination/washing step to a typical aqueous process starting with dissolution in nitric acid. The advantage of removing most of the $\mathrm{Ln}, \mathrm{Am}, \mathrm{Cm}$, and FP in the initial chlorination may allow elimination in the first cycle extraction which removes these compounds. It is unclear if these would be a significant advantage over the reference advanced aqueous case.

\subsubsection{Engineering Issues}

Volatility processes have the disadvantage that they generally operate at elevated temperature, where corrosion problems must be carefully considered. In addition, chlorides are known to cause corrosion issues in many aqueous based systems due to their ability to cause stress corrosion cracking of stainless steels, aluminum and magnesium alloys. It does not seem to induce cracking in most nickel base alloys. Some of the early chloride volatility work used titanium reaction vessels. Ensuring that residual chlorides do not enter a stainless steel system (including the off-gas system) will be essential. 
Preparing a uniform powder by voloxidation of required granularity for subsequent treatment is difficult [Uhlir 2009]. If the particle size is too small the fines may elutriate from the vessel. If the particle size is too large then reaction times will be slowed or reactions will be less complete due to less surface area. Work will be required to determine optimum fuel particle sizes, if it is possible to consistently obtain these particles in a fuel oxidation process, and which type of reactor will allow the necessary reaction control while providing a robust process that is not easily upset.

Filtering of the dusts/aerosols will be important. Remote maintenance of this sort of equipment under plant conditions with irradiated fuels will present additional problems. A Soviet Union study [Veryatin 1972] found that remote control of processes, valve operation, moving parts and other components of equipment in a gaseous halide based system is more complicated than in an aqueous based system. In addition, the need for moving dry materials through the process by pneumatic methods is needed.

At least one case has shown that a hot cell process with dry pneumatic handling of highly radioactive materials is feasible. At the ICPP at the INL, fluidized bed calciners were successfully operated from 1962 through 2000 to solidify high level wastes. Though this process was different than that proposed, it showed that a dry reaction system could be operated in a hot cell environment and that removal of the dust/aerosols is possible. Fine particles were produced in the fluidized bed reaction and an off-gas particle removal and cleanup system was required. This consisted of a primary cyclone to remove the majority of the fines, a venturi scrubber to remove most of the remaining entrained fines, a scrubber separator and mist eliminators to remove aerosols, $\mathrm{Ru}$ adsorbers, and HEPA filters. The fines removed from the system along with the solidified waste were pneumatically transported to storage bins.

\subsubsection{Safety/Environmental}

Chlorine gas is a toxic, corrosive gas that can cause severe burns if inhaled or upon skin contact. It is heavier than air and will collect and persist in low-lying areas if released. It is used relatively safely in the production of a wide range of industrial and consumer products (plastics, solvents, textiles, pharmaceuticals, etc.). It is an important chemical for water purification and disinfectants (bleach, etc.) - usually in the form of hypochlorous acid or sodium hypochlorite instead of $\mathrm{Cl}_{2}$ gas. Table 4-12 summarizes hazard parameters for this proposed system and the reference cases.

Table 4-12. Hazard parameter comparison for chlorination process versus reference process.

\begin{tabular}{|l|l|l|l|l|}
\hline Compound & $\begin{array}{l}\text { IDLH limit, } \\
\text { ppmv }\end{array}$ & $\begin{array}{l}\text { NFPA } \\
\text { ratings }\end{array}$ & Flammability & Comments \\
\hline $\mathrm{Cl}_{2}$ & 10 & $4,0,0$, none & None & Strong oxidizer \\
\hline $\mathrm{HCl}$ & 50 & $\begin{array}{l}3,0,2, \\
\text { corrosive }\end{array}$ & None & \\
\hline $\mathrm{NO}_{2}$ & 20 & $4,0,0$, none & None & \\
\hline $\mathrm{HNO}_{3}$ & 25 & $\begin{array}{l}4,0,3, \\
\text { corrosive }\end{array}$ & None & \\
\hline $\mathrm{O}_{2}$ & None & $\begin{array}{l}0,0,0, \\
\text { oxidizer }\end{array}$ & $\begin{array}{l}\text { None; } \\
\text { supports } \\
\text { combustion }\end{array}$ & \\
\hline
\end{tabular}

\subsubsection{Waste management}

The gaseous FP capture, waste streams, and waste forms are expected to be no different from the reference aqueous separations case. There may be larger amounts of particulate matter in the off-gas systems, with larger amounts of nitrated species, and this particulate matter may exhibit different flow and handling 
properties. The particulate matter could be separately processed into a waste form, but combining this material with the waste stream that contains most of the rest of the FPs is likely to be the preferred option.

The separations process waste streams will be similar to those of the reference aqueous separations case. These waste streams may include a single stream that contains most of FP chlorides dissolved in water, which should be processed into a waste form that can contain the $\mathrm{Cl}$, such as a ceramic, glass ceramic, or phosphate glass waste form. Alternatively, the $\mathrm{Cl}$ could be removed and recycled, enabling this waste form to be vitrified into a BSG waste form.

If an advanced aqueous separations process is used to separate the $\mathrm{U}, \mathrm{Pu}, \mathrm{Np}$, and $\mathrm{Zr}$ into separate product and waste streams, then the separated Zr should be combined with the FP waste stream from the dry chlorination/water wash process.

\subsubsection{Used fuel disposal/suitability for recycle}

The Np, Pu and $\mathrm{Zr}$ oxides, possibly with some $\mathrm{U}$ oxide, are recovered together as solids after the oxychlorination step. The bulk of the uranium is also recovered as an oxide. The U/Pu/ $\mathrm{Np} / \mathrm{Zr}$ material needs to be processed further in order to recycle the $\mathrm{Pu}$ and $\mathrm{Np}$. There are current limitations on the amount of contaminants (fission products, etc.) allowed in the fuel fabrication process. It is anticipated that these limits may change in the future due to development of "impurity-tolerant fuels" to allow fuel fabrication with FP and some other contaminants. Losses of waste elements in materials destined for new fuel must be such that the impurity limits are met for whatever fuel technology and performance levels are established. However, it is noted that the advanced aqueous method would meet the current contaminant limits.

The radiological hazard of fuels made with products from this process depends on what is being recycled. If only recovered uranium is used in the new fuel, the fuel is likely to be radiologically clean enough that a hot cell environment for the fuel fabrication would not be required although contamination control will still be needed. However, fission product contamination could require a fully-remote fuel fabrication. The question of fuel tolerance to impurities is currently being investigated in the FCR\&D Fuels campaign, and would determine to what extent recycle is practical given such impurities in the products from processing.

\subsubsection{Economics/Footprint reduction}

It is typically reported in the literature that a dry reprocessing scheme will reduce the overall recycle plant's footprint (especially in cell space); however, quantitative data supporting this has not been developed. A separation scheme such as that proposed would likely require less space if it does not also include an advanced aqueous separations system. More space would be needed if the product from the dry chlorination is sent to an advanced aqueous separations process versus the oxychlorination process. Investigation into additional off-gas cleanup space/costs also needs to be considered.

Some differences in the proposed system which would affect the footprint include:

- No dissolver or solvent extraction equipment for the dry chlorination/oxychlorination system, so a footprint smaller than the advanced aqueous process is possible.

- Staging and storage for reagents changes - no nitric acid or organics, but added $\mathrm{Cl}_{2}$ gas and hydrochloric acid - analyses need to be done to determine if transport, receiving, and storage for reagents is impacted.

- Since the Pu stream contains other contaminants it may require remote handling inside a hot cell. It is uncertain if the purity of the recovered uranium stream would be great enough to allow hands-on access with contamination control. The advanced aqueous products generally require only contamination control efforts (not remote handling).

\subsubsection{Resource Sustainability}

The chlorination/oxychlorination process will not increase the conservation of uranium resources compared to the advanced aqueous separations reference case, because the reference aqueous case already can recover and recycle the actinides. The conservation of uranium resources depends on the degree to which natural uranium 
is consumed to produce power (which is one way to increase uranium conservation). The conservation of uranium resources also depends on the degree to which natural uranium is consumed to produce power. Fuel cycles in which depleted uranium is used and not discarded, and in which U and TRU in used fuel is recycled, maximize uranium utilization. In the chlorination/oxychlorination process, uranium utilization can be maximized if the recovered $U$ is used in CANDU or breeder reactors, and if the recovered TRU is also recycled.

\subsubsection{Proliferation resistance and physical protection}

As with the other technologies, a number of factors, some of which are technical in nature, determine proliferation risk. One of the main technical issues is whether or not safeguards can be effectively implemented in a facility using the innovative technology, where the goal of safeguards is timely detection of misuse of or diversion from the facility. Assessment of the relative ease or difficulty of applying effective safeguards for this technology involves consideration of product stream contents and characteristics that may hinder implementation of safeguards technologies, including non-destructive assay, MC\&A, and sampling.

The target material in this process is likely to be the plutonium in the UNF. Based on the diagram in Fig. 3-4, several characteristics of the product streams may introduce difficulties in implementing the safeguards technologies, including the presence of elements with higher radiation than plutonium which complicates or even eliminates indirect measurement of plutonium. It should be noted that this same difficulty may occur with advanced aqueous processes that propose to recover more than just the uranium and plutonium. As with the fluoride based processes discussed above, MC\&A begins with an assay of the incoming UNF, which is usually performed in an accountancy tank located immediately after the dissolver for an aqueous process. In this process, sampling of the oxidized powder after the voloxidation step might provide equivalent data for initializing MC\&A analyses. The contaminants in the recovered plutonium should not pose a problem for chemical analysis of process samples. Overall, it appears that the ability to apply safeguards to this technology is generally similar to those for the advanced aqueous process.

The radiation hazard of the product streams can have an impact on physical protection, in that radiation may provide some deterrence to theft. In this case, the plutonium is recovered with $\mathrm{Np}, \mathrm{Zr}$, and some $\mathrm{U}$, and should have relatively low radiation, but the plutonium is expected to be dilute in this product. Further processing would be needed to obtain attractive material.

\subsubsection{Summary}

There are two main products from this process, uranium, and a mixture of $\mathrm{Pu}, \mathrm{Np}, \mathrm{Zr}$, and possibly some $\mathrm{U}$. This process could be utilized in MOC and FR fuel cycles where uranium recovery for re-enrichment is the main goal of separations. For fuel cycles that would recycle more elements, further processing appears to be necessary before this technology would be applicable.

Differentiators of the proposed system compared to aqueous separations include:

- Elimination of the nitric acid dissolver, solvent extraction system, and nitric acid and organic solvent reagents, so footprint and equipment needed inside outside hot cells for these things can be eliminated; but the addition of chloride reagents add footprint and equipment outside the hot cells for receiving and storing

- Off-gas particulate matter capture and management needs to be more extensive to handle the expectedly larger amounts of dust and condensed materials in the fuel oxidation phase

- Organic solvent degradation products and waste acid are eliminated in waste streams (in the options that do not include aqueous separations of $\mathrm{U}$ and $\mathrm{Pu} / \mathrm{Np}$ ).

- Waste streams will contain chlorides which will necessitate the need to either develop a new waste form such as phosphate glass or mineral waste form, or remove and recycle the $\mathrm{Cl}$, enabling the use of BSG.

Research and development information that is still needed to further evaluate this technology in the context of MOC and FR fuel cycles includes: 
- More complete determination of separation factors for the fuel into the product/waste streams and determination if the separation achievable will allow a fuel to be fabricated that can be used in reactors.

- Mass balances needed to assess process flow and equipment size requirements, amount of reagents needed, etc.

- More complete process definition - such as $\mathrm{Cl}$ recycling or not, operating temperatures, corrosion and equipment degradation, handling of solids materials, and process performance

- Development and demonstration of waste form concepts.

\subsubsection{Enhanced Oxidation/Chlorination Processing of UNF}

Table 4-13 compares the product and waste streams of the proposed process to those for the advanced aqueous case.

Table 4-13. Product and waste stream comparison for Enhanced Oxidation/Chlorination system.

\begin{tabular}{|c|c|c|}
\hline Process & $\begin{array}{l}\text { Reference Case: Advanced Aqueous w/ Basic } \\
\text { Voloxidation }\end{array}$ & Enhanced Oxidation/Chlorination \\
\hline $\begin{array}{l}\text { Disassemble } \\
\text { and Chop }\end{array}$ & $\begin{array}{ll}\text { 1. } & \text { Metal Fuel Assembly parts (activated and/or } \\
\text { contaminated) } \\
\text { 2. Chopped fuel elements } \\
\text { 3. Off-gas - Up to } 10 \% \mathrm{Kr}, \mathrm{Xe} \text {, (some C, H-3, } \\
\text { and other FP) }\end{array}$ & Same as reference aqueous case \\
\hline $\begin{array}{l}\text { Fuel } \\
\text { Oxidation }\end{array}$ & $\begin{array}{l}\text { 1. Zr cladding contaminated with FPs and } \\
\text { actinides (when voloxidation is not used to } \\
\text { separate cladding from fuel, the cladding is } \\
\text { separated during dissolution). } \\
\text { 2. Off-gas : }>99 \% \mathrm{H}-3,6 \% \mathrm{Kr}, 6 \% \mathrm{Xe}, 50 \% \mathrm{C} \text {, } \\
1 \% \mathrm{I}, \mathrm{Br},<0.2 \% \mathrm{Ru}, \mathrm{Sb}, \mathrm{Cs} \text { at moderate } \\
\text { temps/rxn times }\end{array}$ & $\begin{array}{l}\text { 1. Zr Cladding: Same as aqueous } \\
\text { 2. Off-gas: increased volatiles over } \\
\text { base volox: } \\
100 \% \mathrm{H}-3, \mathrm{I}, \mathrm{Kr}, \mathrm{Xe} \\
95 \% \mathrm{Cs} \\
50 \% \mathrm{Ru} \\
? \% \mathrm{C}, \mathrm{Tc}, \mathrm{Mo}\end{array}$ \\
\hline $\begin{array}{l}\text { Dissolution/ } \\
\text { Filtration }\end{array}$ & $\begin{array}{l}\text { 1. Undissolved solids (can be combined with FP } \\
\text { in glass, or with Tc, SS, and Zircaloy in } \\
\text { melted MWF) } \\
\text { 2. Off-gas [w/ no volox:all remaining } \mathrm{Kr}, 90 \% \\
\text { of the I, some C-14, some H-3] } \\
\text { 3. Zr cladding (contaminated with FPs and } \\
\text { actinides) when voloxidation is not used to } \\
\text { separate fuel from cladding }\end{array}$ & NA \\
\hline Separation & 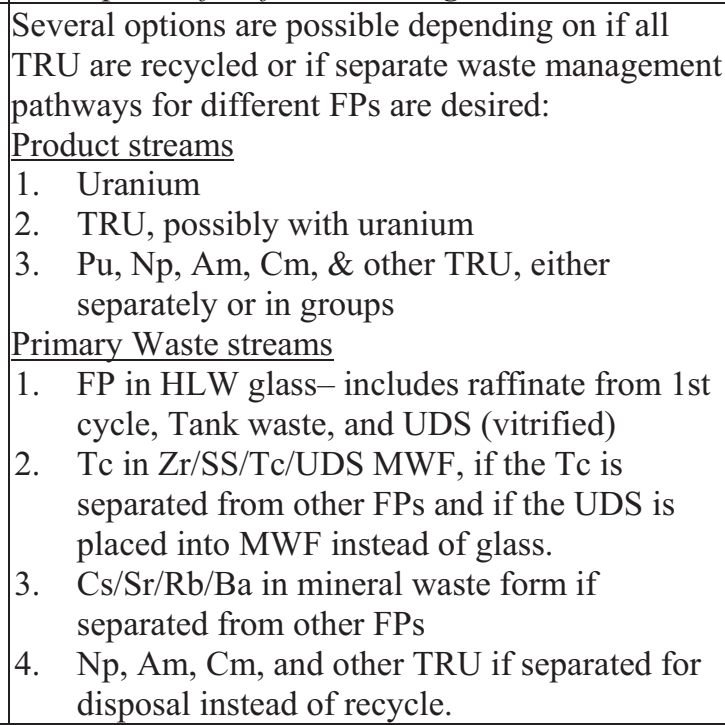 & $\begin{array}{l}\text { Product streams } \\
1 \quad \text { U/TRU } \\
\text { Waste streams } \\
1 . \quad \text { Lanthanide Chlorides }\end{array}$ \\
\hline
\end{tabular}




\begin{tabular}{|l|l|l|}
\hline \multicolumn{1}{|c|}{ Process } & \multicolumn{1}{|c|}{$\begin{array}{c}\text { Reference Case: Advanced Aqueous w/ Basic } \\
\text { Voloxidation }\end{array}$} & \multicolumn{1}{c|}{ Enhanced Oxidation/Chlorination } \\
systems & $\begin{array}{l}\text { The reference gaseous fission product waste forms } \\
\text { are: } \\
\text { 1. } \mathrm{H}-3 \text { in HTO in grouted WF } \\
\text { 2. I-129 in glass-bonded silver zeolite WF } \\
\text { 3. C-14 in CO } \text { grouted WF } \\
\text { 4. Kr-85 (with or without nonradioactive Xe) in } \\
\text { compressed gas cylinders. } \\
\text { Particulate matter formed from entrained dust and } \\
\text { condensed semi-volatile matter in the head end and } \\
\text { dissolver off-gas systems is filtered in cleanable } \\
\text { filters and recycled to the dissolver. Particulate } \\
\text { matter in the process gas streams is recycled or } \\
\text { solidified into a separate waste form. Particulate } \\
\text { matter captured on HEPA filters is disposed with } \\
\text { the filters, although it could also be removed from } \\
\text { the filters (via filter leaching) and combined with } \\
\text { the separated FP waste stream. }\end{array}$ & Same \\
\hline
\end{tabular}

\subsubsection{Separations}

This separation method, as proposed, does not attempt to achieve the same degree of separation achievable with an advanced aqueous process. This process is intended to be an improvement on the AIROX separations process by not only separating volatile and semivolatile FPs from used fuel, but also volatilizing and separating lanthanides from the used fuel to enable the remaining solid-phase $U$ and TRU elements to be more readily recycled as fuel. All other nonvolatile FPs remain with the $\mathrm{U}, \mathrm{Pu}$ and other actinides. The actinide stream can also be further separated in an advanced aqueous process.

This proposed separation method includes an advanced fuel oxidation step based on the AIROX system. Then, the resulting powder is reacted $\left(450^{\circ} \mathrm{C}\right)$ with a strongly reductive chlorinating agent $\left(\mathrm{NH}_{4} \mathrm{Cl}\right)$ to chlorinate the rare earths not volatilized in the oxidation step, and leave the $\mathrm{U}$ and $\mathrm{Pu}$ as oxides. The $\mathrm{Ln}$ chlorides will then be volatilized by increasing the temperature to $1100^{\circ} \mathrm{C}$.

The first step, fuel oxidation with an AIROX-type process, was described previously in this report. There has been extensive work completed for this process. The INL has been working on a variation of the original process called DEOX (Declad and Oxidize) or OREOX (Oxidation and Reduction of Oxide Fuel) with KAERI using LWR oxide fuel or fast reactor mixed oxide (MOX) fuel. The research has determined the amount of FP released depends on the degree of pulverization of the fuel, the processing temperatures, and the processing pressure. Some of the results from this testing are detailed in Table 4-14 [KAERI 2007].

According to another reference, complete removal of I, Tc, and Cs has already been demonstrated [Westphal, 2008]. Much testing with INL and KAERI has already been completed and documented to optimize the fuel oxidation and initial FP volatilization portion of the proposed project. 
Table 4-14. Past results from voloxidation/OREOX testing on UNF.

\begin{tabular}{|l|l|l|l|l|l|}
\hline Element & $\begin{array}{l}\text { Test Conditions for } \\
1^{\text {st }} \text { Voloxidation }\end{array}$ & \% Released & $\begin{array}{l}\text { Test Conditions } \\
\text { for OREOX }\end{array}$ & \% Released & $\begin{array}{l}\text { Total } \\
\text { Released, \% }\end{array}$ \\
\hline $\mathrm{Kr}-85$ & $500^{\circ} \mathrm{C} \& 5 \mathrm{hr}$ & $6.6-17.6$ & $\begin{array}{l}450^{\circ} \mathrm{C} \text { oxidation, } \\
700^{\circ} \mathrm{C} \text { reduction }\end{array}$ & $66.7-83.5$ & $81.5-90.1$ \\
\hline $\mathrm{C}-14$ & $500^{\circ} \mathrm{C} \& 5 \mathrm{hr}$ & $7.5-15$ & $\begin{array}{l}450^{\circ} \mathrm{C} \text { oxidation, } \\
700^{\circ} \mathrm{C} \text { reduction }\end{array}$ & $66.8-76.5$ & $71.8-88.5$ \\
\hline $\mathrm{Cs}$ & $500^{\circ} \mathrm{C} \& 2.5 \mathrm{hr}$ & Not detected & $\begin{array}{l}500^{\circ} \mathrm{C} \text { oxidation, } \\
1000^{\circ} \mathrm{C} \\
\text { reduction }\end{array}$ & $\sim 15$ & $\sim 15^{*}$ \\
\hline $\mathrm{I}-129$ & $\mathrm{Up}$ to $1200^{\circ} \mathrm{C}$ & $86-99$ & & & \\
\hline
\end{tabular}

*at voloxidation up to $1500^{\circ} \mathrm{C}$ over 5 hours $\sim 95 \%$ of Cs removed

The rare earth fission products remain after the DEOX process and are of concern for recycle of actinide elements in new fuel. The rare earth fission products are present in solid solution as oxides with $\mathrm{UO}_{2}$. During the DEOX process they segregate to a rare earth enriched fluorite phase that form nodules on the $\mathrm{U}_{3} \mathrm{O}_{8}$ particles due to solubility differences. The second step in this process is to remove these lanthanides by converting them to chlorides, thus allowing their removal by vaporization. Similar reactions have been performed for rare earth mineral and scrap recovery operations although they have not been applied to nuclear fuel reprocessing. Considering the stabilities of the oxides and chlorides of uranium and the rare earths, uranium oxide should not be affected by the chlorination process but would be reduced back to $\mathrm{UO}_{2}$ [Westphal 2010].

Much of the work with chloride volatility in the past has been on gas-solid chlorination reactions to remove $\mathrm{Zr}$ cladding (Zircex process). This process can be used to separate and recover $\mathrm{U}$ from other structural materials. This process removes $\mathrm{Zr}$ cladding by reaction with $\mathrm{HCl}$ gas at a temperature above the sublimation point of $\mathrm{ZrCl}_{4}\left(331^{\circ} \mathrm{C}\right)$, leaving the declad $\mathrm{UO}_{2}$ and $\mathrm{PuO}_{2}$.

Computations using HSC and SolGasMix indicated that $\mathrm{U}, \mathrm{Np}, \mathrm{Pu}$ and $\mathrm{Zr}$ would remain as oxides over a range of $\mathrm{Cl}_{2}$ partial pressures and temperatures while the $\mathrm{FPs}$ would be chlorinated ( $\mathrm{Ln}$ to $\mathrm{LnOCl}$ or $\mathrm{LnCl}_{3}$, alkali metals to $\mathrm{XCl}$, alkaline metals to $\mathrm{YCl}_{2}$, and transition metals to either chlorides or oxychlorides) [ORNL 2010]. The INL proposal noted several references on the chlorination of rare earth oxides. One process used a two-step reaction (complexation with $\mathrm{NH}_{4} \mathrm{Cl}$ at $220^{\circ} \mathrm{C}$ followed by decomposition to lanthanide chloride and $\mathrm{NH}_{4} \mathrm{Cl}$ at $425^{\circ} \mathrm{C}$ ). Other examples included $\mathrm{Nd}$ recovery from $\mathrm{Nd}-\mathrm{Fe}-\mathrm{B}$ magnet powder scrap and rare earth recovery from Ba-Fe-Si-Mn-Pb-Ln oxidic metal [Westphal 2010].

Previous work completed under a Laboratory Directed Research and Development (LDRD) project at the INL [Christian 1999] modeled the volatilization of lanthanides by chlorination of spent oxide fuel under certain conditions. The modeling was done for temperatures of $1000-1300^{\circ} \mathrm{C}$ with varying partial pressures of $\mathrm{Cl}_{2}$. The results showed that $\mathrm{Gd}$ and $\mathrm{Eu}$ are volatile under all modeled conditions. Nd and Sm volatility can be increased by increasing the temperature without increasing losses of $\mathrm{U}$. Very small amounts of $\mathrm{Pu} / \mathrm{U}$ were predicted to be volatilized under any conditions. INL's proposal indicated that the temperatures of the chlorination would not exceed $1100^{\circ} \mathrm{C}$. The boiling points found in open literature for lanthanide chlorides $\left(\mathrm{Gd}, \mathrm{Dr}, \mathrm{Nd}, \mathrm{Pr}, \mathrm{Ce}, \mathrm{Sm}\right.$ ) range from $1500^{\circ} \mathrm{C}$ to just over $1700^{\circ} \mathrm{C}$. There was not enough information provided in the referenced report [Christian 1999] to understand why the model showed volatilization at much lower temperatures but it is assumed it was due to the operating conditions modeled.

At this point the remaining $\mathrm{U} / \mathrm{Pu} /$ minor actinides and remaining FP could be used in a remotely operated fuel fabrication process. The separation efficiencies for this process are still being determined. It is will also be required to determine the chloride contamination levels of the product stream. The current oxide fuel fabrication $\mathrm{F} / \mathrm{Cl}$ limit is $60 \mathrm{ppm}$. It is not know if there is flexibility in this limit but as halogens can cause very corrosive conditions, it is anticipated that the contamination level in the products going to recycle will have to be low. 


\subsubsection{Engineering Issues}

As the proposed process is envisioned, all four phases (oxidation, initial FP volatilization, chlorination and final FP volatilization) will be performed in a single piece of equipment capable of oxidizing as well as reducing conditions. The current equipment choice is a rotary kiln which is well developed industrially and currently utilized for conversion of $\mathrm{UO}_{2}$ to $\mathrm{UF}_{6}$ on a production scale.

Volatility processes have the disadvantage that they generally operate at elevated temperature, where corrosion problems must be carefully considered. In addition, chlorides are known to cause corrosion issues in many aqueous based systems due to their ability to cause stress corrosion cracking of stainless steels, aluminum and magnesium alloys. It does not seem to induce cracking in most nickel base alloys (nickel alloys are also used in system that use fluorides). Some of the early chloride volatility work used titanium reaction vessels. Ensuring that residual chlorides do not enter a stainless steel system (including the off-gas system) will be essential.

Filtering of the dusts/aerosols will be important. Remote maintenance of this sort of equipment under plant conditions with irradiated fuels will present additional problems. A Soviet Union study [Veryatin 1972] found that remote control of processes, valve operation, moving parts and other components of equipment in a gaseous halide based system is more complicated than in an aqueous based system. In addition, the need for moving dry materials through the process by pneumatic methods is needed.

At least one case has shown that a hot cell process with dry pneumatic handling of highly radioactive materials is feasible. At the ICPP at the INL, fluidized bed calciners were successfully operated from 1962 through 2000 to solidify high level wastes. Though this process was different than that proposed, it showed that a dry reaction system could be operated in a hot cell environment and that removal of the dust/aerosols is possible. Fine particles were produced in the fluidized bed reaction and an off-gas particle removal and cleanup system was required. This consisted of a primary cyclone to remove the majority of the fines, a venturi scrubber to remove most of the remaining entrained fines, a scrubber separator and mist eliminators to remove aerosols, $\mathrm{Ru}$ adsorbers, and HEPA filters. The fines removed from the system along with the solidified waste were pneumatically transported to storage bins.

\subsubsection{Safety/Environmental}

Table 4-15 summarizes hazard parameters for this proposed system and the reference cases.

Table 4-15. Hazard parameter comparison for chlorination process versus reference process.

\begin{tabular}{|c|c|c|c|c|}
\hline Compound & $\begin{array}{l}\text { IDLH limit, } \\
\text { ppmv }\end{array}$ & $\begin{array}{l}\text { NFPA } \\
\text { ratings }\end{array}$ & Flammability & Comments \\
\hline $\mathrm{Cl}_{2}$ & 10 & $4,0,0$, none & None & \\
\hline $\mathrm{NH}_{4} \mathrm{Cl}$ & 300 & $2,0,0$, none & None & \\
\hline $\mathrm{HNO}_{3}$ & 25 & $\begin{array}{l}4,0,3, \\
\text { corrosive }\end{array}$ & None & \\
\hline $\mathrm{O}_{2}$ & None & $\begin{array}{l}0,0,0 \\
\text { oxidizer }\end{array}$ & $\begin{array}{l}\text { None; supports } \\
\text { combustion }\end{array}$ & \\
\hline $\mathrm{O}_{3}$ & 5 & $\begin{array}{c}\text { 4, } 0,4, \\
\text { oxidizer }\end{array}$ & $\begin{array}{l}\text { None; supports } \\
\text { combustion }\end{array}$ & \\
\hline
\end{tabular}

\subsubsection{Waste management}

The gaseous FP capture, waste streams, and waste forms are expected to be no different from the reference aqueous separations case. There may also be larger amounts of particulate matter in the off-gas systems, with larger amounts of chlorinated species, and this particulate matter may exhibit different flow and handling properties. The particulate matter could be separately processed into a waste form, but combining this material 
with the waste stream that contains most of the rest of the FPs, including the Ln, is likely to be the preferred option.

The separations process waste stream contains Ln and other FPs that do not volatilize under the advanced volatilization conditions, but are chlorinated and volatilize during the chlorination and volatilization step downstream of the volatilization stage. The volatilized Ln species will be captured by condensation and filtration or wet scrubbing. This chlorinated waste stream should be processed into a waste form that can contain the $\mathrm{Cl}$, such as a ceramic, glass ceramic, or phosphate glass waste form. Alternatively, the $\mathrm{Cl}$ could be removed and recycled, enabling this waste form to be vitrified into a BSG waste form.

\subsubsection{Used fuel disposal/suitability for recycle}

As shown in Fig, 3-5, the $U$ and TRU elements are recovered in a solid product stream after the chlorination and volatization step. The combined U/TRU product may need to be processed further before it can be used as fuel, depending on the fuel composition and fissile requirements. There are current limitations on the amount of contaminants (FPs, etc.) allowed in the fuel fabrication process. It is anticipated that these limits may change in the future due to development of "impurity-tolerant fuels" to allow fuel fabrication with FP and some other contaminants. Losses of waste elements in materials destined for new fuel must be such that the impurity limits are met for whatever fuel technology and performance levels are established. However, it is noted that the advanced aqueous method would meet the current contaminant limits.

The radiological hazard of fuels made with products from this process depends on what is being recycled. If the U/TRU product is processed so that only the recovered uranium and plutonium are used in the new fuel, the fuel is likely to be radiologically clean enough that a hot cell environment for the fuel fabrication would not be required although contamination control will still be needed. However, if the entire actinide group is used, the radiation from the higher actinides would require a fully-remote fuel fabrication. The question of fuel tolerance to impurities is currently being investigated in the FCR\&D Fuels campaign, and would determine to what extent recycle is practical given such impurities in the products from processing.

\subsubsection{Economics/Footprint reduction}

It is typically reported in the literature that a dry reprocessing scheme will reduce the overall recycle plant's footprint (especially in cell space); however, quantitative data supporting this has not been developed. A separation scheme such as that proposed would almost certainly require less space in the separation hot cells but would then require fuel fabrication in hot cells. Investigation into additional off-gas cleanup space/costs also needs to be considered.

Some differences in the proposed system which would affect the footprint include:

- No dissolver or solvent extraction equipment so a separation footprint smaller than the aqueous process is possible.

- $\quad$ Staging and storage for reagents changes - no nitric acid, liquids wastes, or organics, but added various gases - analyses need to be done to determine if transport, receiving, and storage for reagents is impacted.

\subsubsection{Resource Sustainability}

Enhanced oxidation/chlorination will not increase the conservation of uranium resources compared to the aqueous separations reference case, because the reference aqueous case already can recover and recycle the actinides. The conservation of uranium resources depends on the degree to which natural uranium is consumed to produce power (which is one way to increase uranium conservation). The conservation of uranium resources also depends on the degree to which natural uranium is consumed to produce power. Fuel cycles in which depleted uranium is used and not discarded, and in which $U$ and TRU in used fuel is recycled, maximize uranium utilization. In enhanced oxidation/chlorination, uranium utilization can be maximized if the recovered actinide stream is used in CANDU or breeder reactors. 


\subsubsection{Proliferation resistance and physical protection}

As with the other technologies, a number of factors, some of which are technical in nature, determine proliferation risk. One of the main technical issues is whether or not safeguards can be effectively implemented in a facility using this innovative technology, where the goal of safeguards is timely detection of misuse of or diversion from the facility. Assessment of the relative ease or difficulty of applying effective safeguards for this technology involves consideration of product stream contents and characteristics that may hinder implementation of safeguards technologies, including non-destructive assay, MC\&A, and sampling.

The target material in this process is likely to be the plutonium in the UNF. Based on the diagram in Fig. 3-5, several characteristics of the product streams may introduce difficulties in implementing the safeguards technologies, including the presence of elements with higher radiation than plutonium which complicates or even eliminates indirect measurement of plutonium. It should be noted that this same difficulty may occur with advanced aqueous processes that propose to recover more than just the uranium and plutonium. As with the fluoride based processes discussed above, MC\&A begins with an assay of the incoming UNF, which is usually performed in an accountancy tank located immediately after the dissolver for an aqueous process. In this process, sampling of the oxidized powder after the voloxidation step might provide equivalent data for initializing MC\&A analyses. The contaminants in the recovered plutonium should not pose a problem for chemical analysis of process samples. Overall, it appears that the ability to apply safeguards to this technology is generally similar to those for the advanced aqueous process.

The radiation hazard of the product streams can have an impact on physical protection, in that radiation may provide some deterrence to theft. In this case, the plutonium is recovered with $\mathrm{U}, \mathrm{Np}, \mathrm{Am}$, and $\mathrm{Cm}$, and should have substantial radiation, but the plutonium is expected to be dilute in this product. Further processing would be needed to obtain attractive material.

\subsubsection{Summary}

This process produces a single product stream that contains the actinide elements separated from fission products. While the level of fission product contamination is unknown at this time, in principle this process could be utilized in MOC and FR fuel cycles where actinide recycle is desired, although it should be recognized that subsequent separations would likely be needed to recycle the recovered actinides since the product will be predominantly uranium.

Differentiators of the proposed system compared to aqueous separations include:

- Elimination of the nitric acid dissolver, solvent extraction system, and nitric acid and organic solvent reagents, so footprint and equipment needed inside outside hot cells for these things can be eliminated; but the addition of chloride reagents add footprint and equipment outside the hot cells for receiving and storing.

- Off-gas particulate matter capture and management needs to be more extensive to handle the expectedly larger amounts of dust and condensed materials in the fuel oxidation phase.

- Organic solvent degradation products and waste acid are eliminated in waste streams.

- Waste streams will contain chlorides which will necessitate the need to use either develop a new waste form such as phosphate glass or mineral waste form, or remove and recycle the $\mathrm{Cl}$, enabling the use of BSG.

Research and development information that is still needed to further evaluate this technology in the context of MOC and FR fuel cycles includes:

- More complete determination of separation factors for the fuel into the product/waste streams and determination if the separation achievable will allow a fuel to be fabricated that can be used in reactors.

- Mass balances needed to assess process flow and equipment size requirements, amount of reagents needed, etc. 
- More complete process definition - such as $\mathrm{Cl}$ recycling or not, operating temperatures, corrosion and equipment degradation, handling of solids materials, and process performance.

- Development and demonstration of waste form concepts.

\subsection{Potential Advantages and Disadvantages of Dry Reprocessing}

All of the innovative technologies propose using "dry", i.e., non-aqueous, processing of UNF, either in part or entirely. Advantages and disadvantages that could apply to many of these processes are summarized in [Long 1978]. Advantages of a dry process can include:

- No radiation damage to water or solvent so that fuel could be reprocessed sooner after irradiation. This would be especially advantageous for fast reactors for which the value of fissile and fissionable material in UNF is initially high.

- Fewer, and sometimes simpler, chemical steps may be involved because dissolution of fuel as nitrates and conversion of nitrates back to metal or oxide would be eliminated.

- Processing equipment could be more compact and shielded space would be smaller.

- Larger batches could be reprocessed because the critical mass is greater in the absence of moderating materials.

- Simpler criticality control due to absence of neutron-moderating and reflecting materials.

- Lower waste volumes and solid wastes are directly produced.

- Many processes cannot be modified to produce a pure Pu stream (proliferation-resistant).

Similarly, disadvantages of a dry process can include:

- Processes not as highly developed and not proven on large scale.

- Separations shown to date are incomplete and therefore a direct comparison to the established separation efficiencies of aqueous processes is not possible.

- Fuel is not completely decontaminated (residual FP) and re-fabrication must be done remotely, fuel inspection will be more difficult, etc.

- Operation at high temperature with corrosive or reactive reagents can require special, costly construction materials and makes maintenance difficult.

These five innovative technologies may exhibit all of the advantages listed above, and probably have all of the negative characteristics as well.

In the context of MOC and FR fuel cycles, some general observations about the five innovative technologies can be made, although it must be recognized that process losses and product stream contamination are very important attributes of the separations process for the integrated fuel cycle, information which is not yet available from the projects. At this time, it appears that separations capabilities may not be able to match that achievable by the reference advanced aqueous process except for the head-end nitration processing which uses advanced aqueous processes. Many of the processes under evaluation are not attempting to achieve that degree of separation to improve proliferation resistance (for instance by keeping Pu with FP instead of producing a separate $\mathrm{Pu}$ stream). The performance measures for the MOC or FR fuel cycle are not defined sufficiently at this point to determine whether the innovative separation technologies will be as attractive as the advanced aqueous separations.

It appears that four of the five innovative processes have a uranium stream as the main product stream, although in one case it is also contaminated with $\mathrm{Nb}$ and $\mathrm{Np}$. If of sufficient purity, the uranium product stream could be used directly for re-enrichment, supporting those fuel cycles where re-enrichment is envisioned. The purity of the uranium product stream from these processes (except for the head-end nitration which would be the same as the advanced aqueous process) is still being determined. If insufficiently pure, 
further processing of the uranium product stream would be needed to obtain a product that could be used for new fuel fabrication.

If the recycle of one or more of the TRU elements is desired in a candidate fuel cycle, then further processing of the appropriate product or waste stream may also be needed to recover the TRU elements. The fuel requirements for MOC and FR are generally not defined well enough to know how pure a TRU stream is needed to be beneficially used. A potential advantage in this regard is that the processing throughput requirements for the TRU-containing stream would be greatly decreased in three of the methods since the uranium has already been recovered separately. In addition, the radiation level for the TRU-containing stream is also much lower for these technologies, facilitating processing.

In terms of the measures being used for the assessment, the following general observations can be made:

- Separations - Separations purity is not expected to be as high as for the reference advanced aqueous process except for head-end nitration which uses aqueous processing after the head-end treatment.

- Engineering Issues - All of the gas phase processes face engineering challenges with respect to materials due to the use of halide-bearing or otherwise relatively corrosive reagents, although industrial experience indicates that these can be resolved.

- Safety / Environmental - The innovative processes substitute less hazardous materials to address this issue.

- Waste Management - Most of the innovative process descriptions indicate that they do not efficiently separate and recycle TRU elements (unless these streams are further processed), and so will result in waste streams with higher levels of radiation, heat, and radiotoxicity compared to the reference aqueous separations process that does separate and recycle the TRU elements. The same gaseous fission products (tritium, iodine 129, carbon 14, and krypton 85 that could require capture in aqueous separations will also require capture and conversion to waste forms in the innovative processes. However, the addition of fluorine or chlorine compounds in most of the innovative processes could affect the capture of I-129, and could contaminate and significantly increase amount of the I-129 waste form. Details about how the added halides might impact the capture and waste forms for the gaseous fission products are not yet available. The presence of $\mathrm{F}$ or $\mathrm{Cl}$ species in the waste stream(s) that will contain the non--volatile and semi-volatile radionuclides will impact how the waste streams are handled - either the waste loading might need to be decreased for existing glass waste forms, or the halides in the waste stream(s) will need to be removed, or else new waste forms such as phosphate glass will need to be developed to tolerate and contain the halide species. Researchers have indicated that that "dry" processes should not generate as much waste as aqueous processes, but this conclusion may not account for the impact of halides on the waste forms.

- Used fuel disposal / Suitability for recycle - All of the processes appear suitable for recovery of uranium for re-enrichment. Recovery of one or more TRU elements would generally require further processing, but in several cases smaller facilities would be needed to accomplish further separations since the uranium and many of the fission products have been removed.

- Economics / Footprint reduction - In general the information was not sufficient to make an evaluation at this time.

- Resource sustainability - These separations processes will not increase the conservation of uranium resources compared to the aqueous separations reference case, because the reference aqueous case already can recover and recycle the actinides (which is one of the ways to increase aqueous uranium conservation). The conservation of uranium resources depends on the degree to which natural uranium is consumed to 
produce power. Fuel cycles in which depleted uranium is used and not discarded, and in which $\mathrm{U}$ and TRU in used fuel is recycled, maximize uranium utilization. Those innovative separations processes that are not designed to recover and recycle all of the actinides in the used fuel will not enable uranium utilization as efficiently as those processes that do enable recycle of all of the actinides.

- Proliferation resistance and physical security - The flowsheets developed for the innovative technologies indicate that application of safeguards would be possible, similar to that for aqueous processing. No significant vulnerabilities or advantages with respect to the reference advanced aqueous process were identified. Less complete separations of the TRU elements and FPs by some of the innovative technologies is intended to make the TRU-containing streams more self-protective.

\subsection{Information Needs and Possible Activities}

Since studies of these innovative processes have only recently been initiated, information gaps exist that prevent a more complete evaluation. The following is a list of the data needs, as well as other potential activities that would be conducted in the Systems Analysis campaign.

- More complete determination of separation factors.

- Modeling using Fuel Cycle Integration and Trade-off (FIT) model to estimate viability of recycle product materials, levels of contamination compared to known fuel limits, and separations efficiencies needed to enable viable fuel with acceptable levels of contaminants.

- Analysis to determine if it is economically feasible/desirable to recycle fuel only a few times such as in many MOC cases versus Full Recycle.

- Mass balances to assess process flowrates, equipment size requirements, amounts of reagents, etc.

- More complete process definition such as halide recycling (or not), operating temperatures, corrosion and equipment degradation, handling of solids materials, capture of off-gas particulate matter and gaseous fission products, and process performance.

- Development and demonstration of waste form concepts designed to maximize waste loading considering the presence of halides in the waste streams.

\section{CONCLUSIONS AND RECOMMENDATIONS}

A variety of used nuclear fuel separations processes have been researched, developed, or used for over 60 years. These separations processes are based on either (a) selective solubility of different species in different aqueous, organic liquid, or molten salt solvents, or (b) selective volatility of different species at different temperatures. To date, only limited examples of separations processes have been tested or used at scales beyond demonstration scales. Aqueous separations coupled with limited use of organic solvents have been used at full scale in several different countries. Electrochemical separations using molten salts as the solvent has been performed on a small-scale, non-commercial basis. Separations based on volatility has been researched and demonstrated for the past 50 years, but not tested or used at a production scale.

Five innovative separations projects have been funded by the U.S. DOE through the Separations Campaign to research and develop potentially transformational separations concepts and technologies. These are:

- Nitrogen Trifluoride for UNF Processing

- Reactive Fluoride Gas $\left(\mathrm{SF}_{6}\right)$ for UNF Processing

- Dry Head-end Nitration Processing 
- Chlorination Processing of UNF

- Enhanced Oxidation/Chlorination Processing of UNF

Two of the innovative processes (the $\mathrm{NF}_{3}$ and $\mathrm{SF}_{6}$ separations processes) are based on fluoride volatility separations, using more selective or less hazardous $\mathrm{F}$-species compared to $\mathrm{F}_{2}$ that has been studied in decadesold fluoride volatility separations. One of the processes (Dry Head-end Nitration) nitrates the actinides, enabling them to be soluble in TBP without the upfront nitric acid dissolution used in aqueous separations. Another one of the processes (Chlorination/Oxychlorination) chlorinates the FPs and minor actinides, enabling them to dissolve in water to separate from insoluble $\mathrm{U} / \mathrm{Pu} / \mathrm{Np}$; and then oxychlorinates the $\mathrm{U}$, enabling it to dissolve in water to separate from insoluble $\mathrm{Pu} / \mathrm{Np}$. The Enhanced Oxidation/ Chlorination process uses oxidizing/reducing cycles to volatilize and separate some FPs, and then chlorination to volatilize and separate the lanthanides from the actinides.

While these projects are still in their early stages, a combined Separations Campaign and Systems Analysis Campaign review of these projects has been performed to assess their potential fuel cycle impacts. This review, summarized in this report:

- Describes the features of each innovative process

- Describes where each process might fit within the currently-defined fuel cycle option space

- Describes the reference separations processes

- Indicates how the innovative processes are unique and provide differences compared to the existing reference separations processes, and summarizes data about each process that is currently available

- Identifies data gaps for the innovative processes

- Recommend future research and development needed to address those data gaps.

Two reference cases were identified - one based on an advanced aqueous separations process, and one based on a fluoride volatility process. Voloxidation is included as an option in the reference aqueous separations process, and is included in the fluoride volatility process. Table 5-1 summarizes the reference cases and shows how the innovative separations processes compare to the reference cases.

Table 5-2 summarizes the unique features of the innovative separations processes, their differences from the reference aqueous and fluoride volatility cases, and potential applicability in fuel cycle option space. Even though separations based on selective dissolution in solvents and selective volatility has been researched and used for over 50 years, these innovative processes are somewhat unique compared to prior processes.

Since studies of these innovative processes have only recently been initiated, data gaps exist that prevent a more complete evaluation. 
Table 5-1. Summary of the reference and innovative separations processes.

\begin{tabular}{|c|c|c|c|c|c|c|}
\hline $\begin{array}{c}\text { Reference Advanced } \\
\text { Aqueous Separations with } \\
\text { Voloxidation }\end{array}$ & $\begin{array}{l}\text { Reference Fluoride } \\
\text { Volatility Separations }\end{array}$ & $\mathrm{NF}_{3}$ Separations & $\mathrm{SF}_{6}$ Separations & Dry Head-end Nitration & $\begin{array}{l}\text { Chlorination/ Oxy } \\
\text { chlorination }\end{array}$ & $\begin{array}{c}\text { Enhanced } \\
\text { Oxidation/Chlorination }\end{array}$ \\
\hline $\begin{array}{l}\text { UNF disassembly and } \\
\text { chopping }\end{array}$ & \multicolumn{6}{|c|}{ Same } \\
\hline $\begin{array}{l}\text { Moderate temp } \\
\text { voloxidation }\end{array}$ & Same & Same & $\begin{array}{l}\text { Enhanced with } \mathrm{NO}_{\mathrm{x}} \text { to } \\
\text { volatilize gaseous FPs, } \\
\mathrm{Cs}, \mathrm{Tc} \text {, and other semi- } \\
\text { volatile FPs }\end{array}$ & $\begin{array}{l}\text { Enhanced with } \mathrm{NO}_{\mathrm{x}} \text { to } \\
\text { volatilize gaseous FPs, } \\
\mathrm{Cs}, \mathrm{Tc} \text {, and other semi- } \\
\text { volatile FPs; then further } \\
\text { nitrate with additional } \\
\mathrm{NO}_{2} \text { to make the } \\
\text { actinides soluble in TBP } \\
\text { without initial acid } \\
\text { dissolution }\end{array}$ & $\begin{array}{l}\text { Enhanced with } \mathrm{NO}_{\mathrm{x}} \text { to } \\
\text { volatilize gaseous FPs, Cs, } \\
\mathrm{Tc} \text {, and other semi-volatile } \\
\text { FPs; chlorinate } \mathrm{Ln} \text { and other } \\
\text { FPs, Am, and Cm. }\end{array}$ & $\begin{array}{l}\text { Enhanced } \\
\text { oxidation/reduction cycles } \\
\text { using } \mathrm{O}_{2} \text { and } \mathrm{H}_{2} \text { to } \\
\text { volatilize gaseous FPs, Cs, } \\
\text { Tc, and other semi-volatile } \\
\text { FPs. Chlorinate the } \\
\text { oxidized fuel using } \mathrm{NH}_{3} \mathrm{Cl} \text {; } \\
\text { increase temperature to } \\
1,100^{\circ} \mathrm{C} \text { to volatilize the } \\
\text { Ln chlorides. }\end{array}$ \\
\hline Dissolve fuel in nitric acid & None & None & None & $\begin{array}{l}\text { Dissolve actinide nitrates } \\
\text { in TBP }\end{array}$ & $\begin{array}{l}\text { Dissolve chlorides of Ln and } \\
\text { other FPs, Am, and Cm in } \\
\text { water. }\end{array}$ & None \\
\hline $\begin{array}{l}\text { Separate } \mathrm{U} \text { and } \mathrm{Pu} \\
\text { product streams for } \\
\text { recycle using TBP. } \\
\text { Optionally, also separate } \\
\text { TRU for recycle, and Tc } \\
\text { and } \mathrm{Cs} / \mathrm{Sr} / \mathrm{Rb} / \mathrm{Ba} \text { for } \\
\text { separate waste disposition } \\
\text { from remaining FPs. } \\
\text { FP waste forms (WFs) are } \\
\text { borosilicate glass; } \\
\text { optional } \mathrm{WFs} \text { are a melted } \\
\text { metal } \mathrm{Tc} \mathrm{WF} \text { and a } \\
\text { ceramic } \mathrm{Cs} / \mathrm{Sr} / \mathrm{Rb} / \mathrm{Ba} \mathrm{WF} \text {. }\end{array}$ & $\begin{array}{l}\text { Separate } \mathrm{UF}_{6} \text { and } \mathrm{PuF}_{4} \\
\text { product (less pure than } \\
\text { from aqueous } \\
\text { separations) using } \\
\text { fluoride volatility. } \\
\text { Nonvolatile and } \\
\text { condensed volatile FP } \\
\text { waste streams contain } \\
\text { remaining TRU and } \\
\text { fluorides, and are } \\
\text { combined in BSG (after } \\
\text { F removal) or F-tolerant } \\
\text { phosphate glass/ceramic } \\
\text { waste form. }\end{array}$ & $\begin{array}{l}\text { Separate } \mathrm{UF}_{6} \text { product } \\
\text { (with some Nb, Np } \\
\text { contamination) for } \\
\text { recycle. } \\
\text { Separate TRU product or } \\
\text { waste stream (with } \\
\text { remaining FPs) and } \\
\text { fluorides, recyclable only } \\
\text { after further processing or } \\
\text { in fuel/reactor designs } \\
\text { tolerant of FP and F } \\
\text { contamination. }\end{array}$ & $\begin{array}{l}\text { Separate a }>99 \% \text { pure } \\
\mathrm{UF}_{4} \text { for recycle by } \\
\text { fluorination/ } \\
\text { volatilization and then } \\
\text { hydrolysis or } \\
\text { pyrohydrolysis. } \\
\text { Separate TRU product } \\
\text { or waste stream (with } \\
\text { remaining FPs) and } \\
\text { fluorides, recyclable } \\
\text { only after further } \\
\text { processing or in } \\
\text { fuel/reactor designs } \\
\text { tolerant of FP and F } \\
\text { contamination. } \\
\text { FP waste stream with } \\
\text { Am, Cm and other FP } \\
\text { are combined in BSG } \\
\text { (after F removal) or F- } \\
\text { tolerant phosphate } \\
\text { glass/ceramic waste } \\
\text { form. }\end{array}$ & $\begin{array}{l}\text { Separate U, Pu/Np, and } \\
\text { Am/Cm product streams } \\
\text { for recycle, depending on } \\
\text { advanced aqueous } \\
\text { separations options. } \\
\text { The separated FP WF can } \\
\text { be borosilicate glass or } \\
\text { other equivalent or better } \\
\text { WF. }\end{array}$ & $\begin{array}{l}\text { Dry chlorination produces } \\
\text { undissolved } \mathrm{U} / \mathrm{Pu} / \mathrm{Np} / \mathrm{Zr} \\
\text { oxides are recovered for } \\
\text { recycle or additional } \\
\text { processing by advanced } \\
\text { aqueous separations or oxy- } \\
\text { chlorination for further } \\
\text { separation. } \\
\text { Subsequent oxy-chlorination } \\
\text { produces separate U } \\
\text { chloride product for recycle, } \\
\text { and separate } \mathrm{Pu} / \mathrm{Zr} / \text { residual } \\
\mathrm{U} \text { product stream for fuel } \\
\text { fabrication, further } \\
\text { separations, or waste (BSG } \\
\mathrm{WF).}\end{array}$ & $\begin{array}{l}\text { Separate actinide stream } \\
\text { for fuel fabrication; or } \\
\text { advanced separations if } \\
\text { separated U and TRU } \\
\text { streams are desired or if } \\
\text { higher stream purities from } \\
\text { FPs are required. }\end{array}$ \\
\hline
\end{tabular}


Innovative Separations Technologies

\begin{tabular}{|c|c|c|c|c|c|c|}
\hline $\begin{array}{c}\text { Reference Advanced } \\
\text { Aqueous Separations with } \\
\text { Voloxidation }\end{array}$ & $\begin{array}{l}\text { Reference Fluoride } \\
\text { Volatility Separations }\end{array}$ & $\mathrm{NF}_{3}$ Separations & $\mathrm{SF}_{6}$ Separations & Dry Head-end Nitration & $\begin{array}{l}\text { Chlorination/ Oxy } \\
\text { chlorination }\end{array}$ & $\begin{array}{c}\text { Enhanced } \\
\text { Oxidation/Chlorination }\end{array}$ \\
\hline $\begin{array}{l}\text { Off-gas control systems to } \\
\text { filter particulate matter } \\
\text { and capture H-3, I-129, C- } \\
14 \text {, and } \mathrm{Kr}-85 \text {, each } \\
\text { disposed in a separate } \\
\text { WF. }\end{array}$ & $\begin{array}{l}\text { Same, except that } \\
\text { presence of fluorides in } \\
\text { the filtered particulate } \\
\text { matter may impact } \\
\text { handling and disposal; } \\
\text { and gaseous F species in } \\
\text { the off-gas may impact } \\
\text { the gaseous FP capture } \\
\text { processes and waste } \\
\text { forms, possibly } \\
\text { increasing WF volume } \\
\text { and cost. }\end{array}$ & $\begin{array}{l}\text { Same, except that } \\
\text { presence of fluorides in } \\
\text { the filtered particulate } \\
\text { matter may impact } \\
\text { handling and disposal; } \\
\text { and gaseous F species in } \\
\text { the off-gas may impact } \\
\text { the gaseous FP capture } \\
\text { processes and waste } \\
\text { forms, possibly } \\
\text { increasing WF volume } \\
\text { and cost. }\end{array}$ & $\begin{array}{l}\text { Same, except that } \\
\text { presence of fluorides } \\
\text { in the filtered } \\
\text { particulate matter may } \\
\text { impact handling and } \\
\text { disposal; and gaseous } \\
\text { F species in the off-gas } \\
\text { may impact the } \\
\text { gaseous FP capture } \\
\text { processes and waste } \\
\text { forms, possibly } \\
\text { increasing WF volume } \\
\text { and cost. }\end{array}$ & $\begin{array}{l}\text { Same, except that } \\
\text { presence of nitrates in the } \\
\text { filtered particulate matter } \\
\text { may impact handling and } \\
\text { disposal. }\end{array}$ & $\begin{array}{l}\text { Same, except that presence } \\
\text { of nitrates and chlorides in } \\
\text { the filtered particulate } \\
\text { matter may impact handling } \\
\text { and disposal; and gaseous Cl } \\
\text { species in the off-gas may } \\
\text { impact the gaseous FP } \\
\text { capture processes and waste } \\
\text { forms, possibly increasing } \\
\text { WF volume and cost. }\end{array}$ & $\begin{array}{l}\text { Same, except that presence } \\
\text { of chlorides in the filtered } \\
\text { particulate matter may } \\
\text { impact handling and } \\
\text { disposal; and gaseous } \mathrm{Cl} \\
\text { species in the off-gas may } \\
\text { impact the gaseous FP } \\
\text { capture processes and } \\
\text { waste forms, possibly } \\
\text { increasing WF volume and } \\
\text { cost. }\end{array}$ \\
\hline
\end{tabular}


Table 5-2. Unique features and differences for the innovative separations processes compared to the reference separations processes.

\begin{tabular}{|c|c|c|c|c|c|}
\hline Feature & $\mathrm{NF}_{3}$ Separations & $\mathrm{SF}_{6}$ Separations & Dry Head-end Nitration & Chlorination/ Oxychlorination & $\begin{array}{l}\text { Enhanced } \\
\text { Oxidation/Chlorination }\end{array}$ \\
\hline Main distinction & $\begin{array}{l}\text { The use of nitrogen trifluoride } \\
\left(N F_{3}\right) \text { instead of } F_{2} \text { or other } \\
\text { fluoridating reagents, for } \\
\text { selectively fluorinating and } \\
\text { volatilizing } U \text { and some FPs. }\end{array}$ & $\begin{array}{l}\text { (a) enhanced voloxidation } \\
\text { using } N O_{x} \text { as an oxidant, (b) } \\
\text { the use of } S F_{6} \text { as the } \\
\text { fluorinating reagent, and (c) } \\
\text { the use of hydrolysis or } \\
\text { pyrohydrolysis to condense and } \\
\text { separate some of the volatilized } \\
\text { materials from the still-gaseous } \\
U F_{4} \text { and the fluorides of } U, P u \text {, } \\
\text { and } N p \text {. }\end{array}$ & $\begin{array}{l}\text { (a) a relatively low temperature } \\
\text { voloxidation process made } \\
\text { feasible using } \mathrm{NO}_{2} \text { gas, and (b) } \\
\text { nitration of the powdered fuel } \\
\text { meat using additional } \mathrm{NO}_{2} \text {, that } \\
\text { nitrates the actinides ( } \mathrm{P}, \mathrm{Pu}, \mathrm{Np} \text {, } \\
\text { Am, and } \mathrm{Cm} \text { ) where the nitrates } \\
\text { of these elements are soluble in } \\
T B P \text {, so that an upfront acid } \\
\text { dissolution step unecessary. }\end{array}$ & $\begin{array}{l}\text { (a) chlorination of FPs and } \\
\text { minor actinides in the fuel } \\
\text { following voloxidation, which } \\
\text { enables separation of these } \\
\text { elements by water dissolution } \\
\text { from the } U, P u \text {, and } N p \text {, and } \\
\text { (b) oxychlorination of the } U \\
\text { enabling it to be dissolved in } \\
\text { water and separated from the } \\
\text { insoluble Pu and Np. }\end{array}$ & $\begin{array}{l}\text { (a) high temperature advanced } \\
\text { oxidation process in place of } \\
\text { the reference voloxidation } \\
\text { process, to remove gaseous } \\
\text { and semi-volatile FPs, and (b) } \\
\text { separation of the remaining Ln } \\
\text { by chlorination using a } \\
\text { strongly reductive chlorinating } \\
\text { agent such as } \mathrm{NH}_{4} \mathrm{Cl} \text {. }\end{array}$ \\
\hline \multicolumn{6}{|l|}{ Engineering issues: } \\
\hline Voloxidation & Same & $\begin{array}{l}\text { Enhanced and more complex } \\
\text { with addition of } \mathrm{NO}_{\mathrm{x}} \text { to } \\
\text { volatilize gaseous and semi- } \\
\text { volatile FPs. }\end{array}$ & $\begin{array}{l}\text { Enhanced and more complex } \\
\text { with addition of } \mathrm{NO}_{\mathrm{x}} \text { to } \\
\text { volatilize gaseous and semi- } \\
\text { volatile FPs and nitrate the } \\
\text { remaining solids. }\end{array}$ & $\begin{array}{l}\text { Enhanced and more complex } \\
\text { with addition of } \mathrm{NO}_{\mathrm{x}} \text { to } \\
\text { volatilize gaseous and semi- } \\
\text { volatile FPs. }\end{array}$ & $\begin{array}{l}\text { Enhanced and more complex } \\
\text { with addition of oxidizing and } \\
\text { reducing phases to volatilize } \\
\text { gaseous and semi-volatile FPs. }\end{array}$ \\
\hline $\begin{array}{l}\text { Particulate matter in off- } \\
\text { gas system }\end{array}$ & $\begin{array}{l}\text { More, due to condensation } \\
\text { and capture of volatilized } \\
\text { fluorides. }\end{array}$ & $\begin{array}{l}\text { More, due to condensation and } \\
\text { capture of volatilized fluorides. }\end{array}$ & $\begin{array}{l}\text { More, due to condensation and } \\
\text { capture of semi-volatile FPs. }\end{array}$ & $\begin{array}{l}\text { More, due to condensation } \\
\text { and capture of semi-volatile } \\
\text { chlorides. }\end{array}$ & $\begin{array}{l}\text { More, due to condensation and } \\
\text { capture of semi-volatile } \\
\text { chlorides. }\end{array}$ \\
\hline $\begin{array}{l}\text { Corrosion and corrosion- } \\
\text { resistant alloys }\end{array}$ & $\begin{array}{l}\text { No aqueous } \mathrm{HNO}_{3} \text { corrosion, } \\
\text { but alloys still needed to } \\
\text { protect against high } \\
\text { temperature degradation and } \\
\text { corrosion from fluorides. }\end{array}$ & $\begin{array}{l}\text { No aqueous } \mathrm{HNO}_{3} \text { corrosion, } \\
\text { but alloys still needed to } \\
\text { protect against high } \\
\text { temperature degradation and } \\
\text { corrosion from fluorides. }\end{array}$ & $\begin{array}{l}\text { Aqueous } \mathrm{HNO}_{3} \text { corrosion } \\
\text { remains an issue during aqueous } \\
\text { separations, and alloys are } \\
\text { needed in the "dry" portions of } \\
\text { the process to protect against } \\
\text { high temperature degradation } \\
\text { and corrosion from } \mathrm{NO}_{\mathrm{x}} \text {. }\end{array}$ & $\begin{array}{l}\text { No aqueous } \mathrm{HNO}_{3} \text { corrosion } \\
\text { if no advanced aqueous } \\
\text { separations used, but alloys } \\
\text { still needed to protect against } \\
\text { high temperature degradation } \\
\text { and corrosion from chlorides. }\end{array}$ & $\begin{array}{l}\text { No aqueous } \mathrm{HNO}_{3} \text { corrosion, } \\
\text { but alloys still needed to } \\
\text { protect against high } \\
\text { temperature degradation and } \\
\text { corrosion from chlorides. }\end{array}$ \\
\hline Reagents & $\begin{array}{l}\mathrm{No}_{\mathrm{HNO}_{3} \text { or organic reagents. }} \text { Added } \mathrm{NF}_{3} \text { is less hazardous } \\
\text { than other halide species. }\end{array}$ & $\begin{array}{l}\mathrm{No} \mathrm{HNO}_{3} \text { or organic reagents, } \\
\text { but added } \mathrm{NO}_{\mathrm{x}} \text {. Added } \mathrm{SF}_{6} \text { is } \\
\text { less hazardous than other } \\
\text { halide species. }\end{array}$ & $\begin{array}{l}\text { Added } \mathrm{NO}_{2} \text {, which is highly } \\
\text { toxic; still have } \mathrm{TBP} \text {, and lesser } \\
\text { amounts of } \mathrm{HNO}_{3} \text {. }\end{array}$ & $\begin{array}{l}\text { Added } \mathrm{Cl}_{2} \text { and } \mathrm{HCl} \text {, which } \\
\text { are highly toxic; no } \mathrm{HNO}_{3} \text { or } \\
\text { organic solvents. }\end{array}$ & $\begin{array}{l}\text { Added } \mathrm{H}_{2} \text { (flammable) and } \\
\mathrm{NH}_{4} \mathrm{Cl} \text { (which is less toxic than } \\
\mathrm{Cl} \text { reagents); no } \mathrm{HNO}_{3} \text { or } \\
\text { organic solvents. }\end{array}$ \\
\hline Liquid storage tanks & None & None & Yes, but smaller & Yes, but smaller & None \\
\hline Dissolution & None & None & TBP & Water & None \\
\hline
\end{tabular}


Innovative Separations Technologies

\begin{tabular}{|c|c|c|c|c|c|}
\hline Feature & $\mathrm{NF}_{3}$ Separations & $\mathrm{SF}_{6}$ Separations & Dry Head-end Nitration & Chlorination/ Oxychlorination & $\begin{array}{l}\text { Enhanced } \\
\text { Oxidation/Chlorination }\end{array}$ \\
\hline Product purity & $\begin{array}{l}\text { Tunable separations may } \\
\text { improve purity compared to } \\
\text { reference F volatility process. } \\
\text { Products need remote } \\
\text { handling. Contamination } \\
\text { levels may limit number of } \\
\text { times used fuel can be } \\
\text { recycled. FP and TRU } \\
\text { contamination in recovered } \\
\text { uranium (RU) may affect } \\
\text { disposition if it is determined } \\
\text { to be waste. }\end{array}$ & $\begin{array}{l}\text { Hydrolysis/pyrohydrolysis } \\
\text { improves the separation of U } \\
\text { from TRU and FPs; the actual } \\
\text { contamination levels in the U } \\
\text { product are still not } \\
\text { determined, so the ability to } \\
\text { recycle the U product multiple } \\
\text { times and disposal of RU (if it } \\
\text { is not recycled) is yet to be } \\
\text { determined. }\end{array}$ & $\begin{array}{l}\text { Can be as pure as advanced } \\
\text { aqueous separations reference } \\
\text { case. }\end{array}$ & $\begin{array}{l}\text { The } \mathrm{U} \text { product may be } \\
\text { relatively pure; the } \mathrm{Pu} \\
\text { product contains some } \mathrm{Zr} \text { and } \\
\mathrm{U} \text {. }\end{array}$ & $\begin{array}{l}\text { Product purity is uncertain and } \\
\text { depends on the ability to } \\
\text { efficiently volatilize the FPs } \\
\text { from the actinides. }\end{array}$ \\
\hline Safety/Environmental & $\begin{array}{l}\mathrm{NF}_{3} \text { is non-flammable and less } \\
\text { toxic than } \mathrm{F}_{2}(\mathrm{~g}) \text { or } \mathrm{HF} \text {; but is } \\
\text { an oxidizer and a greenhouse } \\
\text { gas. }\end{array}$ & $\begin{array}{l}\mathrm{SF}_{6} \text { is non-flammable and less } \\
\text { toxic than } \mathrm{F}_{2}(\mathrm{~g}) \text { or } \mathrm{HF} \text {; but is a } \\
\text { greenhouse gas. }\end{array}$ & $\begin{array}{l}\mathrm{NO}_{2} \text { is toxic, and non- } \\
\text { flammable, TBP and nitric acid } \\
\text { used to process the actinides } \\
\text { presents safety and } \\
\text { environmental hazards similar to } \\
\text { those of the advanced aqueous } \\
\text { separations reference case. }\end{array}$ & $\begin{array}{l}\mathrm{Cl}_{2} \text { is highly toxic and a } \\
\text { strong oxidizer, and } \\
\text { nonflammable; } \mathrm{NO}_{2} \text { and } \mathrm{HCl} \\
\text { are highly toxic and } \\
\text { nonflammable. }\end{array}$ & $\begin{array}{l}\mathrm{H}_{2} \text { is flammable; } \mathrm{NH}_{4} \mathrm{Cl} \text { is less } \\
\text { toxic than other } \mathrm{Cl} \text { species. }\end{array}$ \\
\hline Waste management & $\begin{array}{l}\text { Halide contamination limits } \\
\text { waste loading and drives need } \\
\text { for development of a halide- } \\
\text { tolerant WF. If TRU is not } \\
\text { recycled it adds heat and } \\
\text { radiotoxicity to the WF. } \\
\text { No aqueous or organic waste } \\
\text { streams. }\end{array}$ & $\begin{array}{l}\text { Halide contamination limits } \\
\text { waste loading and drives need } \\
\text { for development of a halide- } \\
\text { tolerant WF. If TRU is not } \\
\text { recycled it adds heat and } \\
\text { radiotoxicity to the WF. } \\
\text { No aqueous or organic waste } \\
\text { streams. }\end{array}$ & $\begin{array}{l}\text { Similar to the advanced aqueous } \\
\text { separations reference case - FP } \\
\text { waste stream can be disposed in } \\
\text { BSG or other similar or better } \\
\text { WF. If TRU is not recycled it } \\
\text { adds heat and radiotoxicity to } \\
\text { the WF. }\end{array}$ & $\begin{array}{l}\text { Halide contamination limits } \\
\text { waste loading and drives need } \\
\text { for development of a halide- } \\
\text { tolerant WF. Am and Cm are } \\
\text { not recycled and so add heat } \\
\text { and radiotoxicity to the WF. }\end{array}$ & $\begin{array}{l}\text { Halide contamination limits } \\
\text { waste loading and drives need } \\
\text { for development of a halide- } \\
\text { tolerant WF. }\end{array}$ \\
\hline $\begin{array}{l}\text { Used fuel disposal / } \\
\text { suitability for recycle }\end{array}$ & $\begin{array}{l}\text { Recycle RU in CANDU or } \\
\text { breeder reactors; or further } \\
\text { purify and enrich RU for use } \\
\text { in LWRs (discarding much of } \\
\text { the mass as depleted RU); or } \\
\text { add fissile from another } \\
\text { source to the RU for use in } \\
\text { LWRs; recycle the TRU } \\
\text { stream only after further } \\
\text { handling to dilute or remove } \\
\text { FP contamination. }\end{array}$ & $\begin{array}{l}\text { Recycle RU in CANDU or } \\
\text { breeder reactors; or further } \\
\text { purify and enrich RU for use in } \\
\text { LWRs (discarding much of the } \\
\text { mass as depleted RU); or add } \\
\text { fissile from another source to } \\
\text { the RU for use in LWRs; } \\
\text { recycle the TRU stream only } \\
\text { after further handling to dilute } \\
\text { or remove FP contamination. }\end{array}$ & $\begin{array}{l}\text { Same options as for the } \\
\text { advanced aqueous separations } \\
\text { reference case. Recycle RU in } \\
\text { CANDU or breeder reactors; or } \\
\text { the RU and TRU can be } \\
\text { combined, or combined with } \\
\text { more fissile from another source, } \\
\text { for recycle in LWRs or burner } \\
\text { reactors. }\end{array}$ & $\begin{array}{l}\text { Same options as for the } \\
\text { advanced aqueous separations } \\
\text { reference case. Recycle } \\
\mathrm{RU} / \mathrm{Pu} / \mathrm{Np} \text { in CANDU or } \\
\text { breeder reactors; or the } \\
\mathrm{RU} / \mathrm{Pu} / \mathrm{Np} \text { can be further } \\
\text { processed or combined with } \\
\text { more fissile from another } \\
\text { source, for recycle in LWRs } \\
\text { or burner reactors. }\end{array}$ & $\begin{array}{l}\text { Recycle actinide product in } \\
\text { CANDU or breeder reactors; or } \\
\text { further process to purify or } \\
\text { adjust ratios, or combine with } \\
\text { more fissile from another } \\
\text { source, for recycle in LWRs or } \\
\text { burner reactors. }\end{array}$ \\
\hline
\end{tabular}


Innovative Separations Technologies

May 31, 2011

\begin{tabular}{|c|c|c|c|c|c|}
\hline Feature & $\mathrm{NF}_{3}$ Separations & $\mathrm{SF}_{6}$ Separations & Dry Head-end Nitration & Chlorination/ Oxychlorination & $\begin{array}{l}\text { Enhanced } \\
\text { Oxidation/Chlorination }\end{array}$ \\
\hline $\begin{array}{l}\text { Economics / footprint } \\
\text { reduction }\end{array}$ & $\begin{array}{l}\text { Eliminating aqueous } \\
\text { separations will reduce } \\
\text { footprint and cost; but impacts } \\
\text { of receipt/ storage/use of } \mathrm{NF}_{3} \text {, } \\
\text { more extensive off-gas } \\
\text { systems, and less-pure product } \\
\text { streams, could reduce those } \\
\text { benefits. Analyses could be } \\
\text { done when more data is } \\
\text { available. }\end{array}$ & $\begin{array}{l}\text { Eliminating aqueous } \\
\text { separations will reduce } \\
\text { footprint and cost; but impacts } \\
\text { of receipt/ storage/use of } \mathrm{SF}_{6} \text {, } \\
\text { more extensive off-gas } \\
\text { systems, and less-pure product } \\
\text { streams, could reduce those } \\
\text { benefits. Analyses could be } \\
\text { done when more data is } \\
\text { available. }\end{array}$ & $\begin{array}{l}\text { Eliminating the acid dissolver } \\
\text { and associated equipment and } \\
\text { reagents will reduce footprint } \\
\text { and lower costs; use of } \mathrm{NO}_{2} \\
\text { reagent will add footprint and } \\
\text { costs; the net change in footprint } \\
\text { and costs is yet to be determined } \\
\text { when data is available. }\end{array}$ & $\begin{array}{l}\text { Eliminating the acid dissolver } \\
\text { and associated equipment and } \\
\text { reagents will reduce footprint } \\
\text { and lower costs; use of } \mathrm{NO}_{2} \text {, } \\
\mathrm{Cl}_{2} \text {, and } \mathrm{HCl} \mathrm{reagents} \mathrm{and} \\
\text { water dissolution will add } \\
\text { footprint and costs; the net } \\
\text { change in footprint and costs } \\
\text { is yet to be determined when } \\
\text { data is available. }\end{array}$ & $\begin{array}{l}\text { Eliminating the acid dissolver } \\
\text { and associated equipment and } \\
\text { reagents will reduce footprint } \\
\text { and lower costs; use of } \mathrm{H}_{2} \text { and } \\
\mathrm{NH}_{4} \mathrm{Cl}_{2} \text { will add footprint and } \\
\text { costs; the net change in } \\
\text { footprint and costs is yet to be } \\
\text { determined when data is } \\
\text { available. }\end{array}$ \\
\hline Resource sustainability & $\begin{array}{l}\text { If nearly all of the TRU is not } \\
\text { recycled, then uranium } \\
\text { utilization will be less } \\
\text { compared to the reference } \\
\text { aqueous separations case, } \\
\text { because most of the uranium } \\
\text { will eventually be discarded } \\
\text { as depleted uranium (DU). }\end{array}$ & $\begin{array}{l}\text { If nearly all of the TRU is not } \\
\text { recycled, then uranium } \\
\text { utilization will be less } \\
\text { compared to the reference } \\
\text { aqueous separations case, } \\
\text { because most of the uranium } \\
\text { will eventually be discarded as } \\
\text { DU. }\end{array}$ & $\begin{array}{l}\text { Resource sustainability is similar } \\
\text { to that for advanced aqueous } \\
\text { separations; the same options for } \\
\text { MOC and Full Recycle are } \\
\text { available. }\end{array}$ & $\begin{array}{l}\text { Resource sustainability is } \\
\text { similar to that for advanced } \\
\text { aqueous separations; the same } \\
\text { options for MOC and Full } \\
\text { Recycle are available; Am } \\
\text { and Cm are not recycled and } \\
\text { so energy in these elements is } \\
\text { discarded. }\end{array}$ & $\begin{array}{l}\text { Can maximize resource } \\
\text { sustainability if the actinide } \\
\text { product purity is high enough } \\
\text { for multiple recycles and if all } \\
\text { of the RU and TRU is re-used. }\end{array}$ \\
\hline $\begin{array}{l}\text { Proliferation resistance } \\
\text { and physical security }\end{array}$ & $\begin{array}{l}\text { The separated TRU stream is } \\
\text { self-protective due to FP and } \\
\text { MA. The separated U/PU } \\
\text { stream may not be self- } \\
\text { protective. MC\&A may be } \\
\text { more difficult. Safeguards } \\
\text { would be possible, similar to } \\
\text { that for aqueous processing. } \\
\text { No significant vulnerabilities } \\
\text { or advantages with respect to } \\
\text { the reference advanced } \\
\text { aqueous process were } \\
\text { identified. }\end{array}$ & $\begin{array}{l}\text { The separated TRU stream is } \\
\text { self-protective due to FP and } \\
\text { MA. The separated U/PU } \\
\text { stream may not be self- } \\
\text { protective. MC\&A may be } \\
\text { more difficult. Safeguards } \\
\text { would be possible, similar to } \\
\text { that for aqueous processing. } \\
\text { No significant vulnerabilities } \\
\text { or advantages with respect to } \\
\text { the reference advanced } \\
\text { aqueous process were } \\
\text { identified. }\end{array}$ & $\begin{array}{l}\text { Safeguards similar to those for } \\
\text { advanced aqueous separations } \\
\text { can apply here. No significant } \\
\text { vulnerabilities or advantages } \\
\text { with respect to the reference } \\
\text { advanced aqueous process were } \\
\text { identified. }\end{array}$ & $\begin{array}{l}\text { Safeguards similar to those } \\
\text { for advanced aqueous } \\
\text { separations can apply here. } \\
\text { No significant vulnerabilities } \\
\text { or advantages with respect to } \\
\text { the reference advanced } \\
\text { aqueous process were } \\
\text { identified. }\end{array}$ & $\begin{array}{l}\text { Safeguards similar to those for } \\
\text { advanced aqueous separations } \\
\text { can apply here. No significant } \\
\text { vulnerabilities or advantages } \\
\text { with respect to the reference } \\
\text { advanced aqueous process } \\
\text { were identified. }\end{array}$ \\
\hline
\end{tabular}




\section{REFERENCES}

Benedict, M., Pigford, T., Levi, H., Nuclear Chemical Engineering, McGraw-Hill, Inc., 1981. (pg.462466)

CRC Handbook of Chemistry and Physics, $60^{\text {th }}$ edition, 1979.

CGER (Commission on Geosciences, Environment and Resources), Nuclear Wastes: Technologies for Separations and Transmutation, 1996, pg 152-153.

Christian, J., et al, Dry Recycle of Spent Nuclear Fuel, LDRD Project 99.292 Final Report, December 1999.

DelCul, G.D., et.al., "Novel Dry Head-end Nitration Processing," Fuel Cycle Research and Development Program, 2010 Separations and Waste Forms Working Group Meeting Presentation, August 30, 2010.

DOE 2010, DOE budget Roll Out, February 2010.

Donald, I. W. and B. L. Metcalfe, “A Glass Encapsulated Calcium Phosphate Waste Form for the Immobilization of Actinide-, Fluoride-, and Chloride-containing Radioactive Wastes from the Pyrochemical Reprocessing of Plutonium Metal," Journal of Nuclear Materials, Volume 361, Issue 1, 31 March 2007, Pages 78-93.

Fong, S. K., et al, “Immobilization of Hafnium Surrogates in Fluorapatite," Advances in Science and Technology, Vol. 45 (2006), pp2018-2023

Frank, Steve, "Pyrochemical Salt Meeting," Idaho National Laboratory, March 16, 2011.

Gray, J., et al, Reactive Gas Recycle for Used Nuclear Fuel, FCRD-SEPA-2010-000177, September 24, 2010

Gray, J., et al, FCRD Systems Analysis Input, Savannah River National Laboratory, March 9, 2011.

Johnson, D.R., et.al., "Light Water Reactor Fuel Reprocessing: Dissolution Studies of Voloxidized and Nonvoloxidized Fuel," DP-1520, SRL, April 1980

KAERI, "Hot Experiment on Fission Gas Release Behavior from Voloxidation Process Using Spent Fuel," KAERI/TR-3448/2007.

Kani, Yuko, "New reprocessing system for spent nuclear reactor fuel using fluoride volatility method," Journal of Fluorine Chemistry, 130(2009) 74-82

Kok, K., Nuclear Engineering Handbook, CRC Press, pg 328, 2009.

Long, Justin, Engineering for Nuclear Fuel Reprocessing, American Nuclear Society, 1978, pgs 242-249.

Mallen, J., et al, Evaluation of Conceptual Flowsheets for Incorporating LWR Fuel Materials in an Advnaced Nuclear Fuel Cycle, ORNL/TM-11466, August 1990.

Majumdar, D., et al, "Recycling of Nuclear Spent Fuel with AIROX Processing, DOE/ID-10423, December 1992.

Metcalfe, B.L., Donald I.W., Candidate Waste Forms for the Immobilization of Chloride Containing Radioactive Waste, Journal of Non-Crystalline Solids, Volume 348, 15 November 2004, Pages 225-229. 
Metcalfe, Brian L., Ian W. Donald, Shirley K. Fong, Lee A. Gerrard, Denis M. Strachan, Randall D Scheele, "Calcium Phosphate: A Potential Host for Halide Contaminated Plutonium Wastes," Material Research Society Symposium Proceedings, Vol 124, 2009.

ORNL/TM-2009-draft, Engineering Analysis of Voloxidation Process, draft report.

ORNL, FCR\&D Transformational Separations Technology Research: Dry Chlorination for Processing UNF presentation, Separations and Waste Forms Working Group Meeting, December 7, 2010.

Piet, Steve, et al, 2010, "The FIT Model - Fuel Cycle Integration and Tradeoffs," INL-EXT-10-20190, FCR\&D-SY-2010-000192, September 30, 2010.

Piet, Steve, 2011, personal communication to Julie Trip and Nick Soelberg, February.

Reilly, J. J., "Uranium Recovery from Unirradiated Reactor Fuel Elements", Vol 2, No. 2, April 1963, I\&EC Process Design and Development, pg 127-133.

Riley, Brian, et al, "Tellurite Glasses: an Echem Waste Form," Pacific Northwest National Laboratory, Pyrochemical Salt Web Conference, March 16, 2011.

Sood, D., Patil, S., "Chemistry of Nuclear Fuel Reprocessing: Current Status," Journal of Radioanalytical and Nuclear Chemistry, Vol. 203, No.2, (1996) 547-573

Szulinski, M., "Fluoride Volatility Processing of Reactor Fuels," ISO-627, Isochem Inc, Richland WA, December 4, 1966

Uhlir, J., "Fluroide volatility method for reprocessing LWR and FR fuels", Journal of Fluorine Chemistry, 130 (2009) 89-93.

Veryatin, Y., et.al, "Basic Problems in the Fluoride Method of Reprocessing Fast-Reactor Fuel Elements," 1972 Consultant Bureau, Plenum Publishing Company

Vogel, G, Barghusen, J., Volatility Processes, Reactor and Fuel-Processing Technology, Vol. 11, No. 2, 1968, pg 101-106.

Westphal, B., et al, "Effect of Process Variables During the Head-end Treatment of Spent Oxide Fuel," Nuclear Technology, Vol. 162, No. 2, May 2008.

Westphal, B., et al, "Enhanced Oxidation/Chlorination of Used LWR Fuel to Promote Sustainable Recycle,” Transformational Separation Technologies Review Presentation, July 2010. 